Aus der Abteilung Herz- und Kreislaufphysiologie

(Prof. Dr. med. D. M. Katschinski)

Im Zentrum Physiologie und Pathophysiologie

der Medizinischen Fakultät der Universität Göttingen

\title{
Untersuchungen zur Regulation der Zelladhäsion durch PHD2 in Tumorzellen
}

\author{
INAUGURAL - DISSERTATION \\ zur Erlangung des Doktorgrades \\ der Medizinischen Fakultät der \\ Georg-August-Universität zu Göttingen
}

vorgelegt von

Moritz Thomas Schnelle

aus

Bochum

Göttingen, 2012 
Dekan: Prof. Dr. med. M. P. Schön

I. Berichterstatterin: Prof. Dr. med. D. M. Katschinski

II. Berichterstatter/in: Prof. Dr. med. M. Dobbelstein

III. Berichterstatter/in: Prof. Dr. med. M. Oppermann

Tag der mündlichen Prüfung: 14.08.2012 
1 EINLEITUNG

$\begin{array}{lll}1.1 & \text { Sauerstoff } & 1\end{array}$

1.2 Hypoxie-induzierbarer Faktor-1 (HIF-1) 1

1.2.1 Bedeutung für den Organismus 1

$\begin{array}{lll}1.2 .2 & \text { Struktur } & 2\end{array}$

1.2.3 Regulation 3

1.2.3.1 Hydroxylierungen von Pro $^{402}$ und Pro ${ }^{564} \quad 5$

1.3 PHD-Enzyme 5

1.3.1 Unterschiedliche Isoformen 5

$\begin{array}{lll}1.3 .2 & \text { Inhibition } & 7\end{array}$

1.3.3 Regulation und Interaktion $\quad 8$

1.4 Zelladhäsion $\quad 10$

$\begin{array}{lll}\text { 1.4.1 Integrine } & 10\end{array}$

1.4.2 Regulation des Zellzyklus und Beteiligung an der Tumormetastasierung 11

$\begin{array}{lll}\text { 1.4.3 Einfluss von HIF-1 } \alpha & 13\end{array}$

$\begin{array}{lll}1.5 & \text { Cofilin } & 13\end{array}$

$\begin{array}{lll}1.6 & \text { Fragestellung und Zielsetzung dieser Arbeit } & 14\end{array}$

2 MATERIAL UND METHODEN 16

2.1 Zelllinien $\quad 16$

2.1.1 Tetrazyklin-induzierbare PHD2-knock-down-Zellen 16

2.1.2 Stabil transfizierte PHD2-knock-down-Zellen (HeLa, MDA-MB231, MCF7) 16

2.1.3 MEF-Hif- $1 \alpha^{+/+}$- und MEF-Hif- $1 \alpha^{-/-}$-Zellen 17

$\begin{array}{lll}2.2 & \text { Zellkultur } & 18\end{array}$

2.3 Analyse der zellulären Adhäsionseigenschaften mittels Adhäsions-Assay 18

2.4 Bestimmung der Zellzahl und -vitalität 19

2.5 Immunfluoreszenz-Mikroskopie 20

$\begin{array}{lll}2.6 & \text { Proteinextraktion und -bestimmung } & 21\end{array}$

2.7 $\quad$ SDS-Polyacrylamid-Gelelektrophorese und Western Blot 22

2.8 Lipofektamin-vermittelte, transiente Transfektion 23

2.9 RNA-Isolation $\quad 24$

2.10 cDNA-Synthese 25

2.11 Quantitative real-time-Polymerase-Ketten-Reaktion (qRT-PCR) 25 
3.1 Funktionelle Charakterisierung der verwendeten Zelllinien 28

3.1.1 Nachweis des PHD2-knock-downs auf Proteinebene in den HeLa-, MDA-MB231- und MCF7-Zellen

3.1.2 Nachweis des PHD2-knock-downs auf RNA-Ebene in den HeLa-, MDA-MB231- und MCF7-Zelllinien 29

3.1.3 Die Beeinflussung der Zellproliferation durch den PHD2-knock-down in den HeLa-Zellen

3.1.4 Die Beeinflussung der Zellproliferation und -vitalität durch den PHD2-knockknown in den MDA-MB-231-Zellen

3.1.5 Die Beeinflussung der Zellproliferation und -vitalität durch den PHD2-knockdown in den MCF7-Zellen

3.2 Der PHD2-knock-down bewirkt in vitro eine verminderte Adhäsion unterschiedlicher Tumorzellreihen an die extrazelluläre Matrix (ECM)

3.2.1 Etablierung des Adhäsions-Assays und Untersuchung der HeLa-Zellen auf ihr Adhäsionsverhalten

3.2.2 Adhäsionsverhalten der MDA-MB-231-Zellen

3.2.3 Adhäsionsverhalten der T-REx-HeLa-Zellen/P2.1.1-16-Zellen 39

3.2.4 Adhäsion auf Laminin

3.3 Das Fehlen von PHD2 in den PHD2-knock-down-Klonen ist für die verminderte Adhäsion an die ECM verantwortlich Durch Inhibition der Rho-associated kinase (ROCK) kann die Adhäsion der HeLa-PHD2-knock-down-Zellen gesteigert werden

3.4 PHD2 hat keinen Einfluss auf die Ausbildung und Verteilung fokaler Adhäsionen in MDA-MB-231- und MCF7-Zellen

3.5 SPARC und SPP1 als mögliche Kandidatengene, die PHD2-reguliert Einfluss auf die Zelladhäsion nehmen

4 DISKUSSION

5 ZUSAMMENFASSUNG

6 ANHANG

6.1 Abbildungsverzeichnis

6.2 Tabellenverzeichnis 


\section{Abkürzungsverzeichnis}

\begin{tabular}{|c|c|}
\hline Abb. & Abbildung \\
\hline $\mathrm{ADF}$ & Aktin-depolymerisierender Faktor \\
\hline ARD1 & engl. arrest-defective- 1 protein \\
\hline ARNT & engl. aryl hydrocarbon nuclear translocator \\
\hline ATF-4 & engl. activating transcription factor- 4 \\
\hline ATP & Adenosintriphosphat \\
\hline bHLH & engl. basic helix-loop-helix \\
\hline BSA & Rinderserumalbumin (engl. bovine serum albumin) \\
\hline $\mathrm{CBP}$ & CREB-bindendes Protein \\
\hline $\mathrm{Cdk}$ & engl. cyclin dependent kinase \\
\hline cDNA & komplementäre DNA (engl. complementary DNA) \\
\hline C. elegans & Caenorhabditis elegans \\
\hline $\mathrm{Cfl}$ & Cofilin \\
\hline CIN & Chronophin \\
\hline CMV & Zytomegalievirus \\
\hline $\mathrm{CO}_{2}$ & Kohlenstoffdioxid \\
\hline CREB & engl. cAMP response element-binding protein \\
\hline DAPI & 4',6'-Diamidino-2-phenylindol \\
\hline DEPC & Diethylpyrocarbonat \\
\hline DFO & Desferrioxamin \\
\hline DGC & Dystrophin-Glykoprotein-Komplex \\
\hline 3,4-DHB & Ethyl-3,4-dihydroxybenzoat \\
\hline DMEM & Dulbecco's modified Eagle's medium \\
\hline DMOG & Dimethyloxalylglycin \\
\hline DNA & Desoxyribonukleinsäure (engl. deoxyribonucleic acid) \\
\hline dNTP & Desoxyribonukleosidtriphosphat \\
\hline DTT & Dithiothreitol \\
\hline ECM & extrazelluläre Matrix (engl. extracellular matrix) \\
\hline EDTA & Ethylendiamintetraacetat \\
\hline EGF & engl. epidermal growth factor \\
\hline EGL-9 & engl. egg laying abnormal-9 \\
\hline EGLN & EGL-9 homolog \\
\hline EMT & engl. epithelial to mesenchymal transition \\
\hline EPO & Erythropoietin \\
\hline Erk & engl. extracellular signal regulated kinase \\
\hline et al. & und andere (lat. et alii) \\
\hline FA & fokale Adhäsion (engl. focal adhesion) \\
\hline FAD & Flavin-Adenin-Dinukleotid \\
\hline FAK & engl. focal adhesion kinase \\
\hline $\mathrm{Fe}$ & Eisen (lat. ferrum) \\
\hline FKBP & FK506-bindendes Protein \\
\hline FKS & fetales Kälberserum \\
\hline FIH & engl. factor inhibiting HIF \\
\hline GADD & engl. growth arrest or cell death \\
\hline GLUT1 & Glukose-Transporter 1 \\
\hline GTP & Guanosintriphosphat \\
\hline h & Stunden (engl. hours) \\
\hline HBS & HEPES-gepufferte Salzlösung (engl. HEPES buffered saline) \\
\hline HEPES & N-2-Hydroxyethylpiperazin-N'-2-ethansulfonat \\
\hline
\end{tabular}




\begin{tabular}{|c|c|}
\hline $\mathrm{HIF}$ & Hypoxie-induzierbarer Faktor \\
\hline H-ras & engl. harvey rat sarcoma virus oncogene 1 \\
\hline HRE & engl. hypoxia response element \\
\hline $\operatorname{IgG}$ & Immunglobulin $\mathrm{G}$ \\
\hline $\mathrm{IKK} \beta$ & engl. inhibitor of NF- $\kappa \mathrm{B}$ kinase $\beta$ \\
\hline ING & engl. inhibitor of growth family member \\
\hline iNOS & induzierbare NO-Synthase \\
\hline $\mathrm{kDa}$ & kilo Dalton \\
\hline $\mathrm{K}_{\mathrm{M}}$ & Michaelismentenkonstante \\
\hline $\log$ & Logarithmus \\
\hline LOX & Lysyloxidase \\
\hline $\mathrm{MEF}$ & Maus-embryonale Fibroblasten (engl. mouse-embryonic fibroblasts) \\
\hline $\mathrm{mmHg}$ & Millimeter Quecksilbersäule \\
\hline Morg & engl. mitogen-activated protein kinase organizer \\
\hline mRNA & Boten-RNA (engl. messenger RNA) \\
\hline NAD & Nikotinsäureamid-Adenin-Dinukleotid \\
\hline $\mathrm{NF}-\kappa \mathrm{B}$ & engl. nuclear factor- $\kappa \mathrm{B}$ \\
\hline NLS & engl. nuclear localization signal \\
\hline $\mathrm{O}_{2}$ & Sauerstoff \\
\hline OD & optische Dichte \\
\hline ODDD & engl. oxygen-dependent degradation domain \\
\hline PAK & p21-aktivierte Kinase \\
\hline PAS & Per/ARNT/Sim \\
\hline PBS & Phosphat-gepufferte Salzlösung (engl. phosphat buffered saline) \\
\hline PCR & Polymerase-Ketten-Reaktion (engl. polymerase chain reaction) \\
\hline Pen & Penicillin \\
\hline $\mathrm{pH}$ & $\begin{array}{l}\text { negativ dekadischer Logarithmus der Hydroniumionenkonzentration (lat. } \\
\text { pondus hydrogenii) }\end{array}$ \\
\hline PHD & Prolyl-4-Hydroxylase-Domäne-Proteine \\
\hline pVHL & von-Hippel-Lindau-Tumorsuppressorprotein \\
\hline qRT-PCR & engl. quantitative real time polymerase chain reaction \\
\hline RING & engl. really interesting new gene \\
\hline RNA & Ribonukleinsäure (engl. ribonucleic acid) \\
\hline ROCK & engl. rho-associated, coiled-coil-forming protein kinase \\
\hline $\mathrm{rpm}$ & Umdrehungen pro Minute (engl. revolutions per minute) \\
\hline SCID & engl. severe combined immunodeficiency \\
\hline SD & Standardabweichung (engl. standard deviation) \\
\hline SDS & Natriumdodecylsulfat (engl. sodium dodecyl sulfate) \\
\hline SEM & Standardfehler (engl. standard error of the mean) \\
\hline SGCE & Sarcoglycan epsilon \\
\hline shRNA & engl. short hairpin RNA \\
\hline Siah & engl. seven in absentia homologue \\
\hline SIP1 & engl. smad interacting protein 1 \\
\hline siRNA & engl. short interfering RNA \\
\hline SPARC & engl. secreted protein acidic and rich in cysteine \\
\hline SPP1 & engl secreted phosphoprotein 1 \\
\hline SSH & engl. slingshot \\
\hline Strep & Streptomycin \\
\hline Tab. & Tabelle \\
\hline TAD & Transaktivierungsdomäne \\
\hline Tet & Tetrazyklin \\
\hline
\end{tabular}


T-REx

Tris

$\mathrm{U}$

$\mathrm{V}$

VEGF

engl. tetracycline-regulated expression

Tris-(hydroxymethyl-)aminomethan

Enzymeinheit (engl. unit)

Volt

engl. vascular endothelial growth factor 


\section{$1 \quad$ Einleitung}

\subsection{Sauerstoff}

Molekularer Sauerstoff ist essenziell für die Aufrechterhaltung physiologischer Zellfunktionen. Durch die Reduktion des molekularen Sauerstoffs mit Hilfe der im Zitratzyklus gewonnenen Reduktionsäquivalente $\mathrm{NADH} / \mathrm{H}^{+} \mathrm{bzw} . \mathrm{FADH} / \mathrm{H}^{+}$wird die nötige Energie gewonnen, um in der oxidativen Phosphorylierung ATP zu gewinnen. ATP wird von der Zelle beispielsweise für die Funktion diverser Ionentransporter (z.B. $\mathrm{Na}^{+} / \mathrm{K}^{+}$-ATPase, membranständige $\mathrm{Ca}^{2+}$-ATPase) und für zahlreiche Stoffwechselwege in der Zelle (Fettsäuresynthese, Cholesterinbiosynthese) genutzt. Der vom Organismus benötigte Sauerstoff erreicht mittels Inspiration die kleinsten Lungenalveolen, um dort dem Partialdruckgefälle folgend durch die Blut-Luft-Schranke in die Erythrozyten zu gelangen. Dort wird er koordinativ am $\mathrm{Fe}^{2+}$ des Häms gebunden. Im Austausch diffundiert $\mathrm{CO}_{2}$, ebenfalls dem Partialdruckgefälle folgend, aus dem Blut in die Alveolen und kann abgeatmet werden. Im Blut kann der Sauerstoff nun von den Erythrozyten in die jeweiligen Gewebe transportiert werden. Dabei ist der Sauerstoffpartialdruck im Gewebe mit unter $40 \mathrm{mmHg}$ deutlich geringer als in den Arterien, wo er ca. $100 \mathrm{mmHg}$ beträgt. Da das Sauerstoffangebot von vielen Faktoren abhängt und stark schwanken kann, müssen die Zellen in der Lage sein, auf diese Schwankungen adäquat zu reagieren.

\subsection{Hypoxie-induzierbarer Faktor-1 (HIF-1)}

\subsubsection{Bedeutung für den Organismus}

Eine bedarfsgerechte Versorgung des Organismus mit Sauerstoff wird als Normoxie, das völlige Fehlen des Sauerstoffs als Anoxie bezeichnet. Hypoxie dagegen beschreibt einen Zustand, in dem das Sauerstoff-Angebot der Zellen unterhalb des Bedarfs liegt, zum Beispiel ausgelöst durch einen Aufenthalt in hoch gelegenen Gebieten oder durch Erkrankungen bedingt (z.B. bei Myokardinfarkt und peripherer arterieller Verschlusskrankheit). Kommt es zu einer geringeren Sauerstoff-Versorgung der Zellen des jeweiligen Gewebes, reagieren diese darauf mit einer veränderten Genexpression. Dieses ist auf den Transkriptionsfaktor Hypoxie-induzierbarer Faktor-1 (HIF-1) zurückzuführen, der sich unter hypoxischen Bedingungen in der Zelle anreichert (Wang GL et al. 1995). HIF-1 sorgt nun für die Aufrechterhaltung der Sauerstoff-Homöostase innerhalb der Zelle, indem es die Transkription diverser Zielgene induziert. Zu den durch diese Gene kodierten Proteinen zählen der vascular endothelial growth factor (VEGF) (Forsythe et al. 1996) für die Angiogenese, die 
induzierbare NO-Synthase (iNOS) (Melillo et al. 1995) und die Häm-Oxygenase 1 (Lee PJ et al. 1997) für die Vasodilatation, die Tyrosin-Hydroxylase (Norris und Millhorn 1995) zur Regulation der Atemfrequenz, der Glukose-Tansporter GLUT1 (Ebert et al. 1995), welcher an der anaeroben Glykolyse beteiligt ist sowie das Hormon Erythropoietin (EPO) (Wang GL und Semenza 1993), welches in der Niere produziert wird und die Erythropoiese im Knochenmark anregt. Somit sorgt HIF-1 über die vermehrte Expression der genannten Proteine dafür, dass einerseits die Sauerstoff-Versorgung erhöht wird und andererseits die Zelle ihren Metabolismus einem geringeren Sauerstoff-Angebot anpasst.

Der Transkriptionsfaktor HIF-1 ist ein Heterodimer und besteht aus einer konstitutiv im Nukleus exprimierten, 91-94 kDa großen HIF-1ß-Untereinheit (diese Untereinheit wird auch als aryl hydrocarbon nuclear translocator bzw. ARNT bezeichnet) und einer der drei HIF- $\alpha-$ Untereinheiten (HIF-1 $\alpha$, HIF-2 $\alpha$, HIF-3 $\alpha$ ) (Wang GL et al. 1995, Gu et al. 1998, Ema et al. 1997). Die am besten untersuchte $\alpha$-Isoform ist das ubiquitär vorkommende HIF-1 $\alpha$ (ca. 120 kDa). Im Gegensatz zu HIF-1 $\beta$ wird HIF-1 $\alpha$ in Abhängigkeit der intrazellulären SauerstoffKonzentration stabilisiert oder proteasomal degradiert.

HIF- $2 \alpha$ und HIF-1 $\alpha$ sind in ihrer Struktur und Funktion ähnlich, sie werden jedoch organspezifisch exprimiert (Ema et al. 1997, Wiesener et al. 1998). Trotz ihrer strukturellen und funktionellen Ähnlichkeit besitzen HIF-1 $\alpha$ und HIF-2 $\alpha$ unterschiedliche Zielgene. HIF-2 $\alpha$ beeinflusst beispielsweise, anders als HIF-1 $\alpha$, nicht die Expression der glykolytischen Enzyme (Hu CJ et al. 2003). Gemeinsam ist beiden Isoformen, dass sie eine wichtige Rolle in der Embryogenese spielen. In Maus-Embryos steigt die Expression von HIF-1 $\alpha$ zwischen Tag 8.5 und 9.5. HIF-1 $\alpha$-knock-out-Mäuse sind nicht lebensfähig und sterben am Tag 10.5 aufgrund von Fehlern in der Entwicklung des Gefäßsystems und von sowohl kardialen wie auch neuronalen Abnormalitäten (Carmeliet et al. 1998, Iyer et al. 1998). Hif-2 $\alpha^{-/-}$-Mäuse sterben zwischen Tag 9.5 und 16.5, da HIF-2 $\alpha$ eine Rolle bei der Umgestaltung des vaskulären Netzwerkes und der Herzfunktion des Embryos spielt (Compernolle et al. 2002, Peng et al. 2000, Scortegagna et al. 2003, Tian H et al. 1998). Die Rolle von HIF-3 $\alpha$ (Gu et al. 1998) ist bislang noch nicht abschließend geklärt.

\subsubsection{Struktur}

Der heterodimere Transkriptionsfaktor HIF-1 gehört zur Familie der basic helix-loophelix (bHLH)-Transkriptionsfaktoren und sowohl die $\alpha$ - wie auch die $\beta$-Untereinheit besitzen jeweils Per/ARNT/Sim (PAS)-Domänen. Bei HIF-1 $\alpha$ ist diese Domäne für die Dimerisierung mit der HIF-1 $\beta$-Untereinheit und für die Bindung an die spezifische Basen-Sequenz 
5-G/ACGTG`-3` verantwortlich. Diese spezifische Sequenz befindet sich als sogenanntes hypoxia response element (HRE) im Promotorbereich diverser, Hypoxie-induzierbarer Zielgene (Wang GL et al. 1995, Yang J et al. 2005).

HIF-1 $\alpha$ besitzt zusätzlich noch zwei Transaktivierungsdomänen, eine am N-Terminus (NTAD) und eine am C-Terminus (C-TAD), an die spezifische Co-Aktivatoren binden können (Jiang et al. 1997, Pugh et al. 1997). Beispielsweise führt die Hydroxylierung des Asn ${ }^{803}$ innerhalb der C-TAD durch den factor inhibiting HIF-1 (FIH-1) zu einer Inhibition der transkriptionellen Aktivität von HIF-1 (Lando et al. 2002).

Eine weitere, funktionell wichtige Domäne innerhalb des HIF-1 $\alpha$-Proteins ist die oxygendependent degradation domain (ODDD). Dort findet Sauerstoff-abhängig durch Hydroxylierung der beiden Aminosäuren Pro $^{402}$ und Pro ${ }^{564}$ die Markierung für den proteasomalen Abbau statt (Huang LE et al. 1998, Ivan et al. 2001, Jaakkola et al. 2001).

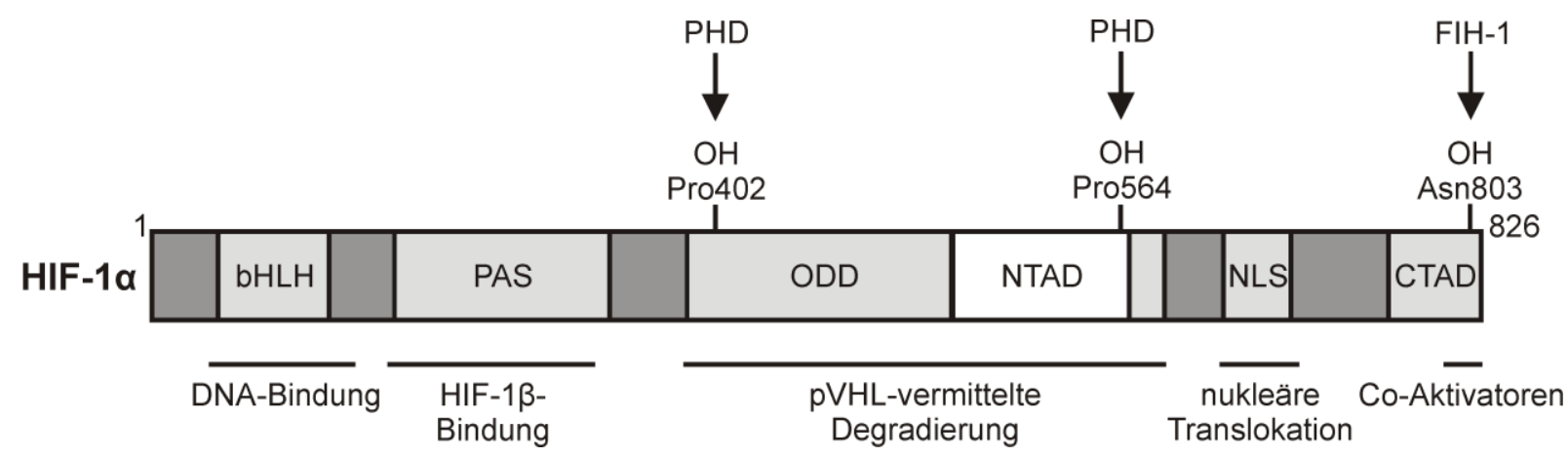

Abbildung 1: Proteindomänen von HIF-1a.

Dargestellt wird der funktionelle und strukturelle Aufbau des Transkriptionsfaktors HIF-1 $\alpha$ samt der posttranslatorischen Modifikationen spezifischer Aminosäuren-Reste. Die dazu nötigen Enzyme sind ebenfalls genannt. Abkürzungen: bHLH (basische helix-loop-helixDomäne), PAS (Per/ARNT/Sim-Domäne), ODDD (oxygen-dependent degradation domain), N-TAD (N-terminale transaktivierende Domäne), NLS (nuclear localization signal), C-TAD (C-terminale transaktivierende Domäne), PHD (Prolyl-4-Hydroxylase-Domäne-Protein), FIH1 (factor inhibiting HIF-1), pVHL (von-Hippel-Lindau-Tumorsuppressor), OH (Hydroxylierung) [modifiziert nach Rocha 2007, Seite 391]

\subsubsection{Regulation}

Die ODDD ist entscheidend an der Sauerstoff-abhängigen HIF-1 $\alpha$-Regulation durch die Prolyl-4-Hydroxylase-Domäne-Proteine (PHDs) beteiligt. In Zellen, welche adäquat mit Sauerstoff versorgt werden, hat HIF-1 $\alpha$ lediglich eine Halbwertszeit von weniger als 5 Minuten, was auf die schnelle proteasomale Degradation zurückzuführen ist (Huang LE et al. 1998). Durch die PHD-abhängigen Hydroxylierungen von Pro ${ }^{402}$ und Pro ${ }^{564}$ innerhalb der ODDD von HIF-1 $\alpha$ ist es der E3-Ligase pVHL, dem Produkt des von-Hippel-LindauTumorsuppressor-Gens, möglich, an HIF-1 $\alpha$ zu binden und es durch Polyubiquitinierung für 
den proteasomalen Abbau zu markieren (Maxwell et al. 1999). Dabei ist pVHL Teil eines Multiproteinkomplex, der aus den Proteinen Elongin B, Elongin C, Rbx 1 und Cul2 aufgebaut ist (Kamura et al. 1999, Lisztwan et al. 1999, Stebbins et al. 1999). Somatische Mutationen im von-Hippel-Lindau-Gen werden zum Beispiel in den meisten sporadischen klarzelligen Nierentumoren beobachtet. Davon zu unterscheiden ist das von-Hippel-Lindau-Syndrom. Bei dieser dominant-vererbten Krankheit ist eine Keimbahnmutation Ursache des Krankheitsbildes. Zahlreiche gut- und bösartige Tumoren, wie z.B. Angiome der Retina, sind Bestandteil dieser Erkrankung. Klarzellige Nierenkarzinome sind ebenfalls eine häufige Manifestation des von-Hippel-Lindau-Syndroms. Umgekehrt jedoch sind Nierentumoren nur in weniger als 2\% auf dieses Syndrom zurückzuführen (Foster et al. 1994, Gnarra et al. 1994).

Wichtige Co-Faktoren für die transkriptionelle Aktivität von HIF-1 sind die homologen, ubiquitär exprimierten Proteine p300 und CBP (CREB-bindendes Protein), welche funktionelle Histon-Acetyltransferasen sind (Carrozza et al. 2003). Mittels seiner CysteinHistidin-reichen Domäne bindet p300 an die C-TAD von HIF-1 $\alpha$ und sorgt vermutlich über die Acetylierung von Histonen für eine Umgestaltung der Chromatinstruktur, was den Zugang von HIF-1 an die DNA erleichtert und somit die transkriptionelle Aktivität steigert (Arany et al. 1996). Das erwähnte Protein FIH-1 katalysiert unter normoxischen Bedingungen die Hydroxylierung von HIF-1 $\alpha$ an $\mathrm{Asn}^{803}$, was die Bindung von p300/CBP an HIF-1 $\alpha$ verhindert. Die Folge davon ist eine verminderte transkriptionelle Aktivität (Lando et al. 2002).

Zusammenfassend wird demnach durch die erwähnten Hydroxylierungen unter normoxischen Bedingungen einerseits die proteasomale Degradierung von HIF-1 $\alpha$ gefördert und gleichzeitig die transkriptionelle Aktivität inhibiert.

Jeong et al. haben 2002 ferner beobachtet, dass HIF-1 $\alpha$ neben Hydroxylierungen auch acetyliert werden kann. Es wurde beschrieben, dass das arrest-defective-1 protein (ARD1) in der Lage ist, das in der ODDD lokalisierte Lysin ${ }^{532} \mathrm{zu}$ acetylieren und somit den Zugang von pVHL an HIF-1 $\alpha$ zu erleichtern. Allerdings wurde diese Beobachtung durch Arnesen et al. 2005 nicht bestätigt. Es konnte zwar ebenfalls eine Interaktion zwischen HIF-1 $\alpha$ und ARD1 festgestellt werden, jedoch keine ARD1-vermittelte Acetylierung. Zur genaueren Beurteilung dieser Interaktion werden weitere Untersuchungen erforderlich sein. 
Verantwortlich für die bereits erwähnten Hydroxylierungen an Pro ${ }^{402}$ und Pro $^{564}$ sind die PHDs, die in drei Isoformen vorkommen (PHD1, PHD2, PHD3) (Epstein et al. 2001). Diese Enzyme zählen zur Familie der Fe (II)- und 2-Oxoglutarat-abhängigen Dioxygenasen. Wie bei allen Oxygenasen ist auch hier $\mathrm{O}_{2}$ Co-Substrat.

Die PHDs erkennen die spezifische Aminosäure-Sequenz Leu-Xaa-Xaa-Leu-Ala-Pro an der ODDD von HIF-1 $\alpha$ und hydroxylieren das am Ende dieser Sequenz stehende Prolin. Huang J et al. haben 2002 gezeigt, dass weder Mutationen der beiden Leucine innerhalb der ODDD noch Veränderungen des Alanins einen Einfluss auf die Hydroxylierung von HIF-1 $\alpha$ haben. Ausschlaggebend für die PHD-katalysierte Hydroxylierung ist lediglich das Prolin selbst am Ende der Sequenz.

PHD1, PHD2 und PHD3 weisen einen ähnlichen $\mathrm{K}_{\mathrm{M}^{-}}$Wert bezüglich Sauerstoff auf, was dafür spricht, dass die $\mathrm{O}_{2}$-Konzentration den gleichen Einfluss auf die katalytische Aktivität von allen drei PHDs hat. Der $\mathrm{K}_{\mathrm{M}}$-Wert der PHDs liegt zwischen 230 und $250 \mu \mathrm{M}$ und ist somit größer als die Konzentration des gelösten $\mathrm{O}_{2}$ in der Atmosphäre. Daher sind die PHDs als intrazelluläre Sauerstoffsensoren gut geeignet (Hirsilä et al. 2003).

Bei der Hydroxylierung von HIF-1 $\alpha$ entsteht neben den Hydroxyprolinen aus 2Oxoglutarat $\mathrm{CO}_{2}$ und Succinat. Ein weiterer Co-Faktor ist Ascorbat, ein Anti-Oxidans, was dafür sorgt, dass das in der Reaktion entstandene Fe (III) wieder zu Fe (II) reduziert wird (Myllyla et al. 1978). Somit ergibt sich folgende Reaktionsgleichung:

Prolin + 2-Oxoglutarat $\stackrel{\mathrm{PHD}}{\longrightarrow}$ 4-Hydroxyprolin + Succinat $+\mathrm{CO}_{2}$

$\mathrm{Fe}(\mathrm{II}), \mathrm{O}_{2}$,

Ascorbat

Abbildung 2: Durch die PHDs katalsysierte Hydoxylierung von HIF-1 $\alpha$.

Die PHDs katalysieren die Hydroxylierungen an $\mathrm{Pro}^{402}$ und $\mathrm{Pro}^{564}$ von HIF-1 $\alpha$. Für diese Reaktion werden neben 2-Oxoglutarat die Co-Faktoren Sauerstoff $\left(\mathrm{O}_{2}\right)$, Ascorbat und zweiwertiges Eisen (Fe II) benötigt. Reaktionsprodukte sind die hydroxylierten Proline, Succinat und Kohlenstoffdioxid $\left(\mathrm{CO}_{2}\right)$

\subsection{PHD-Enzyme}

\subsubsection{Unterschiedliche Isoformen}

Man unterscheidet bei den PHDs die drei verschiedenen Isoformen PHD1 (40 bzw. 43 kDa), PHD2 (46 kDa) und PHD3 (17 bzw. 24 kDa). Diese Enzyme werden auch als EGLN 
1-3 bezeichnet, da sie die humane Form der in Caenorhabditis elegans entdeckten Egl-9 (egg laying abnormal-9) darstellen (Ivan et al. 2002).

Alle drei Isoformen weisen eine deutliche Homologie in der C-terminalen katalytischen Domäne auf, in der N-terminalen Domäne unterscheiden sie sich jedoch voneinander. Des Weiteren unterscheiden sie sich in ihrer Gewebespezifität. So werden zum Beispiel besonders hohe PHD1-Level im Hoden nachgewiesen, wohingegen PHD3 vor allem im Herzmuskelgewebe exprimiert wird (Lieb et al. 2002, Cioffi et al. 2003). Aber die drei PHDIsoformen unterscheiden sich nicht nur in ihrem Gewebe-spezifischen Vorkommen, sondern auch in der Lokalisation innerhalb der Zelle. So tritt PHD1 vor allem im Nukleus auf, PHD2 ist vorwiegend im Zytoplasma lokalisiert und PHD3 kommt in beiden Zellkompartimenten vor (Metzen et al. 2003).

Auch in ihrer Substratspezifität unterscheiden sich die PHDs. Alle drei Isoformen sind in der Lage, das Pro ${ }^{564}$ von HIF-1 $\alpha$ zu hydroxylieren, wohingegen das Pro ${ }^{402}$ ausschließlich ein Substrat von PHD1 und PHD2 darstellt. Die $\mathrm{K}_{\mathrm{M}}$-Werte von PHD1 und PHD2 gegenüber dem Pro $^{402}$ sind sogar 20 bis 50 Mal höher als für Pro ${ }^{564}$. Dieser Befund macht deutlich, dass wichtige regulatorische Unterschiede zwischen Pro ${ }^{402}$ und Pro $^{564}$ bestehen (Epstein et al. 2001).

PHD2 spielt die entscheidende Rolle bei der HIF-1 $\alpha$-Degradierung in Normoxie (Berra et al. 2003). PHD3 hingegen wird in Normoxie nur zu einem sehr geringen Teil exprimiert. Erst unter länger andauernden hypoxischen Bedingungen kommt es zu einer vermehrten PHD3Expression (Appelhoff et al. 2004). PHD3 stellt, wie auch PHD2, selbst ein HIF-1-Zielgen dar. Folglich kommt es unter hypoxischen Bedingungen zu einer HIF-1-abhängigen, gesteigerten Transkriptionsrate von PHD2 und PHD3 (Metzen et al. 2005, Stiehl et al. 2006). Die HIF-1-Abhängigkeit dieses negativen Feedbacks beschrieben del Peso et al. 2003. Sie zeigten, dass eine hypoxisch-induzierte Expression von PHD2 und PHD3 in HIF-1 $\alpha$ defizienten Zellen ausblieb.

PHD1 und PHD3 können jeweils in zwei unterschiedlichen Molekülgrößen auftreten. Bei PHD1 sind die beiden unterschiedlichen Größen (40 kDa und $43 \mathrm{kDa}$ ) auf alternative Initiation der Translation zurückzuführen (Tian YM et al. 2006), bei PHD3 (17 kDa und 24 $\mathrm{kDa}$ ) auf alternatives Splicing (Cervera et al. 2006).

Wie HIF-1 $\alpha$ und HIF-2 $\alpha$ spielen auch die PHDs eine wichtige Rolle in der Embryogenese. Phd2 ${ }^{-/}$-Mäuse weisen Defekte in Plazenta und Herzentwicklung auf. Zu den Defekten der Plazenta zählt zum Beispiel eine verringerte Vaskularisierung des Labyrinths, im Herz sind unterentwickelte Trabeculae, ein unverschlossenes interventrikuläres Septum 
und vergrößerte Atrien zu beobachten. Schließlich sterben diese Mäuse in der Embryogenese zwischen Tag 12.5 und 14.5 (Takeda et al. 2006, Minamishima et al. 2008). Phd1 ${ }^{-/}$-Mäuse hingegen sind lebensfähig, zeigen äußerlich keinen Phänotyp, jedoch einen veränderten Metabolismus. So wird in Skelettmuskelzellen dieser Mäuse eine Umstellung von der oxidativen zur anaeroben Energiegewinnung nachgewiesen (Aragones et al. 2008). Phd $3^{-1-}$ Mäuse sind ebenfalls lebensfähig, zeigen jedoch eine Minderfunktion des sympathoadrenalen Systems. Durch die verminderte Innervation des Zielgewebes kommt es dadurch beispielsweise zur Hypotension (Bishop et al. 2008).

\subsubsection{Inhibition}

PHDs benötigen für ihre Funktion als Prolyl-Hydroxylase von HIF-1 $\alpha$ diverse CoFaktoren $\left(\mathrm{O}_{2}\right.$, Ascorbat, Fe (II) und 2-Oxoglutarat). Diese Faktoren stellen Möglichkeiten dar, die Funktion der PHDs zu inhibieren.

Bei ischämischen Erkrankungen wäre der Einsatz solcher Inhibitoren denkbar. Durch die PHD-Hemmung wird HIF-1 $\alpha$ stabilisiert und aktiviert seine Zielgene, wie beispielsweise VEGF. Der 2-Oxoglutarat-Antagonist Dimethyloxalylglyzin (DMOG) sorgt in ischämischem Skelettmuskelgewebe für eine gesteigerte Angiogenese, was den Heilungsprozess verbessern kann (Milkiewicz et al. 2004). Neben DMOG gibt es weitere 2-Oxoglutarat-Analoga, die als PHD-Inhibitoren eingesetzt werden könnten. N-Oxalylglyzin, Ethyl-3,4-dihydroxybenzoat (3,4-DHB) und L-Mimosin steigern die HIF-1-Aktivität inklusive gesteigerter Expressionen seiner Zielgene (Warnecke et al. 2003).

Ein weiterer PHD-Inhibitor ist der Eisenchelator Desferrioxamin (DFO). Jedoch ist die hemmende Wirkung von DFO nicht bei allen Hydroxylasen gleich stark. So wiesen Hirsilä et al. 2005 nach, dass die Aktivitäten von PHD1 und PHD2 kaum, von PHD3 hingegen fast komplett durch Zugabe von DFO zu inhibieren waren. Dieser Befund deutet an, dass das Eisen vor allem bei PHD1 und PHD2 in einem sehr stabil gebundenen Zustand vorliegen muss.

Darüber hinaus ist bekannt, dass die beiden Metalle Zink und Cobalt die PHD- und FIH1-Aktivität hemmen. Diese Inhibition könnte auf das kompetitive Blockieren der Eisenbindungsstelle durch Zink bzw. Cobalt zurückzuführen sein. Eine andere Hypothese ist, dass Zink bzw. Cobalt die intrazelluläre Ascorbat-Konzentration vermindert und infolgedessen das in der Prolyl-Hydroxylierung entstandene Fe (III) nicht mehr zu Fe (II) reduziert werden kann. Folglich wären die PHDs nicht mehr in der Lage, ihre Funktion auszuüben (Salnikow et al. 2004). Es könnte ferner sein, dass Cobalt über die Bindung an 
HIF-1 $\alpha$ verhindert, dass pVHL binden kann und demnach eine proteasomale Degradierung von HIF-1 $\alpha$ ausbleibt (Yuan et al. 2003). Eventuell kommen auch kombinierte Effekte der beschriebenen, potentiellen Wirkungsmechanismen von Zink und Cobalt in Frage.

Eine Alternative zu den PHD-Inhibitoren könnte auch die direkte Injektion von VEGF in das ischämische Gewebe sein. Allerdings sind durch VEGF-Überexpression induzierte Gefäße häufig undicht und nicht regulär ausgebildet, was zu Ödemen und Gefäßtumoren führen kann (Flamme et al. 1995). Das unterstreicht die Sensitivität dieses Systems und zeigt, weshalb es so schwierig ist, therapeutisch einzugreifen. Auch bei den erwähnten PHDInhibitoren gibt es zahlreiche Nebenwirkungen. So sorgen sie auch für die Inhibition der Kollagen-Prolyl-Hydroxylase, was zu einer verminderten Kollagensynthese führt. Die Folgen sind Bindegewebsschwächen und Katarakte (Holmes et al. 1981, Warnecke et al. 2003). Des Weiteren wurde als Nebenwirkung eine verminderte Zellproliferation beobachtet. Dieser Befund fiel besonders bei L-Mimosin- und 3,4-DHB-Behandlung in der Zellkultur auf (Warnecke et al. 2003). Trotz dieser und weiterer Nebenwirkungen sind PHD-Inhibitoren für den therapeutischen Einsatz denkbar. Neben Ischämie-bedingten Erkrankungen könnte auch die chronische Anämie, welche durch eine Niereninsuffizienz hervorgerufen wird, auf diese Weise behandelt werden. Durch die HIF-1-Stabilisierung käme es zu einer gesteigerten EPOExpression, die der Anämie entgegenwirken würde.

\subsubsection{Regulation und Interaktion}

Es gibt neben HIF-1 $\alpha$ zahlreiche Proteine, mit denen die PHDs interagieren. Manche dieser Proteine interagieren selektiv nur mit einer der drei PHD-Isoformen, andere unspezifisch mit allen drei PHDs. Im Folgenden wird eine Auswahl der PHD-Interaktionen und -Regulationen dargestellt, die zeigen sollen, wie komplex und vielfältig die Rolle der PHDs innerhalb der Zellen ist.

Ein Regulator der PHDs ist Siah2 (seven in absentia homologue 2), welches zur Familie der RING (really interesting new gene)-Domäne enthaltenden E3-Ligasen zählt (Lorick et al. 1999). Hu G und Fearon haben 1999 gezeigt, dass auf der einen Seite die RING-Domäne und der N-Terminus von Siah in der Lage sind, E2-Proteine zu binden, wohingegen der CTerminus mit den Co-Faktoren bzw. den Substraten interagiert. Viele dieser durch Siah ubiquitinierten Proteine werden daraufhin proteasomal degradiert (Hu G et al. 1997), wie auch die PHDs. Hier ist zu beachten, dass Siah2 nicht für alle PHDs gleich affin ist, sondern vor allem PHD3 und abgeschwächt auch PHD1 ubiquitiniert und somit für den proteasomalen Abbau markiert (Nakayama et al. 2004, Möller et al. 2009). Viele Proteine, 
die mit Siah interagieren, haben ein Val-Xaa-Pro-Motiv. Sowohl Mutationen im Valin als auch Veränderungen des Prolins setzen hierbei eine eigentlich vorhandene Interaktion mit Siah außer Kraft (House et al. 2003). PHDs ihrerseits besitzen diese Sequenz nicht, sind aber trotzdem in der Lage, von Siah2 ubiquitiniert zu werden. Es ist noch unklar, ob daran zusätzliche Proteine, die eine Adaptorfunktion zwischen den PHDs und Siah2 übernehmen, beteiligt sind.

Zwei Beispiele von Proteinen, die jeweils nur mit einer Isoform der PHDs interagieren, sind Morg1 (mitogen-activated protein kinase organizer 1) und ING4 (inhibitor of growth family member 4). Morg1 sorgt vermutlich für die spezifische Interaktion zwischen PHD3 und HIF-1 $\alpha$ (Hopfer et al. 2006), wohingegen ING4 ausschließlich mit PHD2 interagiert. Dabei wurde von Ozer et al. 2005 beschrieben, dass PHD2 über die Rekrutierung von ING4 die HIF-1 $\alpha$-Aktivität indirekt reguliert. ING4 ist nämlich Bestandteil eines ChromatinRemodeling-Komplexes und somit in der Lage, die HIF-1 abhängige Genexpression zu regulieren.

Ein weiteres, nur mit PHD2 interagierendes Protein ist die Peptidyl-Prolyl cis/trans Isomerase FKBP38 (FK506-bindendes Protein 38), die spezifisch PHD2 bindet und dessen Stabilität reguliert (Barth et al. 2007).

Ein spezifisch mit PHD1 in Zusammenhang stehendes Protein ist the inhibitor of $N F-\kappa B$ kinase $\beta$ (IKK $\beta$ ). Es wird hier eine Regulatorfunktion von PHD1 vermutet. IKK $\beta$ besitzt, wie HIF-1 $\alpha$, die Sequenz Leu-Xaa-Xaa-Leu-Ala-Pro, welche für die Interaktion mit PHD1 verantwortlich ist. PHD-Inhibition sorgt für einen Anstieg der IKK $\beta$-Aktivität, was zu einem Anstieg der NF-кB (mammalian nuclear factor- $\kappa B$ )-Aktivität führt (Cummins et al. 2006). NF-kB ist ein Transkriptionsfaktor, der beispielsweise die Entzündungsantwort durch die Aktivierung seiner Zielgene induziert. So sorgt NF-кB für die Expression bestimmter Adhäsionsmoleküle in Endothelzellen und Leukozyten. Diese Adhäsionsmoleküle sind im Rahmen der Extravasation der weißen Blutkörperchen für die Interaktion zwischen Leukozyten und Endothelzellen verantwortlich und somit Voraussetzung für eine adäquate Immunantwort (Eck et al. 1993).

Neben HIF-1 $\alpha$ und vermutlich IKK $\beta$ gibt es ein weiteres Protein, welches von den PHDs, genauer von PHD3, reguliert wird. Dieses ist the activating transcription factor-4, kurz ATF4, welches zur ATF/CREB-Familie der basic-leucine-zipper-Transkriptionsfaktoren zählt (Hai und Hartman 2001). Reguliert wird ATF-4 weder von PHD1 noch von PHD2, sondern ausschließlich von PHD3 (Köditz et al. 2007). Köditz et al. haben 2007 des Weiteren gezeigt, dass ATF-4, wie HIF-1 $\alpha$, eine ODDD besitzt, die in diesem Fall jedoch 5 Proline enthält. 
Verantwortlich für die Polyubiquitinierung von ATF-4 ist die $\mathrm{SCF}^{\beta T R C P}$-Ubiquitin-Ligase (Lassot et al. 2001). Die ATF-4-Expresssion wird bei Hypoxie, oxidativem Stress oder bei Aminosäurenmangel induziert und hat über die Aktivierung seiner Zielgene Einfluss auf das Überleben der Zelle (Blais et al. 2004). Eines dieser Zielgene ist GADD 153. GADD steht für growth arrest or cell death, was die Beteiligung dieses Proteins am Überleben der Zelle verdeutlicht. Es kann sowohl den Zellzyklusarrest wie auch die Apoptose induzieren (Barone et al. 1994, Matsumoto et al. 1996). 2004 entdeckten Ameri et al. erhöhte ATF-4-Spiegel in abgestorbenen Gewebearealen nahe Tumorgewebe, was einen Zusammenhang zwischen Tumoren und ATF-4 vermuten lässt.

Diese zahlreichen, beschriebenen Regulations- und Interaktionsprinzipien verdeutlichen, dass PHDs nicht nur über die Regulation von HIF-1 $\alpha$ eine wichtige Rolle bei der SauerstoffHomöostase der Zelle spielen, sondern auch die Entzündungsantwort, Apoptose und Tumorgenese mit beeinflussen.

\subsection{Zelladhäsion}

\subsubsection{Integrine}

Integrine stellen das Bindeglied zwischen der Zelle und der extrazellulären Matrix (ECM) dar. Zur ECM zählen Fibronektine, Kollagene, Laminine und diverse Proteoglykane, an denen Zellen adhärieren können. Strukturell sind Integrine heterodimere Rezeptoren, die aus einer $\alpha$ - und einer $\beta$-Untereinheit aufgebaut sind. In Säugetieren sind 18 verschiedene $\alpha$-, sowie 8 unterschiedliche $\beta$-Isoformen bekannt. Durch die unterschiedlichen Kombinationsmöglichkeiten ergibt sich eine Vielzahl von Integrin-Heterodimeren, die sich in ihrer Liganden-Affinität jedoch häufig überlappen (Hynes 1992, Hynes 2002).

Integrine besitzen eine Transmembrandomäne, sowie eine extra- und eine intrazelluläre Domäne. Die extrazelluläre Domäne ist für die Bindung des Liganden verantwortlich. Die meist kleine, intrazelluläre Domäne (40-60 Aminosäuren) der Integrine ist über sogenannte focal adhesion-Proteine (FA-Proteine), wie Vinculin oder Talin, mit dem Zytoskelett der Zelle verbunden. Talin ist in diesem Zusammenhang für die initiale Verbindung zwischen Integrinen und F-Aktin verantwortlich (Zhang et al. 2008), Vinculin hingegen verstärkt die Talin-Aktin-Bindung, indem es selbst beide Proteine bindet. In diesem Zusammenhang wurde beschrieben, dass Fibroblasten, die kein Vinculin exprimieren, nur sehr schwach und instabil an der extrazellulären Matrix adhärieren können (Saunders et al. 2006). Bindet ein IntegrinRezeptor ein Protein der ECM, kommt es zur Anhäufung von Integrin-Rezeptoren an der Membran, was als integrin-clustering bezeichnet wird und eine Umgestaltung des 
Aktingerüstes der Zelle zur Folge hat. Durch weitere Organisation von Integrinen und assoziierten Proteinen zu Multi-Protein-Aggregaten, den sogenannten fokalen Kontakten, kommt es schließlich zur stabilen Adhäsion der Zelle an die ECM (Burridge et al. 1988, van der Flier und Sonnenberg 2001).

Wie alle membranständigen Rezeptoren übernehmen Integrine auch eine Funktion im Rahmen des outside-in-signaling. So konnte gezeigt werden, dass Zellen bei einer ungenügenden Integrin-vermittelten Zelladhäsion apoptotisch wurden. Integrine sind demnach auch am Zellüberleben bzw. am Zelltod beteiligt (Meredith et al. 1993). Neben dem outside-in-signaling sind Integrine auch am umgekehrten Vorgang, dem inside-out-signaling, beteiligt. Es können also auch Signalwege innerhalb der Zelle Einfluss auf die Funktion der Integrine nehmen. So aktiviert die Proteinkinase $\mathrm{C}$ das Integrin $\alpha 5 \beta 1$ in chinese-hamsterovarial-Zellen (Vuori und Ruoslahti 1993). Ein klinisch wichtiges Beispiel des inside-outsignaling ist die Bindung von Fibrinogen an das Integrin $\alpha \operatorname{IIb} \beta 3$ während der primären Hämostase. Erst durch die intrazelluläre Aktivierung des Integrins wird dessen Affinität so moduliert, dass Fibrinogen binden kann (Shattil et al. 1997).

Die erwähnten Funktionen und Interaktionen stellen zwar nur einen kleinen Ausschnitt dar, verdeutlichen jedoch die Komplexität und Vielfalt der Integrine.

\subsubsection{Regulation des Zellzyklus und Beteiligung an der Tumormetastasierung}

Integrine interagieren mit zahlreichen Wachstumsfaktoren. So sorgt im Rahmen des outside-in-signaling die Integrin-vermittelte Zelladhäsion an Fibronektin für eine Aktivierung der GTPasen Cdc42 und Rac, welche zur Rho-Familie zählen (Price et al. 1998). Cdc42 und Rac aktivieren p21-dependent protein kinases (PAKs), welche ihrerseits die extracellular signal regulated kinase (Erk) in ihrer Aktivität regulieren. Die Erk spielt eine entscheidende Rolle in der Expression von Cyclin D1 (Weber et al. 1997, Miyamoto et al. 1996). Cyclin D1 ist ein wichtiger Regulator des Zellzyklus, der zusammen mit der cyclin dependent kinase 4/6 ( $\mathrm{Cdk}$ 4/6) für das Fortschreiten durch die postmitotische G1-Phase sorgt (Albanese et al. 1995, Lavoie et al. 1996). In diesem Zusammenhang haben viele Arbeitsgruppen beobachtet, dass die Induktion von Cyclin D1 durch Stimulation mit Wachstumsfaktoren ausbleibt, wenn keine Verbindung der Zellen zur ECM vorliegt. Dieser Befund verdeutlicht die Rolle der Zelladhäsion im Rahmen der Zellzyklusregulation (Bohmer et al. 1996, Zhu X et al. 1996). 
Die zelluläre Adhäsion an die ECM hat ferner Einfluss auf eine mögliche Tumormetastasierung. So wurde bereits erwähnt, dass bei fehlender Adhäsion an die ECM Zellen apoptotisch werden. Diese spezielle Form der Apoptose wird nach dem griechischen Wort für Heimatlosigkeit als anoikis bezeichnet (Frisch und Francis 1994). Folglich kann der Verlust der Verankerung an die ECM bei dysplastisch veränderten Zellen deren Proliferation verhindern und somit einer möglichen Tumormetastasierung entgegenwirken. Jedoch ist es Tumorzellen, die in der Lage sind, zu metastasieren, möglich, dieser Form der Apoptose zu entgehen und in ihnen fremden Umgebungen zu überleben ( $Z$ hu $Z$ et al. 2001). Eine Strategie von Tumorzellen, anoikis $\mathrm{zu}$ verhindern, ist die Expression spezieller Integrine, die intrazellulär über die Aktivierung diverser Signaltransduktionswege am Überleben der Zelle beteiligt sind. Melanomzellen exprimieren bei einem erhöhten Malignitätsgrad beispielsweise das Integrin $\alpha 5 \beta 3$, welches in frühen Melanomzellen bzw. untransformierten Melanozyten nicht auftritt (Albelda et al. 1990). Dieses Heterodimer verhindert anoikis vermutlich über eine Veränderung des Bcl-2-Bax-Quotienten zugunsten des antiapoptischen Bcl-2 (Petitclerc et al. 1999). Ebenfalls von Bedeutung für eine Tumormetastasierung ist die epithelial to mesenchymal transition (EMT). Hier werden zahlreiche mesenchymale Gene in Epithelzellen aktiviert, sodass diese ihren epithelialen Charakter verlieren und mesenchymale Eigenschaften, wie zum Beispiel den Verlust der fokalen Kontakte, annehmen. Die EMT stellt eine Grundvoraussetzung für eine mögliche Metastasierung dar. Ein in diesem Zusammenhang wichtiges Protein ist der Transkriptionsfaktor NF- $\mathrm{B}$, welcher konstitutiv in Brustdrüsen-, Prostata-, Kolorektal- und Ovarialtumoren exprimiert wird (Karin et al. 2002) und der sowohl an der Apoptose-Resistenz wie auch an der Aktivierung mesenchymaler Gene (Huber et al. 2004) beteiligt ist. Des Weiteren sind metastasierte Tumorzellen in der Lage, ihre neue Umgebung zu modulieren und die Zelladhäsion in fremdem Gewebe zu fördern. Die von Melanomzellen exprimierten Wachstumsfaktoren stimulieren benachbarte Fibroblasten zu einer verstärkten Produktion der ECM-Proteine Laminin, Kollagen und Fibronektin (Berking et al. 2001, Meier et al. 2000). Dadurch ergibt sich wiederum eine verbesserte Adhäsion der Tumorzellen in einer ihnen eigentlich fremden Umgebung.

Zusammenfassend ist festzustellen, dass Zelladhäsion nicht ausschließlich für die mechanische Verankerung der Zellen im Gewebe verantwortlich ist, sondern darüber hinaus in der Lage ist, viele Eigenschaften der Zelle zu regulieren und zu verändern. 


\subsubsection{Einfluss von HIF-1a}

Corley et al. haben 2005 den Einfluss von HIF-1 $\alpha$ auf die Zelladhäsion von glatten Muskelzellen untersucht. Dazu wurden glatte Muskelzellen der Aorta und der Koronararterien mit einem HIF-1 $\alpha$-cDNA-enthaltenden Plasmid adenoviral transduziert, was in einer zellulären Überexpression von HIF-1 $\alpha$ resultierte. Anschließend wurde das Adhäsionsverhalten dieser Zellen mit nicht-transfizierten bzw. kontroll-transfizierten glatten Muskelzellen verglichen. Dabei zeigte sich eine verminderte Adhäsion der HIF-1 $\alpha$ überexprimierenden Muskelzellen auf Kollagenen, Fibronektin, Elastin und Laminin. Verglichen mit den nicht- bzw. kontroll-transfizierten Zellen zeigte sich bei den HIF-1 $\alpha$ überexprimierenden Zellen eine Reduktion der Zelladhäsion um 27\% (glatte Muskelzellen der Aorta) bzw. 38\% (glatte Muskelzellen der Koronararterien). Als nächstes untersuchten Corley et al., worauf dieses unterschiedliche Adhäsionsverhalten zurückzuführen war. Dabei wurde keine Differenz in der Größe, Verteilung und Anzahl der fokalen Kontakte festgestellt, jedoch ein Unterschied in der Phosphorylierung der focal adhesion kinase (FAK), die über Tyrosin-Phosphorylierungen eine wichtige Rolle in der Regulation der Zelladhäsion übernimmt. So wiesen die HIF-1 $\alpha$-überexprimierenden Zellen eine geringere Phosphorylierung der FAK auf, was mit einer verminderten Aktivität der FAK einherging. Eine verminderte Aktivität der FAK hat verminderte Tyrosin-Phosphorylierungen diverser Proteine zur Folge, die an der Zelladhäsion beteiligt sind (Panetti 2002). Somit hat HIF-1 $\alpha$ Einfluss auf die Zelladhäsion über eine Regulation der FAK-Phosphorylierung.

\subsection{Cofilin}

Cofilin zählt zu den Aktin-bindenden Proteinen. Es ist in der Lage, Aktinfilamente zu depolymerisieren und zu trennen, was für die Dynamik des Aktingerüstes und demnach für die Zellmobilität unabdingbar ist (McGough et al. 1997). Neben den beiden Isoformen Cofilin-1 (Cfl-1) und -2 (Cfl-2) ist der Aktin-depolymerisierende Faktor (ADF bzw. Destrin) Bestandteil der Cofilin/ADF-Familie. Cfl-1, Cfl-2 und ADF unterscheiden sich in ihrem Gewebe- und Zell-spezifischen Vorkommen im Säugetier-Organsimus. Cfl-1 ist in fast allen adulten Zellen vorhanden, mit Ausnahme des differenzierten Skelettmuskel- und Herzmuskelgewebes, da dort ausschließlich Cfl-2 exprimiert wird (Ono et al. 1994). Deshalb wird Cfl-1 auch als non-mucle cofilin (n-Cofilin) bzw. Cfl-2 als muscle cofilin (m-Cofilin) bezeichnet. ADF wird vor allem in Epithel- und Endothelzellen exprimiert (Nakashima et al. 2005). 
Reguliert werden die unterschiedlichen Cofiline durch Phosphorylierung bzw. Dephosphorylierung am $\mathrm{Ser}^{3}$, wobei die phosphorylierte Form die inaktive Variante darstellt (Agnew et al. 1995, Moriyama et al. 1996). Verantwortlich für die Phosphorylierungen sind die LIM-Kinasen 1 und 2. Es konnte gezeigt werden, dass sie durch die $\mathrm{Ser}^{3}$ Phosphorylierung Cofilin inaktivieren und somit Einfluss auf die Organisation des Zytoskeletts haben (Arber et al. 1998). Die LIM-Kinasen werden ihrereseits indirekt durch die kleine GTPase Rho aktiviert (Sumi et al. 1999, Yang N et al. 1998). Zwischengeschaltet ist die rho-associated, coiled-coil-forming protein kinase (ROCK), welche von Rho aktiviert wird und dann wiederum selbst die LIM-Kinasen phosphoryliert und somit aktiviert (Maekawa et al. 1999). Die Aktivierung der LIM-Kinasen führt dann, wie bereits erwähnt, zur Phosphorylierung und Inaktivierung von Cofilin. Auf der anderen Seite sind die slingshotPhosphatase ( $\mathrm{SSH}$ ) und die Chronophin-Phosphatase (CIN) für die Dephosphorylierung des Cofilins am $\mathrm{Ser}^{3}$ verantwortlich und reaktivieren auf diese Weise das Protein (Niwa et al. 2002, Gohla et al. 2005).

Vor kurzer Zeit wurde ein Zusammenhang zwischen der Cofilin-Aktivität und der Ausbildung bzw. Verteilung fokaler Kontakte entdeckt. So nahm die Dynamik der fokalen Kontakte ab, wenn vermehrt phosphoryliertes, also inaktives, Cofilin vorlag. Die Größe der einzelnen Kontakte nahm zwar zu, die Anzahl jedoch war deutlich erniedrigt (Marshall et al. 2009).

\subsection{Fragestellung und Zielsetzung dieser Arbeit}

Der Transkriptionsfaktor HIF-1 spielt nicht nur eine wichtige Rolle bei der Anpassung von Zellen an hypoxische Bedingungen, sondern er übernimmt auch unterschiedliche Funktionen bei der Tumorgenese und Metastasierung, was bereits in vielen Publikationen gezeigt werde konnte. Entscheidend beteiligt an der Regulation von HIF-1 ist das ubiquitär exprimierte Enzym PHD2, welches, je nach Sauerstoffangebot, die Untereinheit HIF-1 $\alpha$ durch Prolyl-Hydroxylierungen für den proteasomalen Abbau markiert.

Im Rahmen dieser Arbeit wurde der Einfluss von PHD2 auf die Zelladhäsion an Bestandteile der extrazellulären Matrix diverser Tumorzellen in vitro untersucht. Die Adhäsionsfähigkeit von maligne transformierten Zellen ist eine wichtige Eigenschaft im Metastasierungsprozess. Wohingegen die Rolle von HIF-1 bzw. HIF-1 $\alpha$ in Bezug auf den Prozess der Metastasierung bereits Gegenstand zahlreicher wissenschaftlicher Veröffentlichungen und Untersuchungen ist, ist über die, möglicherweise auch HIF-1 $\alpha$ unabhängigen, Funktionen von PHD2 in Bezug auf die Tumormetastasierung bedeutend 
weniger bekannt. Deshalb wurde in dieser Arbeit nicht nur qualitativ die Rolle von PHD2 an der Zelladhäsion von Tumorzellen beobachtet, sondern auch mittels Western Blot, Immunfluoreszenz und qRT-PCR versucht, PHD2-abhängige, intrazelluläre Vorgänge zu identifizieren, die mit dem beobachteten Phänotyp in Verbindung stehen könnten. Das sollte zu einem detaillierteren Verständnis über den Vorgang der Metastasierung führen.

Die Charakterisierung des Metastasierungsprozesses ist ein wichtiger Schritt für die Entwicklung innovativer Therapiestrategien. PHDs spielen bislang in der Therapie der chronischen Anämie eine Rolle, indem durch PHD-Inhibitoren die HIF-1 $\alpha$-Aktivität gesteigert wird. Das hat eine vermehrte, renale EPO-Produktion zur Folge, die der Anämie bei Niereninsuffizienz entgegenwirkt. Dieses Therapieprinzip wird derzeit anhand von Studien auf seine Wirksamkeit überprüft. Jedoch könnte die Beeinflussung der PHDs auch bei anderen Erkrankungen, wie zum Beispiel der hier erwähnten malignen Entartung, von entscheidender Bedeutung neuer Therapiemöglichkeiten sein. 


\section{Material und Methoden}

\subsection{Zelllinien}

\subsubsection{Tetrazyklin-induzierbare PHD2-knock-down-Zellen}

Die Grundlage dieser Zelllinie sind HeLa-Zellen. Allgemein handelt es sich bei den HeLa-Zellen um humane Epithelzellen eines Zervix-Adenocarcinoms, welche von der American Type Culture Collection (ATCC, Rockville, MD, USA) bezogen wurden.

T-REx-HeLa-Zellen (Invitrogen, Karlsruhe, Deutschland) sind HeLa-Zellen, welche mit dem Plasmid pcDNA ${ }^{\text {TM}}$ 6/TR transfiziert wurden. Dieses Plasmid kodiert für einen konstitutiv exprimierten Tetrazyklin-Repressor (TetR). Zusätzlich sorgt ein Blasticidinresistenzgen bei Zugabe von Blasticidin (5 $\mu \mathrm{g} / \mathrm{ml}$; Invitrogen) für die Selektion der Zellen, die das beschriebene Plasmid stabil integriert haben.

Frau Dr. med. Sinja Le Huu etablierte in der Abteilung für Herz- und Kreislaufphysiologie der Universitätsmedizin Göttingen auf Grundlage der beschriebenen TREx-HeLa-Zellen eine neue Zelllinie (P2.1.1-16), bei der unter Zugabe von Tetrazyklin eine shRNA gebildet wird, welche den Abbau der PHD2-mRNA durch RNAsen induziert. Dazu wurden die T-REx-HeLa-Zellen mit einem pENTR ${ }^{\mathrm{TM}} / \mathrm{H} 1 / \mathrm{TO}-\mathrm{shPHD} 2-k o d i e r e n d e n$ Plasmid stabil transfiziert. Die Expression der shRNA steht unter der Kontrolle der TATA-Box eines CMV-Promotors. Vor und hinter der TATA-Box der kodierenden Region liegt ein TetOperator (TetO), an welchen der TetR in Abwesenheit von Tetrazyklin in Form eines Homodimers bindet. Dadurch wird die Bindungsstelle der Polymerase-III-Promotorregion blockiert und die shRNA vermindert gebildet. In Anwesenheit von Tetrazyklin im Zellkulturmedium und dessen Bindung an den TetR wird dieser in seiner Konformation so verändert, dass er nicht mehr an den TetO binden kann. Folglich wird die Polymerase-III an ihre Promotorregion binden und die shRNA wird vermehrt exprimiert.

Bei dieser etablierten Zelllinie erfolgt die Selektion der Zellen, die das Plasmid stabil in das Genom integriert hatten, mit Zeocin ${ }^{\mathrm{TM}}$ (375 $\mu \mathrm{g} / \mathrm{ml}$; Invitrogen). Die Zugabe von Tetrazyklin (10 $\mu \mathrm{g} / \mathrm{ml}$; Sigma-Aldrich, St. Spruce, USA) muss alle $48 \mathrm{~h}$ erneuert werden.

\subsection{2}

Stabil transfizierte PHD2-knock-down-Zellen (HeLa, MDA-MB231, MCF7)

HeLa-Zellen sind humane Zellen eines Zervix-Adenokarzinoms, wohingegen es sich bei den MDA-MB-231- und den MCF7-Zellen um humane Brustkrebszellen handelt. Die 
Proliferation der MCF7-Zellen kann zudem durch Östrogene stimuliert, bzw. durch AntiÖstrogene inhibiert werden (Lippman et al. 1976).

In der Arbeitsgruppe von Prof. Dr. R. Wenger (Universität Zürich, Schweiz) wurden aus diesen drei Zelllinien die PHD2-knock-down-Klone 1B6 bzw. $3 \mathrm{~B} 7$ (HeLa), \#3 bzw. \#4 (MDA-MB-231) und C1 bzw. C7 (MCF7) generiert. Dazu wurden die Zellen jeweils stabil mit einem Mission ${ }^{\circledR}$ pLKO.1-puro-shPHD2-kodierenden Plasmid (Sigma-Aldrich) transfiziert. Ferner wurde in allen drei Zelllinien eine sh-transfizierte Kontrolle (sh-Kontrolle) durch Transfektion mit dem Plasmid Mission ${ }^{\circledR}$ pLKO.1-puro (Sigma-Aldrich) erzeugt. Ein Puromycinresistenzgen innerhalb der Plasmide ermöglicht durch Zugabe von Puromycin (CarlRoth, Karlsruhe, Deutschland; HeLa: $10 \mu \mathrm{g} / \mathrm{ml}$; MDA-MB-231: $4 \mu \mathrm{g} / \mathrm{ml}$; MCF7: 1 $\mu \mathrm{g} / \mathrm{ml})$ in das Zellkulturmedium die Selektion der Zellen, die das Plasmid stabil in ihr Genom integriert haben. Diese Zellen wurden uns freundlicherweise von Prof. Dr. R. Wenger zur Verfügung gestellt.

\subsubsection{MEF-Hif-1 $\alpha^{+/+}$- und MEF-Hif-1 $\alpha^{-/-}$-Zellen}

In der Arbeitsgruppe von Prof. R. S. Johnson (University of California San Diego, La Jolla, USA) wurden Maus-embryonale Fibroblasten (MEF) aus HIF-1 $\alpha$-knock-out-Mäusen gewonnen. Sowohl die MEFs aus den HIF-1 $\alpha$-knock-out-Mäusen als auch aus HIF-1 $\alpha$ Wildtyp-Geschwisterembryonen wurden am Tag E9.5 isoliert. Diese Zellen wurden mit einem SV40 large T Antigen- und einem H-ras-enthaltenden Plasmid transfiziert und dadurch immortalisiert bzw. transformiert.

Aus diesen Ausgangszelllinien (MEF-Hif- $1 \alpha^{-/-}$bzw. MEF-Hif- $1 \alpha^{+/+}$), die Prof. R. S. Johnson freundlicherweise zur Verfügung stellte, wurden von Frau Dr. rer. nat. A. Zieseniß in der Abteilung Herz- und Kreislaufphysiologie am Zentrum für Physiologie der Universitätsmedizin Göttingen PHD2-knock-down-Klone hergestellt. Dazu wurden die Zellen mit dem Mission ${ }^{\circledR}$ pLKO.1-puro-mPHD2-9740-shRNA-kodierenden Plasmid (SigmaAldrich) stabil transfiziert. Aus den MEF-Hif-1 $\alpha^{-/-}$wurden dadurch die PHD2-knock-downKlone 40F10B4 und 41A7B4, aus den MEF-Hif-1 $\alpha^{+/+}$die PHD2-knock-down-Klone 40B2D3 und 40F5B4 generiert. Außerdem wurde durch stabile Transfektion mit dem Plasmid Mission ${ }^{\circledR}$ pLKO.1-puro-non-target (Sigma-Aldrich) eine sh-transfizierte Kontrolle erstellt. Bei den MEF-Hif-1 $\alpha^{-/-}$-Zellen handelte es sich dabei um die Klone CE11B5 und CE8C3, bei den MEF-Hif-1 $\alpha^{+/+}$-Zellen dagegen waren es die Klone CC8B4 und CC8D3. Durch Zugabe von Puromycin (4 $\mu \mathrm{g} / \mathrm{ml}$; CarlRoth) in das Zellkulturmedium wurden die Zellen, die das jeweilige Plasmid stabil in das Genom integriert hatten, selektioniert. 


\subsection{Zellkultur}

Die Kultivierung der HeLa-, MDA-MB-231-, MCF7- und MEF-Zellen erfolgte in Dulbecco's modified Eagle's medium (DMEM; PAN, Aidenbach, Deutschland) mit 4,5 g/l Glukose, 110 mg/l Pyruvat, 3,7 g/l $\mathrm{NaHCO}_{3}$ und $584 \mathrm{mg} / \mathrm{l}$ Glutamin. Zusätzlich wurden die Antibiotika Penicillin (100 U/ml) und Streptomycin $(100 \mu \mathrm{g} / \mathrm{ml})$, sowie $10 \%$ fetales Kälberserum (FKS; Biochrom, Berlin, Deutschland) eingesetzt. Zur Selektion wurde Puromycin (CarlRoth; HeLa: $10 \mu \mathrm{g} / \mathrm{ml}$; MDA-MB-231: $4 \mu \mathrm{g} / \mathrm{ml}$; MCF7: $1 \mu \mathrm{g} / \mathrm{ml}$, MEF: 4 $\mu \mathrm{g} / \mathrm{ml})$ verwendet.

Die Kultivierung der T-REx-HeLa-Zellen erfolgte ähnlich. Es wurde jedoch $10 \%$ Tetfreies FKS verwendet und zur Selektion Blasticidin (5 $\mu \mathrm{g} / \mathrm{ml}$; Invitrogen) in das Zellkulturmedium hinzugefügt.

Diese Zellen wurden in einem Zellkultur-Brutschrank (Binder, Tuttlingen, Deutschland) bei $20 \% \mathrm{O}_{2}, 5 \% \mathrm{CO}_{2}$ und $37^{\circ} \mathrm{C}$ kultiviert. Um die Zellen hypoxischen Bedingingen auszusetzen, erfolgte die Kultivierung in einer Hypoxie-Werkbank (InVIVO2, Ruskinn, Bridgend, UK) unter $1 \% \mathrm{O}_{2}, 5 \% \mathrm{CO}_{2}$ und $37^{\circ} \mathrm{C}$.

\subsection{Analyse der zellulären Adhäsionseigenschaften mittels Adhäsions- Assay}

Der durchgeführte Adhäsions-Assay diente dem Nachweis unterschiedlicher Verhaltensweisen der $\mathrm{zu}$ untersuchenden Zellpopulationen in Bezug auf die Adhäsionsfähigkeit an Fibronektin, einem Bestandteil der extrazellulären Matrix. Dazu wurde eine unbeschichtete 96-Loch-Platte (Sarstedt, Newton, USA) mit bovinem Fibronektin (R\&D Systems, Minneapolis, USA) beschichtet, sodass sich bei $60 \mu \mathrm{l}$ je Vertiefung eine Konzentration von $1 \mu \mathrm{g}$ Fibronektin $/ \mathrm{cm}^{2}$ ergab. Diese Platte wurde über Nacht bei $4^{\circ} \mathrm{C}$ gelagert. Es folgten zwei Waschvorgänge der 96-Loch-Platte mit $100 \mu$ Waschpuffer $(0,1 \%$ BSA in DMEM) je Vertiefung. Durch Zugabe von $100 \mu$ eines weiteren Puffers $(0,5 \%$ BSA in DMEM) in jede Vertiefung der 96-Loch-Platte und Inkubation für 60 Minuten bei $37^{\circ} \mathrm{C}$ wurden die unspezifischen Proteinbindungsstellen des Fibronektins geblockt. Daraufhin wurden $1 \times 10^{4}$ Zellen, was bei einer Ausgangskonzentration der jeweiligen Zellsuspension von $2 \times 10^{5}$ Zellen/ml einem Volumen von $50 \mu$ l entsprach, der $\mathrm{zu}$ untersuchenden Zellpopulationen ausplattiert und für circa 30 Minuten bei $37^{\circ} \mathrm{C}$ inkubiert. Die Inkubationszeiten schwankten jedoch zwischen den Zelllinien, da sich die Geschwindigkeit in der Bildung von Zellausläufern und damit der Adhäsion unterschieden. Im Anschluss wurde die 96-Loch-Platte im Microplate Reader Model 680 (Bio-Rad Laboratories, München, 
Deutschland) für 15 Sekunden geschüttelt, sodass sich die bis zu diesem Zeitpunkt nicht fest adhärierten Zellen wieder vom Fibronektin lösten. Es folgten drei Waschvorgänge mit jeweils $100 \mu 1$ Waschpuffer (0,1\% BSA, DMEM), die Fixierung mit $50 \mu 1$ Paraformaldehyd (4\%, mit $\mathrm{NaOH}$ in PBS gelöst und anschließend mit $\mathrm{HCl}$ neutralisiert), gefolgt von einem erneuten Waschvorgang mit $100 \mu \mathrm{l}$ Waschpuffer $(0,1 \%$ BSA in DMEM) und schließlich die Färbung der fixierten, adhärierten Zellen mit $20 \mu \mathrm{Kristallviolett}(5 \mathrm{mg} / \mathrm{ml}$ in $2 \% \mathrm{EtOH})$ je Vertiefung der 96-Loch-Platte. Durch Zugabe von $100 \mu \mathrm{l}$ Natriumdodecylsulfat $(2 \%$, gelöst in destilliertem Wasser) je Vertiefung lösten sich die fest adhärierten, gefärbten Zellen vom mit Fibronektin beschichteten Untergrund und die Lichtabsorption konnte bei einer Wellenlänge von $595 \mathrm{~nm}$ mit dem Microplate Reader Model 680 (Bio-Rad Laboratories) gemessen werden.

Um den Einfluss der ROCK (rho-associated, coiled-coil-forming protein kinase) auf die Zelladhäsion näher zu untersuchen, wurden sowohl Wildtyp- als auch PHD2-knock-downZellen (Klon 3B7) der HeLa-Zelllinie mit dem zellgängigen ROCK-Inhibitor Y27632 (Biaffin, Kassel, Deutschland) behandelt (100 Minuten, $10 \mu \mathrm{M}$ ).

\subsection{Bestimmung der Zellzahl und -vitalität}

Um die unterschiedlichen Wachstumsgeschwindigkeiten verschiedener Zellen quantitativ beurteilen zu können, wurden die HeLa- und MCF7-Zellen jeweils mit einer Zielkonzentration von $2 \times 10^{5} / \mathrm{ml}$ und die MDA-MB-231-Zellen mit einer Zielkonzentration von $1,14 \times 10^{5} / \mathrm{ml}$ in $6-\mathrm{cm}$-Schalen ausgesät. Daraufhin ließ man die Zellen unter normoxischen $\left(20 \% \mathrm{O}_{2}\right)$ oder hypoxischen Bedingungen $\left(1 \% \mathrm{O}_{2}\right)$ in einem Brutschrank bzw. in der Hypoxie-Werkbank (Ruskinn) inkubieren. In bestimmten zeitlichen Abständen wurden die Zellkonzentrationen in den jeweiligen Schalen bestimmt, indem erst das alte Medium abgesaugt und dann mit frischem Medium gewaschen wurde. Dann ließ man die Zellen mit $600 \mu \mathrm{T}$ Trypsin (0,05\% Trypsin, 0,02\% EDTA) je 6-cm-Schale für circa 5 Minuten bei $37^{\circ} \mathrm{C}$ inkubieren. Die nun abgelösten Zellen wurden in $3 \mathrm{ml}$ neuem Medium aufgenommen und 16 $\mu 1$ dieser Zellsuspension in eine Cellometer ${ }^{\circledR}-Z a ̈ h l k a m m e r$ pipettiert, um sich durch eine automatische, mikroskopische Bestimmung die Zellkonzentration berechnen zu lassen (Nexcelom Bioscience, Massachusetts, USA). Diese Zellkonzentrationen konnten daraufhin untereinander und zu verschiedenen Zeitpunkten miteinander verglichen werden.

Die Verdoppelungszeit G kann mittels folgender Formel berechnet werden:

$\mathrm{G}=\left(\log _{10} 2 \times\left(\mathrm{t}_{1}-\mathrm{t}_{0}\right)\right) /\left(\log _{10} \mathrm{~N}_{1}-\log _{10} \mathrm{~N}_{0}\right)$ 
Dabei stellt $\mathrm{N}_{0}$ die Zellkonzentration an einem definierten Zeitpunkt $\mathrm{t}_{0}$ dar, wohingegen $\mathrm{N}_{1} \mathrm{zu}$ einem späteren Zeitpunkt $\mathrm{t}_{1}$ bestimmt wird.

Um die Zellvitalität, das heißt den Anteil der vitalen Zellen prozentual bezogen auf die Gesamtzellzahl, zu bestimmen, wurden die abgelösten Zellen nach Aufnahme in $3 \mathrm{ml}$ Medium im Verhältnis 1:1 mit einer 0,2\%igen Trypanblau-Lösung (in $\mathrm{H}_{2} \mathrm{O}$ filtriert) gemischt. Die vitalen Zellen waren in der Lage, das in die Zelle gelangte Trypanblau wieder aktiv mittels Transport aus der Zelle heraus zu befördern, die bereits nicht mehr vitalen Zellen waren dazu nicht fähig und färbten sich blau an. Der Anteil an blau-gefärbten Zellen konnte nun erneut mittels Cellometer® (Nexcelom Biosciences) bestimmt werden.

\subsection{Immunfluoreszenz-Mikroskopie}

Die Immunfluoreszenz dient der intrazellulären Lokalisation spezifischer Proteine auf mikroskopischer Ebene. Nach Platzierung von einem Deckglas je Vertiefung einer 6-LochPlatte (Sarstedt) wurden die zu untersuchenden Zellen jeweils mit der Zielkonzentration von $5 \times 10^{4} / \mathrm{ml}$ in die 6-Loch-Platten ausgesät. Nach einer Inkubationszeit von $48 \mathrm{~h}$ bei $37^{\circ} \mathrm{C}$ wurden die Zellen mit $1 \mathrm{ml}$ PBS (137 mM NaCl, 2,7 mM KCl, 4,3 mM Na $2 \mathrm{HPO}_{4} \times \mathrm{x}_{2} \mathrm{O}, 1,4$ $\mathrm{mM} \mathrm{KH}_{2} \mathrm{PO}_{4}$ ) je Vertiefung gewaschen und daraufhin mit dem gleichen Volumen Paraformaldehyd (4\%; gelöst in $\mathrm{NaOH}$ und mit $\mathrm{HCl}$ neutralisiert) fixiert. Es folgten zwei erneute Waschvorgänge mit je $1 \mathrm{ml}$ PBS pro Vertiefung, die Permeabilisierung der Zellen durch Zugabe von $1 \mathrm{ml}$ einer 0,2\%igen Triton X100-Lösung (gelöst in 1x PBS) je Vertiefung, 2 weitere Waschvorgänge mit PBS (1 ml/Vertiefung) und schließlich die Blockierung unspezifischer Proteinbindungsstellen mit $1 \mathrm{ml}$ 1\% BSA (gelöst in 1x PBS) je Vertiefung. Die beschriebenen Schritte erfolgten alle mit Ausnahme der Waschvorgänge für eine Dauer von 15 Min.. Anschließend wurden die Deckgläser jeweils auf einem $50 \mu$ l-Aliquot platziert, in welchem das anti-hVin-1-monoklonale-Maus-IgG (Sigma-Aldrich), in 1x PBS gelöst, vorlag ( $2 \mu \mathrm{g} / \mathrm{ml}$ ). Nach Inkubation bei Raumtemperatur für eine Stunde in einem abgedunkelten Raum erfolgten 7 Waschvorgänge der Deckgläser mit PBS (jeweils 1 ml/Vertiefung). Als sekundärer Antikörper wurde das anti-Maus-polyklonale-Ziegen-IgG Texas Red (SigmaAldrich) verwendet ( $4 \mu \mathrm{g} / \mathrm{ml}$, gelöst in 1x PBS). Dieser Antikörper besitzt einen gekoppelten Fluoreszenz-Farbstoff, der bei Bestrahlung mit Licht einer spezifischen Wellenlänge angeregt wird und Licht der Wellenlänge $605 \mathrm{~nm}$ (rot) abstrahlt. Nach Inkubation in einem abgedunkelten Raum für erneut eine Stunde bei Raumtemperatur wurden die Deckgläser auf einem $50 \mu$-Aliquot platziert, welches DAPI (Sigma-Aldrich), gelöst in 1\% BSA $(1 \mu \mathrm{g} / \mathrm{ml})$, enthielt. Bei DAPI handelt es sich um 4',6-Diamidin-2-phenylindol. Es ist ein Fluoreszenz- 
Farbstoff, der sich an die DNA anlagert und somit den Zellkern markiert. Er wird durch Licht einer Wellenlänge von $595 \mathrm{~nm}$ angeregt und emittiert es mit einer Wellenlänge von $461 \mathrm{~nm}$ (blau). Nach 5-minütiger Inkubation wurden die Deckgläser intensiv mit PBS gewaschen. Die mit Mowiol eingedeckelten Deckgläser wurden bei $4^{\circ} \mathrm{C}$ in einem abgedunkelten Raum aufbewahrt. Die Fluoreszenz-Mikroskopie erfolgte am Axio Observer D1 (Carl Zeiss, Göttingen, Germany).

\subsection{Proteinextraktion und -bestimmung}

Die zu untersuchenden Zellen wurden, abhängig vom Wachstumsverhalten der jeweiligen Zellpopulation, in einer Anzahl von $0,3-1 \times 10^{5}$ Zellen/ml ausgesät und für $48 \mathrm{~h}$ unter normoxischen $\left(20 \% \mathrm{O}_{2}\right)$ Bedingungen gehalten. Parallel wurde eine zweite Gruppe der gleichen Zellen in identischer Anzahl ausgesät, jedoch nach 24 h unter 20\% Sauerstoff für weitere $24 \mathrm{~h}$ in hypoxische Bedingungen $\left(\begin{array}{lll}1 \% & \mathrm{O}_{2}\end{array}\right)$ versetzt. Später konnten die unterschiedlichen Proteinexpressionen in Normoxie bzw. Hypoxie mittels Western Blots nachgewiesen werden.

Um zelluläres Protein zu erhalten, wurde zweimal mit $4^{\circ} \mathrm{C}$ kaltem PBS gewaschen, bevor die Zellen mit $200 \mu$ Lysepuffer (10 mM Tris pH 8,0, 1 mM EDTA, $400 \mathrm{mM} \mathrm{NaCl,} \mathrm{0,1 \%}$ Triton, Protease-Inhibitor Cocktail von Roche (Mannheim, Deutschland)) je Schale behandelt wurden. Das Lysat wurde 20 Minuten bei $4^{\circ} \mathrm{C}$ zentrifugiert und das Pellet anschließend verworfen. Der Überstand wurde bei $-20^{\circ} \mathrm{C}$ gelagert.

Um die Proteinkonzentrationen zu bestimmen, wurde die Methode nach Bradford (Bradford 1976) gewählt. Dazu wurde ein Protein-Assay-Reagenz (Bio-Rad) verwendet, das den Farbstoff Coomassie brilliant blue G-250 enthielt. Bindet dieser Farbstoff Proteine, ändert sich sein Absorptionsmaximum von $465 \mathrm{~nm}$ auf $595 \mathrm{~nm}$, sodass eine Zunahme an Absorption mit einer erhöhten Proteinkonzentration einhergeht. Auf einer 96-Loch-Platte wurden $200 \mu \mathrm{l}$ der Protein-Assay-Reagenz zu je 1-3 $\mu$ l der Proteinextrakte gegeben. Als Standard wurden unterschiedliche Mengen (0-6 $\mu \mathrm{g})$ von bovinem Serumalbumin (BSA) eingesetzt. Zur Quantifizierung der Proteinmenge wurde am Microplate Reader Model 680 (Bio-Rad) bei einer Wellenlänge von $595 \mathrm{~nm}$ die Absorption gemessen. Mithilfe der Standardkurve konnten die unbekannten Proteinkonzentrationen schließlich bestimmt werden. 


\subsection{SDS-Polyacrylamid-Gelelektrophorese und Western Blot}

Bei der SDS-Polyacrylamid-Gelelektrophorese werden die Proteine im elektrischen Feld ihrer Größe nach aufgeteilt. Das SDS (Natriumdodecylsulfat), ein negativ-geladenes Detergens, besetzt die Oberfläche der Proteine vollständig, wobei die Menge an gebundenem SDS und somit die Ladung ein Maß für die Molekülgröße ist. Bevor man die Proteine, welche sich in 5x Laemmlipuffer (190 mM SDS, $55 \mathrm{mM}$ EDTA, $55 \mathrm{mM} \mathrm{NaH} \mathrm{PO}_{4}, 20 \% \beta-$ Mercaptoethanol, 25\% Glycerin, 0,1\% Bromphenolblau) befanden, auf ein 7,5-15\%iges SDSPolyacrylamidgel aufgetragen hat, mussten diese durch Erhitzen bei $95^{\circ} \mathrm{C}$ für 5 Minuten denaturieren. Nach Zugabe von SDS-Laufpuffer (25 mM Tris, $250 \mathrm{mM}$ Glycin, 0,1\% SDS) und dem Auftragen der Proteine wurde die Elektrophorese gestartet, wobei in eine der Geltaschen ein 170-10 kDa Protein-Marker (PageRuler Prestained Protein Ladder; Fermentas, St. Leon-Rot, Deutschland) aufgetragen wurde, um die Größe der zu bestimmenden Proteine einordnen zu können. Im Anschluss wurden die Proteine auf eine Nitrocellulosemembran (GE Healthcare, München, Deutschland) übertragen. Dazu wurde Transferpuffer (48 mM Tris, 39 mM Glycin, 1,3 mM SDS, 20\% Methanol) und eine Blotkammer (Peqlab Biotechnologie $\mathrm{GmbH}$, Erlangen, Deutschland) benötigt, in der sich die Proteine innerhalb von 60 Minuten bei $2 \mathrm{~mA} / \mathrm{cm}^{2}$ elektrophoretisch vom Gel auf die Nitrocellulosemembran übertragen ließen. Es folgte ein einstündiger Blockierungsvorgang mit 5\% Magermilchpulver (gelöst in PBS). Dadurch wurden unspezifische Proteinbindungsstellen geblockt. Anschließend wurde der primäre Antikörper, verdünnt in 5\% Magermilchpulver auf die Membran gegeben und über Nacht im Kühlraum bei $4^{\circ} \mathrm{C}$ inkubiert. Pro Membran wurden etwa $5 \mathrm{ml}$ der AntikörperLösung benötigt. Dabei wurden folgende primäre Antikörper in den genannten Konzentrationen verwendet: anti-PHD2-polyklonales-Kaninchen-IgG (1:1000; Novus, Littleton, USA), anti-PHD3-polyklonales-Kaninchen-IgG (1:1000; abcam, Cambridge, USA), anti-HIF-1- $\alpha$-Maus-IgG (1:1000; BD Biosciences, Heidelberg, Deutschland) und anti- $\beta$ Aktin-monoklonales-Maus-IgG (1:1000; Sigma, Taufkirchen, Deutschland). Nachdem der primäre Antikörper über seine spezifischen Bindungsstellen an das für ihn passende Protein gebunden hat, wurde überschüssiger Antikörper durch 3 zehn-minütige Waschvorgänge mit PBS entfernt. Daraufhin wurde der sekundäre Antikörper auf die Membran gegeben, erneut in Form einer Lösung in 5\% Magermilchpulver. Den sekundären Antikörper ließ man für eine Stunde inkubieren und anschließend wurde wiederum 3 Mal mit PBS für je zehn Minuten gewaschen. Sekundäre Antikörper wurden, passend $\mathrm{zu}$ der Herkunft des primären Antikörpers, folgende benutzt: anti-Kaninchen-polyklonales-Ziegen-IgG (1:30000; Santa 
Cruz Biotechnology, Kalifornien, USA) und anti-Maus-polyklonales-Ziegen-IgG (1:1000; Santa Cruz Biotechnology).

Als letzter Schritt wurde der Blot entwickelt, indem die Membran 1 Minute lang mit einer Lösung aus 0,1 M Tris/ $\mathrm{HCl} \mathrm{pH} 8,5,1 \% \mathrm{H}_{2} \mathrm{O}_{2}, 1,25 \mathrm{mM}$ Luminol und 0,225 mM Cumarsäure behandelt wurde. In der folgenden Reaktion wurde das Luminol durch eine MeerrettichPeroxidase, welche am sekundären Antikörper gebunden vorlag, oxidiert. Dadurch wurde eine Chemilumineszenz ausgelöst, welche mittels einer Kamera (LAS-3000, Fujifilm, Düsseldorf, Deutschland) nachgewiesen werden konnte. Alternativ wurde, nach Zusatz der Cumarsäure, des Luminols und des $\mathrm{H}_{2} \mathrm{O}_{2}$, durch Übertragung der Chemilumineszenz auf einen Röntgenfilm (GE Healthcare) dieser schließlich in der Dunkelkammer manuell entwickelt.

\subsection{Lipofektamin-vermittelte, transiente Transfektion}

Die Lipofektamin-vermittelte Transfektion dient dem Einbringen eines DNA-Fragments in Zellen. Die kationischen Lipide im Lipofektamin, welche als Liposomen in Form von kleinen Vesikeln vorkommen, binden die zu transfizierende DNA. Diese kationischen Komplexe binden an die anionische Zellmembran und fusionieren mit dieser. Das Expressionsplasmid kann dann abgelesen werden, ohne vorher zwangsläufig in das Genom der Zelle integriert worden zu sein.

Für die Transfektion mit dem PHD2-Gen wurde das pcDNA3.1-HA-PHD2-kodierende Plasmid verwendet, in welchem PHD2 unter der Kontrolle eines CMV-Promoters konstitutiv exprimiert wird. Für die Negativkontrolle wurden die Zellen mit dem pcDNA3.1-Plasmid (Invitrogen) transfiziert.

Für die Transfektion wurden die MDA-MB-231-Wildtyp-Zellen (WT) mit der Zielkonzentration $\quad 0,8 \times 10^{5} / \mathrm{ml}$, PHD2-knock-down-Zellen des Klones \#4 mit der Konzentration $1 \times 10^{5} / \mathrm{ml}$ in $10-\mathrm{cm}$-Schalen ausgesät und für 24 Stunden bei $37^{\circ} \mathrm{C}$ inkubiert. Das Zellkulturmedium enthielt DMEM (PAN ${ }^{\mathrm{TM}}$ biotech GmbH, Passau, Deutschland), 10\% FCS $\left(\mathrm{PAN}^{\mathrm{TM}}\right.$ biotech $\left.\mathrm{GmbH}\right)$ und Pen./Strep. (PAN ${ }^{\mathrm{TM}}$ biotech $\left.\mathrm{GmbH}\right)$. Am folgenden Tag wurde das Medium gegen ein Pen./Strep.-freies Medium ausgetauscht, um die Effizienz der Transfektion zu erhöhen.

Für die PHD2-Transfektion wurden $15 \mu \mathrm{g}$ des pcDNA3.1-HA-PHD2-kodierenden Plasmids mit $9 \mu \mathrm{g}$ des pcDNA3.1-Plasmids und $35 \mu$ l Lipofektamin ${ }^{\mathrm{TM}} 2000$ (Invitrogen) mit OptiMEM $^{\mathrm{TM}}$ (Invitrogen) auf $3 \mathrm{ml}$ aufgefüllt und gut durchmischt. Nach 20-minütiger Inkubation bei Raumtemperatur wurde dieses Volumen jeweils zum Zellkulturmedium der 
Wildtyp-Zellen und den Zellen des PHD2-knock-down-Klons \#4 hinzugefügt. Nach weiteren 5 Stunden Inkubation bei $37^{\circ} \mathrm{C}$, die der Aufnahme des Plasmids in die Zellen diente, wurde das Kulturmedium erneut gewechselt. Für die Transfektion der Negativkontrolle wurde analog verfahren. Es wurde nur anstelle der $15 \mu \mathrm{g}$ des HA-PHD2-enthaltenden Plasmids insgesamt $24 \mu \mathrm{g}$ des HA-PHD2-freien pcDNA3.1-Plasmids verwendet. Die Überexpression wurde mittels Western Blots überprüft.

\section{$2.9 \quad$ RNA-Isolation}

Zur RNA-Isolation wurden die Zellen jeweils mit der Konzentration 1x10 $/ \mathrm{ml}$ in 6-LochPlatten ausgesät. Nach Inkubation der Zellen für 48 Stunden bei $37^{\circ} \mathrm{C}$ wurden sie mit kaltem PBS gewaschen und nach Zugabe von $750 \mu$ l Solution D (4 M Guanidinthiocyanit, $25 \mathrm{mM}$ Natriumacetat, 0,5\% Sarcosyl) je Vertiefung lysiert. $750 \mu \mathrm{l}$ je Probe wurden anschließend in Zentrifugenröhrchen überführt und auf Eis gehalten. Es wurden $75 \mu 12 \mathrm{M}$ Natriumacetat pH 4,0, $750 \mu \mathrm{l}$ Phenol und $150 \mu$ Chloroform-Isoamylalkohol (49:1) je Probe hinzugefügt und häufig gevortext. Im Folgenden wurde die entstandene Suspension für 20 Minuten bei $4^{\circ} \mathrm{C}$ und $12000 \mathrm{rpm}$ zentrifugiert. Dadurch wurde die Suspension in eine untere, Proteinenthaltene, eine mittlere, DNA-enthaltene und eine obere, RNA-enthaltene wässrige Phase aufgeteilt. Die obere Phase wurde daraufhin in ein neues Zentrifugenröhrchen überführt und nach Zugabe von $750 \mu \mathrm{l}$ Isopropanol für 1 Stunde bei $-20^{\circ} \mathrm{C}$ inkubiert. Es folgte ein weiterer Zentrifugationsschritt für 20 Minuten bei $12000 \mathrm{rpm}$ und $4^{\circ} \mathrm{C}$. Der Überstand wurde verworfen, das Pellet in $75 \mu \mathrm{l}$ Solution D gelöst und in ein weiteres Zentrifugenröhrchen überführt. Es folgte ein weiterer Fällungsschritt durch Zugabe von $75 \mu \mathrm{l}$ Isopropanol, Inkubation für 1 Stunde bei $-20^{\circ} \mathrm{C}$ und Zentrifugation bei $12000 \mathrm{rpm}$ und $4^{\circ} \mathrm{C}$ für 20 Minuten. Der Überstand wurde verworfen und die RNA durch Vortexen bei $-20^{\circ} \mathrm{C}$ in $75 \%$ igem Ethanol gewaschen. Die RNA wurde erneut bei $4^{\circ} \mathrm{C}, 12000 \mathrm{rpm}$ für 20 Minuten zentrifugiert und nach Verwerfen des Überstandes für 30 Minuten getrocknet. Das RNAPellet wurde in $20 \mu \mathrm{l}$ DEPC- $\mathrm{H}_{2} \mathrm{O} \quad(0,2 \%$ Diethylpyrocarbonat $)$ aufgenommen. Die Konzentration und Reinheit der gefällten RNA wurde anhand der optischen Dichte bei 260 $\mathrm{nm}$ und $280 \mathrm{~nm}$ fotometrisch bestimmt (SmartSpec Plus Spectrophotometer, BioRad, München, Deutschland). Die Lagerung der RNA erfolgte bei $-80^{\circ} \mathrm{C}$. 


\subsection{0 cDNA-Synthese}

Durch diese Methode wird aus der RNA mittels reverser Transkriptase, welches eine virale, RNA-abhängige DNA-Polymerase ist, ihre komplementäre cDNA gebildet (First Strand cDNA Synthesis Kit, Fermentas). Dabei sorgen Oligo(dT) $)_{18}$-Primer, welche an das 3'Ende der Poly $(\mathrm{A})^{+}$mRNA binden, für die spezifische cDNA-Synthese aus mRNA. Es wurden $2 \mu \mathrm{g}$ RNA mit $1 \mu \mathrm{l}$ Oligo(dT) ${ }_{18}$-Primer $(0,5 \mu \mathrm{g} / \mathrm{ml})$ gemischt und mit DEPC-behandeltem Wasser auf ein Totalvolumen von $11 \mu \mathrm{l}$ aufgefüllt. Nach 5-minütiger Inkubation bei $70^{\circ} \mathrm{C}$ wurden $4 \mu \mathrm{l} 5 \mathrm{x}$ Reaktionspuffer $(250 \mathrm{mM}$ Tris- $\mathrm{HCl}, 250 \mathrm{mM} \mathrm{KCl}, 20 \mathrm{mM} \mathrm{MgCl} 2,50 \mathrm{mM}$ DTT), $1 \mu$ l Ribonuclease-Inhibitor (20 U/ $\mu \mathrm{l})$ und $2 \mu$ leines $10 \mathrm{mM}$ dNTP-Mixes hinzugefügt. Durch Inkubation für 5 Minuten bei $37^{\circ} \mathrm{C}$ konnten sich die Primer anlagern. Nach Zugabe von $2 \mu \mathrm{l}$ reverser Transkriptase $(20 \mathrm{U} / \mu \mathrm{l})$ wurde die cDNA durch Inkubation für eine Stunde bei $37^{\circ} \mathrm{C}$ synthetisiert. Die Reaktion wurde durch 5-minütiges Erhitzen auf $70^{\circ} \mathrm{C}$ durch Inaktivierung der reversen Transkriptase abgestoppt und die cDNA anschließend bei $-20^{\circ} \mathrm{C}$ gelagert.

\subsection{Quantitative real-time-Polymerase-Ketten-Reaktion (qRT-PCR)}

Durch die Polymerase-Ketten-Reaktion können spezifische DNA-Fragemente amplifiziert werden. $\mathrm{Zu}$ einem Zyklus gehören die Denaturierung der doppelsträngigen DNA, das Anlagern des Primers (sog. annealing) und die Elongation durch eine hitzestabile DNAPolymerase (taq-Polymerase). In der qRT-PCR kommt hinzu, dass durch Fluoreszenzmarkierung die Menge des amplifizierten Produktes bestimmt werden kann (Mx3005P, Strategene, La Jolla, USA). Als fluoreszierender Marker wurde SYBR Green I verwendet, welches mit der DNA interkaliert und bei Bindung doppelsträngiger DNA fluoresziert. Als Referenzfarbstoff wurde $\operatorname{ROX}^{\mathrm{TM}}$ benutzt. Die ermittelten Werte der Gene wurden auf das ribosomale Protein L28 bezogen, um mögliche Unterschiede, durch die RNAIsolation oder die reverse Transkription bedingt, auszugleichen.

Für die qRT-PCR wurden $1 \mu \mathrm{l}$ cDNA, 12,5 $\mu \mathrm{l}$ SYBR Advantage qPCR Premix (2x), jeweils $0,5 \mu \mathrm{l}$ des forward- und des reverse-Primers (je $10 \mu \mathrm{M}$ ) und $0,5 \mu 1 \mathrm{ROX}^{\mathrm{TM}}$ mit $\mathrm{dH}_{2} \mathrm{O}$ auf $25 \mu \mathrm{l}$ aufgefüllt. Die Auflistung der verwendeten Primer findet sich in Tabelle 1, die Bedingungen für die qRT-PCR sind in der Tabelle 2 dargestellt. 


\begin{tabular}{|c|c|c|}
\hline Bezeichnung & $\begin{array}{c}\text { Oligonukleotidsequenz } \\
\left(5^{\prime}-3^{\prime}\right)\end{array}$ & Hybridisierungstemp. \\
\hline L28_for & GCAATTCCTTCCGCTACAAC & $58^{\circ} \mathrm{C}$ \\
\hline L28_rev & TGTTCTTGCGGATCATGTGT & $58^{\circ} \mathrm{C}$ \\
\hline PHD2_for & TTGCTGACATTGAACCCAAA & $56^{\circ} \mathrm{C}$ \\
\hline PHD2_rev & TTACCGACCGAATCTGAAGG & $56^{\circ} \mathrm{C}$ \\
\hline PHD3_for & AGATCGTAGGAACCCACACG & $60^{\circ} \mathrm{C}$ \\
\hline PHD3_rev & CAGATTTCAGAGCACGGTCA & $60^{\circ} \mathrm{C}$ \\
\hline ADAMTS13_for & TGCGGGCGAGGTCTGATGGA & $60^{\circ} \mathrm{C}$ \\
\hline ADAMTS13_rev & GGCCACAGCTGGCCGAACAT & $60^{\circ} \mathrm{C}$ \\
\hline CDH1_for & ACGGCAAGGTGTGCGAGCTG & $60^{\circ} \mathrm{C}$ \\
\hline CDH1_rev & ACGGGGTGGTCTCCTGCCTC & $60^{\circ} \mathrm{C}$ \\
\hline COL1A1_for & ATCCGGAGCCCAGAGGGCAG & $60^{\circ} \mathrm{C}$ \\
\hline COL1A1_rev & GGCTCCGGTGTGACTCGTGC & $60^{\circ} \mathrm{C}$ \\
\hline COL4A2_for & GTGGCTGCTGCTGGGGACAG & $55^{\circ} \mathrm{C}$ \\
\hline COL4A2_rev & TTGCCCCGGGTGTCCAGGAA & $55^{\circ} \mathrm{C}$ \\
\hline COL6A1_for & GACCACACGTACCGGCGCAA & $60^{\circ} \mathrm{C}$ \\
\hline COL6A1_rev & CCCCTGGAGCCCTTCTCCCC & $60^{\circ} \mathrm{C}$ \\
\hline MMP7_for & AGCCCAGATGTGGAGTGCCA & $58^{\circ} \mathrm{C}$ \\
\hline MMP7_rev & CCCCATGAGCTCCTCGCGCA & $58^{\circ} \mathrm{C}$ \\
\hline SGCE_for & ACGCAGCAGAACTTGCCACA & $55^{\circ} \mathrm{C}$ \\
\hline SGCE_rev & TGCCAACATGCATAACATATGCCAGA & $55^{\circ} \mathrm{C}$ \\
\hline SPARC_for & GAGGCAGGAGACCACCCCGT & $60^{\circ} \mathrm{C}$ \\
\hline SPARC_rev & GCTTGATGCCGAAGCAGCCG & $60^{\circ} \mathrm{C}$ \\
\hline Spp1_for & AGCCCCACAGACCCTTCCAAGT & $60^{\circ} \mathrm{C}$ \\
\hline Spp1_rev & TTCGGTTGCTGGCAGGTCCG & $60^{\circ} \mathrm{C}$ \\
\hline Spp1a_for & GCAGAATCTCCTAGCCCCACAGAATG & $60^{\circ} \mathrm{C}$ \\
\hline Spp1a_rev & TGCTGGCAGGTCCGTGGGAA & $60^{\circ} \mathrm{C}$ \\
\hline Spp1b_for & TCTCCTAGCCCCACAGACCCTTC & $60^{\circ} \mathrm{C}$ \\
\hline Spp1b_rev & TTCGGTTGCTGGCAGGTCCG & $60^{\circ} \mathrm{C}$ \\
\hline Spp1c_for & GTTCTGAGGAAAAGCAGAATGCTGTG & $60^{\circ} \mathrm{C}$ \\
\hline Spp1c_rev & GTTGCTGGCAGGTCCGTGGG & $60^{\circ} \mathrm{C}$ \\
\hline VTN_for & CCCCAAGTGACTCGCGGGGA & $55^{\circ} \mathrm{C}$ \\
\hline VTN_rev & AGGCGTCGAAGGGCTTCCCA & $55^{\circ} \mathrm{C}$ \\
\hline
\end{tabular}


Tabelle 2: Durchführung der qRT-PCR

\begin{tabular}{|c|c|c|c|c|c|}
\hline & Schritt & Temperatur & $\begin{array}{c}\text { Dauer } \\
\text { [Sekunden] }\end{array}$ & Detektion & Zyklen \\
\hline Initiale Denaturierung & Denaturierung & $95^{\circ} \mathrm{C}$ & 30 & aus & 1 \\
\hline PCR & $\begin{array}{c}\text { Denaturierung } \\
\text { Annealing } \\
\text { Elongation }\end{array}$ & $\begin{array}{c}95^{\circ} \mathrm{C} \\
\text { s. Tabelle } \\
1 \\
72^{\circ} \mathrm{C}\end{array}$ & $\begin{array}{l}10 \\
20 \\
20\end{array}$ & $\begin{array}{l}\text { aus } \\
\text { aus } \\
\text { an }\end{array}$ & 40 \\
\hline $\begin{array}{l}\text { Amplifizierung der } \\
\text { Dissoziationskurve }\end{array}$ & $\begin{array}{c}\text { Denaturierung } \\
\text { Annealing } \\
\text { Denaturierung }\end{array}$ & $\begin{array}{c}95^{\circ} \mathrm{C} \\
\text { s. Tabelle } \\
1 \\
95^{\circ} \mathrm{C}\end{array}$ & $\begin{array}{l}60 \\
30 \\
30\end{array}$ & $\begin{array}{l}\text { aus } \\
\text { an }\end{array}$ & 1 \\
\hline
\end{tabular}

\subsection{Statistische Auswertung}

Die statistische Auswertung der Daten erfolgte mit GraphPad 3.0 (GraphPad Software Inc., La Jolla, USA). Dazu wurden über den einseitigen Student T-Test für unabhängige Proben die Mittelwerte auf signifikante Unterschiede überprüft. Als Signifikanzniveaus wurden dabei $\mathrm{p}<0,05$ (Symbol: ${ }^{*}$ ) und $\mathrm{p}<0,01$ (Symbol: ${ }^{* *}$ ) gewählt. Die Ergebnisse wurden zum größten Teil als Mittelwert \pm Standardfehler (mean \pm SEM) und in seltenen Fällen als Mittelwert \pm Standardabweichung (mean \pm SD) angegeben. Neben GraphPad 3.0 wurde das Programm Corel Draw X3 (Corel Corporation, Ottawa, Kanada) für die graphische Darstellung verwendet. Der schriftliche Satz wurde mit Microsoft Office Word 2003 (Microsoft Corporation, Redmond, USA) erstellt. Für die Literaturverwaltung wurde das Programm Endnote X1 verwendet. 


\section{Ergebnisse}

\subsection{Funktionelle Charakterisierung der verwendeten Zelllinien}

\subsubsection{Nachweis des PHD2-knock-downs auf Proteinebene in den HeLa-, MDA-MB-231- und MCF7-Zellen}

Der Einfluss von PHD2 auf die Zelladhäsion wurde im Rahmen dieser Arbeit anhand von stabil transfizierten PHD2-knock-down-Zellen verschiedener Zelllinien untersucht. Dazu musste im Vorfeld ein tatsächlicher PHD2-knock-down in diesen Zellen bestätigt werden, um spätere Befunde korrekt deuten und bewerten zu können. Es wurden mittels Western Blot in den HeLa-, MDA-MB-231- und MCF7-Zellen die Proteinlevel von PHD2 und HIF-1 $\alpha$ unter normoxischen $\left(20 \% \mathrm{O}_{2}\right)$ und hypoxischen $\left(1 \% \mathrm{O}_{2}\right)$ Bedingungen bestimmt (Abb. 3). In den HeLa-Zellen wurde außerdem die Proteinexpression des HIF-1 $\alpha$-Zielgens PHD3 untersucht.

A

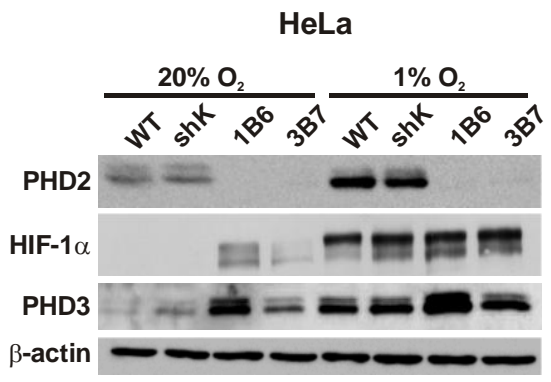

C

MCF7
B

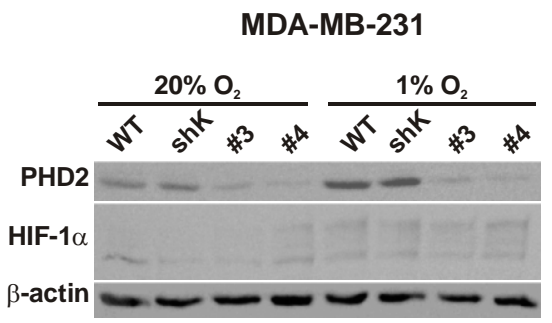

Abbildung 3: Der PHD2-knock-down ist in allen drei Zelllinien (HeLa, MDA-MB-231 und MCF7) auf Proteinebene nachzuweisen.

Im Western Blot wurden die Proteinlevel von PHD2 und HIF-1 $\alpha$ in den Wildtyp- (WT), den sh-transfizierten Kontroll-Zellen (shK) und den PHD2-knock-down-Klonen (HeLa: 1B6 und 3B7, MDA-MB-231: \#3 und \#4 bzw. MCF7: C1 und C7) der HeLa- (A), MDA-MB-231- (B) und MCF7-Zellen (C) bestimmt. Dazu wurden die Zellen $48 \mathrm{~h}$ unter normoxischen $\left(20 \% \mathrm{O}_{2}\right)$ bzw. hypoxischen $\left(1 \% \mathrm{O}_{2}\right)$ Bedingungen inkubiert. In den HeLa-Zellen erfolgte zusätzlich die Proteinbestimmung des HIF-1 $\alpha$-Zielgens PHD3.

Der PHD2-knock-down ist auf Proteinebene am deutlichsten in den HeLa-Zellen zu detektieren, jedoch ist er auch in den MDA-MB-231- und den MCF7-Zellen jeweils unter normoxischen $\left(20 \% \mathrm{O}_{2}\right)$ und hypoxischen $\left(1 \% \mathrm{O}_{2}\right)$ Bedingungen nachzuweisen (Abb. 3A-C). PHD2 hydroxyliert den Transkriptionsfaktor HIF-1 $\alpha$ am Pro ${ }^{402}$ und Pro ${ }^{564}$ innerhalb der 
ODDD und markiert es somit für die Polyubiquitinierung durch den von-Hippel-LindauTumorsuppressor (pVHL). Die Folge davon ist die proteasomale Degradation von HIF-1 $\alpha$ (Maxwell et al. 1999, Ivan et al. 2001, Jaakkola et al. 2001, Yu et al. 2001). Dieser Zusammenhang erklärt den Befund in Abbildung 3A, dass HIF-1 $\alpha$ in den Wildtyp- und den kontroll-transfizierten HeLa-Zellen unter normoxischen Bedingungen $\left(\begin{array}{lll}20 \% & \mathrm{O}_{2}\end{array}\right)$ auf Proteinebene kaum vorhanden ist. In den PHD2-knock-down-Klonen 1B6 und 3B7 hingegen kann HIF-1 $\alpha$ nicht für den proteasomalen Abbau markiert werden und wird deshalb auf Proteinebene verstärkt nachgewiesen (Abb. 3A). Bei den MCF7-Zellen ist dieser Zusammenhang im Western Blot schwächer ausgeprägt (Abb. 3C), in den MDA-MB-231Zellen ist er gar nicht nachzuvollziehen (Abb. 3B).

Unter hypoxischen Bedingungen $\left(1 \% \mathrm{O}_{2}\right)$ steht PHD2 nicht genug $\mathrm{O}_{2}$ zur Verfügung, um HIF-1 $\alpha$ zu hydroxylieren. Aus diesem Grund ist das HIF-1 $\alpha$-Proteinlevel in allen Zellen unter hypoxischen Bedingungen hoch, dieser Effekt ist vor allem in den MCF7-Zellen zu beobachten (Abb. 3C).

Da PHD3 ein Zielgen von HIF-1 darstellt, verhält sich seine Expression in den HeLaZellen analog zu der von HIF-1 $\alpha$ (Abb. 3A).

\subsubsection{Nachweis des PHD2-knock-downs auf RNA-Ebene in den HeLa-, MDA-MB-231- und MCF7-Zelllinien}

Um die HeLa-, MDA-MB-231- und MCF7-Zellen weiter funktionell in Bezug auf ihren PHD2-knock-down zu charakterisieren, wurden die RNA-Level von PHD2 und dem HIF-1 $\alpha$ Zielgen PHD3 mittels quantitativer real-time-Polymerase-Ketten-Reaktion (qRT-PCR) bestimmt. Dazu wurden die MCF7- und die MDA-MB-231-Zellen teilweise mit Östrogen behandelt, um einen möglichen Effekt in den Östrogen-stimulierbaren MCF7-Zellen zu beobachten. Die MDA-MB-231-Zellen hingegen sind nicht durch Östrogene in ihrem Wachstum zu beeinflussen. Die in Abbildung 4 dargestellten positiven (fold up) und negativen (fold down) Vervielfältigungen errechneten sich wie folgt:

Der gemessene $\mathrm{C}_{\mathrm{t}^{-}}$Wert des Haushaltsgens L28, welches für ein ribosomales Protein kodiert, wurde von dem $\mathrm{C}_{\mathrm{t}}$-Wert des zu untersuchenden Gens subtrahiert. Dadurch konnten Ungenauigkeiten, die durch die RNA-Isolation oder die qRT-PCR entstanden sind, ausgeglichen werden. Mit diesem errechneten $\Delta \mathrm{C}_{\mathrm{t}}$-Wert konnte die Veränderung der Genexpression bezogen auf die Wildtyp-Zellen über folgende Formel berechnet werden:

$\Delta \Delta \mathrm{Ct}=2^{-\Delta \mathrm{Ct}(\mathrm{PHD} 2-\text { knock-down-Klon) }} / 2^{-\Delta \mathrm{Ct}(\text { Wildtyp) }}$ 
A

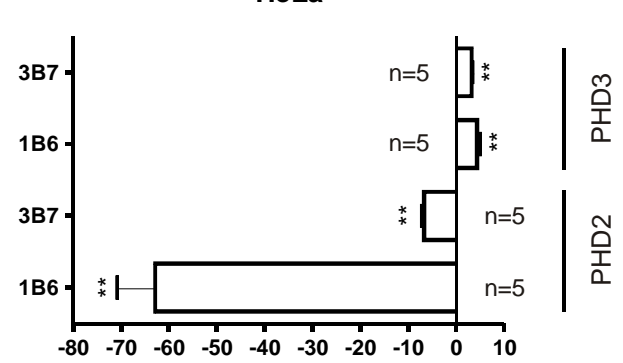

B

C

MCF7

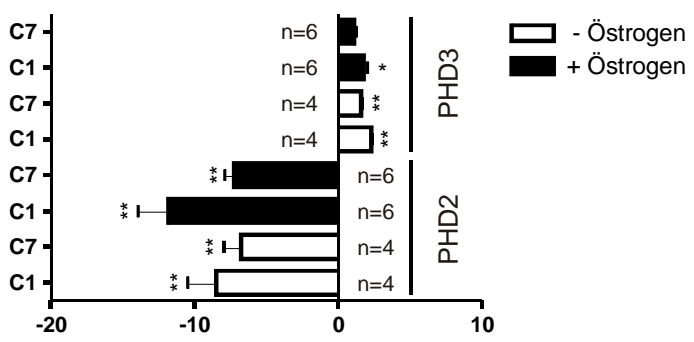

Abbildung 4: Verglichen mit den Wildtyp-Zellen führt der PHD2-knock-down in den HeLa- (A), den MDA-MB-231- (B) und den MCF7-Zellen (C) auf RNA-Ebene zu einer verminderten PHD2 -und einer erhöhten PHD3-Expression.

Nach RNA-Isolation und deren Umschreibung in cDNA wurden die $\mathrm{C}_{\mathrm{t}}$-Werte der $\mathrm{zu}$ untersuchenden Gene (PHD2, PHD3) mittels qRT-PCR bestimmt. Nach Berechnung der $\Delta \mathrm{C}_{\mathrm{t}^{-}}$ Werte wurde die Veränderung der Genexpression der PHD2-knock-down-Klone, verglichen mit den jeweiligen Wildtyp-Zellen, anhand der Formel 3.1 errechnet. Ein errechneter Wert $<1$ bedeutete eine Herunterregulation des Gens und wurde deshalb durch -1 dividiert. Ein errechneter Wert $>1$ bedeutete eine Heraufregulation des Gens im PHD2-knock-down-Klon. mean \pm SEM; $\mathrm{n}=$ Anzahl biologischer Replikate; $* * \mathrm{p}<0,01, * \mathrm{p}<0,05$

In der Abbildung 4 ist der signifikante PHD2-knock-down auf RNA-Ebene in den Klonen der HeLa- (Abb. 4A), der MDA-MB-231- (Abb. 4B) und der MCF7-Zellen (Abb. 4C) dargestellt. Regulatorisch kommt es über den reduzierten Abbau von HIF-1 $\alpha$ zu einer verstärkten Expression seines Zielgens PHD3. Auch die Steigerung des PHD3-RNA-Levels, verglichen mit den Wildtyp-Zellen, ist in fast allen Fällen signifikant. Die einzige Ausnahme in diesem Zusammenhang ist der mit Östrogen behandelte PHD2-knock-down-Klon C7 der MCF7-Zellen (Abb. 4C). Durch die Zugabe von Östrogenen konnte kein eindeutiger Einfluss auf die PHD2- und PHD3-Expression nachgewiesen werden.

\subsubsection{Die Beeinflussung der Zellproliferation durch den PHD2-knock- down in den HeLa-Zellen}

Um die HeLa-Zellen in Bezug auf ihre Proliferation in vitro näher zu charakterisieren, wurden Wildtyp-, sh-transfizierte Kontroll-Zellen und die beiden PHD2-knock-down-Klone 1B6 und 3B7 jeweils mit einer Konzentration von $2 \times 10^{5} / \mathrm{ml}$ in $6-\mathrm{cm}-$ Schalen ausgesät und diese unter normoxischen $\left(20 \% \mathrm{O}_{2}\right)$ Bedingungen inkubiert (Abb. 5). $\mathrm{Zu}$ den angegebenen 
Zeitpunkten wurden die Zellkonzentrationen mit dem Cellometer (Nexcelom) automatisch bestimmt.

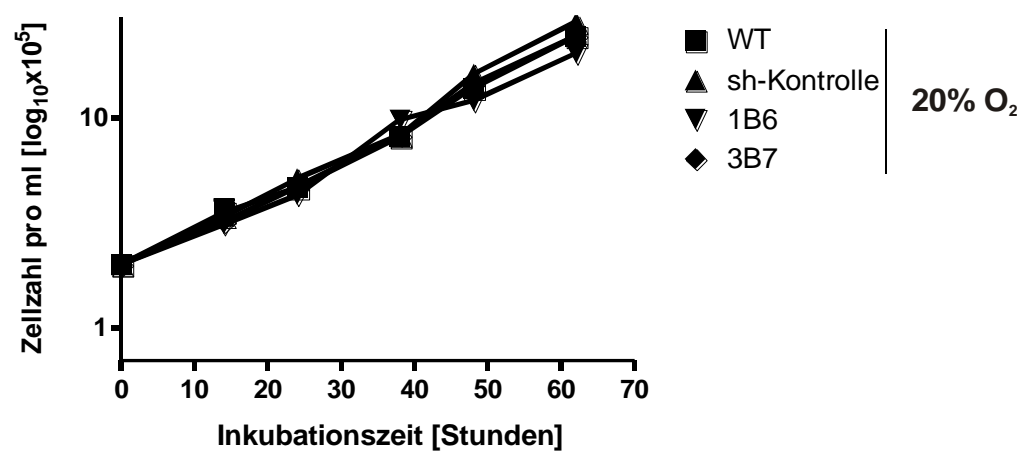

Abbildung 5: Der PHD2-knock-down in den HeLa-Zellen hat keinen Einfluss auf die Zellproliferation unter normoxischen $\left(20 \% \mathrm{O}_{2}\right)$ Bedingungen.

Wildtyp- (WT), sh-transfizierte Kontroll-Zellen (sh-Kontrolle) und die PHD2-knock-downKlone 1B6 und 3B7 der HeLa-Zellen wurden jeweils mit der Zielkonzentration $2 \times 10^{5} / \mathrm{ml}$ in 6$\mathrm{cm}-$ Schalen ausgesät. Anschließend wurden die Zellen unter normoxischen $\left(\begin{array}{lll}20 \% & \mathrm{O}_{2}\end{array}\right)$ Bedingungen inkubiert. $\mathrm{Zu}$ den angegebenen Zeitpunkten wurden die Zellkonzentrationen mit dem Cellometer (Nexcelom) bestimmt. mean \pm SEM; $n=4$ biologische Replikate

Unter normoxischen Bedingungen $\left(20 \% \mathrm{O}_{2}\right)$ hat der PHD2-knock-down in den HeLaZellen keinen signifikanten Einfluss auf das Proliferationsverhalten. Zur quantitativen Beschreibung der gewonnen Proliferationsdaten wurden daraufhin die Verdoppelungszeiten $(\mathrm{G})$ in der exponentiellen Wachstumsphase mittels folgender Formel errechnet:

$\mathrm{G}=\left(\log _{10} 2 \times\left(\mathrm{t}_{1}-\mathrm{t}_{0}\right)\right) /\left(\log _{10} \mathrm{~N}_{1}-\log _{10} \mathrm{~N}_{0}\right)$

Als Intervallgrenzen wurden gewählt: $\mathrm{t}_{0}=0 \mathrm{~h} ; \mathrm{t}_{1}=48 \mathrm{~h}$

Tabelle 3: $\quad$ Auflistung von Verdoppelungszeiten (G) der HeLa-Wildtyp- (WT), -sh-transfizierten KontrollZellen (sh-Kontrolle) und der beiden PHD2-knock-down-Klone (1B6 und 3B7) unter normoxischen $\left(20 \% \mathrm{O}_{2}\right)$ Bedingungen

\begin{tabular}{ccc}
\hline HeLa & $\mathbf{O}_{2}$ & $\begin{array}{c}\text { Verdoppelungszeit G } \\
\text { [Stunden] }\end{array}$ \\
\hline WT & $20 \%$ & 15,22 \\
sh-Kontrolle & $20 \%$ & 14,59 \\
1B6 & $20 \%$ & 16,42 \\
3B7 & $20 \%$ & 14,71 \\
\hline
\end{tabular}

Die errechneten Verdoppelungszeiten (Tab. 3) bestätigen den Befund aus Abbildung 5, dass sich das Proliferationsverhalten auch während der exponentiellen Phase durch den PHD2-knock-down in den HeLa-Zellen nicht signifikant verändert. 
Analog zu den HeLa-Zellen wurden die Wildtyp-, die sh-transfizierten Kontroll-Zellen und die beiden PHD2-knock-down-Klone \#3 und \#4 der MDA-MB-231-Zellen auf ihr Proliferationsverhalten untersucht. Dazu wurden diese Zellen jeweils mit einer Konzentration von $1,14 \times 10^{5} / \mathrm{ml}$ in 6 -cm-Schalen ausgesät. Anschließend wurden die Zellen sowohl unter normoxischen $\left(20 \% \mathrm{O}_{2}\right)$ als auch unter hypoxischen Bedingungen $\left(1 \% \mathrm{O}_{2}\right)$ inkubiert. $\mathrm{Zu}$ den angegebenen Zeitpunkten wurden die Zellkonzentrationen und der Anteil vitaler Zellen mit dem Cellometer (Nexcelom) automatisch bestimmt.

A

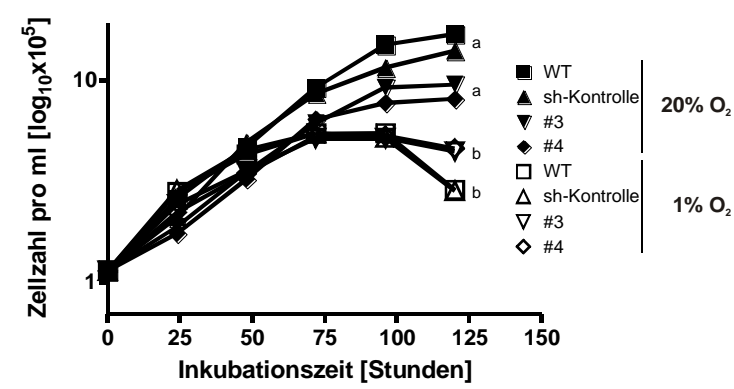

B

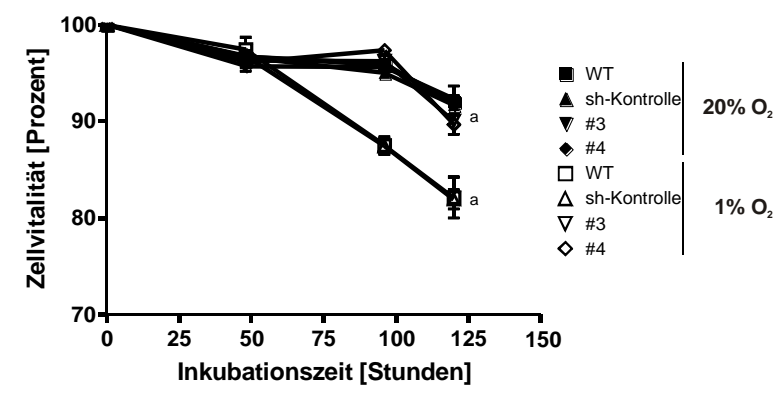

Abbildung 6: Der PHD2-knock-down in den MDA-MB-231-Zellen hat Einfluss auf die Zellproliferation (A) und die -vitalität $(B)$ unter normoxischen $\left(20 \% \mathrm{O}_{2}\right)$ und hypoxischen $\left(\mathbf{1 \%} \mathrm{O}_{2}\right)$ Bedingungen.

MDA-MB-231-Wildtyp- (WT), -sh-transfizierte Kontroll-Zellen (sh-Kontrolle) und die PHD2knock-down-Klone \#3 und \#4 wurden mit der Zielkonzentration $1,14 \times 10^{5} / \mathrm{ml}$ in 6 -cm-Schalen ausgesät. Anschließend wurden die Zellen unter normoxischen $\left(20 \% \mathrm{O}_{2}\right)$ bzw. hypoxischen $\left(\begin{array}{ll}1 \% & \mathrm{O}_{2}\end{array}\right)$ Bedingungen inkubiert. $\mathrm{Zu}$ den angegebenen Zeitpunkten wurden die Zellkonzentrationen mit dem Cellometer (Nexcelom) (A) bzw. die Zellvitatalitäten mittels Trypanblau-Färbung (B) bestimmt. mean \pm SEM; $n=3$ biologische Replikate

Abb. 6A:

a: WT und sh-Kontrolle jeweils signifikant gegenüber \#3 und \#4 bei $20 \% \mathrm{O}_{2}(\mathrm{p}<0,01)$ b: \#3 und \#4 jeweils signifikant gegenüber WT und sh-Kontrolle bei $1 \% \mathrm{O}_{2}(\mathrm{p}<0,01)$

Abb. 6B:

a: \#3 und \#4 jeweils signifikant gegenüber WT $(\mathrm{p}<0,05)$ und sh-Kontrolle $(\mathrm{p}<0,01)$ bei $1 \% \mathrm{O}_{2}$

Unter normoxischen Bedingungen $\left(20 \% \mathrm{O}_{2}\right)$ zeigte sich eine signifikant verminderte Proliferation der beiden PHD2-knock-down-Klone \#3 und \#4 gegenüber den Wildtyp- und den sh-transfizierten Kontroll-Zellen nach 120 Stunden. Unter hypoxischen Bedingungen $\left(\begin{array}{ll}1 \% & \mathrm{O}_{2}\end{array}\right)$ hingegen hatten die PHD2-knock-down-Klone einen signifikanten Proliferationsvorteil nach 120 Stunden (Abb. 6A). Dieser letzte Befund war analog auch bei dem Anteil der vitalen Zellen zu beobachten. Die beiden PHD2-knock-down-Klone \#3 und \#4 hatten einen signifikant größeren Anteil an vitalen Zellen nach 120 Stunden Inkubation unter hypoxischen Bedingungen (Abb. 6B). 
Mittels der Formel 3.2 wurden die unterschiedlichen Verdoppelungszeiten (G) der MDAMB-231-Zellen in der exponentiellen Wachstumsphase berechnet.

Als Intervallgrenzen wurden gewählt: $\mathrm{t}_{0}=24 \mathrm{~h} ; \mathrm{t}_{1}=48 \mathrm{~h}$ (Normoxie und Hypoxie)

Tabelle 4: $\quad$ Auflistung von Verdoppelungszeiten (G) der MDA-MB-231-Wildtyp- (WT), -sh-transfizierten Kontroll-Zellen (sh-Kontrolle) und der beiden PHD2-knock-down-Klone (\#3 und \#4) unter normoxischen $\left(20 \% \mathrm{O}_{2}\right)$ bzw. hypoxischen $\left(1 \% \mathrm{O}_{2}\right)$ Bedingungen

\begin{tabular}{ccc}
\hline MDA-MB-231 & $\mathbf{O}_{2}$ & $\begin{array}{c}\text { Verdoppelungszeit G } \\
\text { [Stunden] }\end{array}$ \\
\hline WT & $20 \%$ & 27,94 \\
sh-Kontrolle & $20 \%$ & 19,47 \\
\# 3 & $20 \%$ & 26,66 \\
\# 4 & $20 \%$ & 26,95 \\
WT & $1 \%$ & 38,63 \\
sh-Kontrolle & $1 \%$ & 36,67 \\
\# 3 & $1 \%$ & 44,05 \\
\# 4 & $1 \%$ & 37,62 \\
\hline
\end{tabular}

Die Werte in Tabelle 4 zeigen, dass während der exponentiellen Wachstumsphase keine signifikante Änderung des Proliferationsverhaltens durch den PHD2-knock-down beobachtet werden kann. Unter normoxischen Bedingungen $\left(20 \% \mathrm{O}_{2}\right)$ verhalten sich die beiden PHD2knock-down-Klone \#3 und \#4 wie die Wildtyp-Zellen, unter hypoxischen Bedingungen (1\% $\mathrm{O}_{2}$ ) zeigt sich eine ähnliche Wachstumsgeschwindigkeit zwischen \#4 und den Wildtyp- bzw. den sh-transfizierten Kontroll-Zellen. In vitro scheint PHD2 demnach in den MDA-MB-231Zellen keinen Einfluss auf die Wachstumsgeschwindigkeit in der exponentiellen Phase zu haben. Jedoch muss berücksichtigt werden, dass der PHD2-knock-down in den MDA-MB231-Zellen einen signifikanten Einfluss auf das Wachstumsverhalten und die Zellvitalität nach längerer Inkubation $(120$ h) hat, wie die Abbildung 6 verdeutlicht.

\subsubsection{Die Beeinflussung der Zellproliferation und -vitalität durch den PHD2-knock-down in den MCF7-Zellen}

Analog zu den MDA-MB-231-Zellen wurden Proliferations- und Vitalitätskurven von den MCF7-Zellen erstellt, die in einer Zielkonzentration von $2 \times 10^{5} / \mathrm{ml}$ in 6-cm-Schalen ausgesät wurden. Diese Kurven sind in der Abbildung 7 dargestellt. 
A

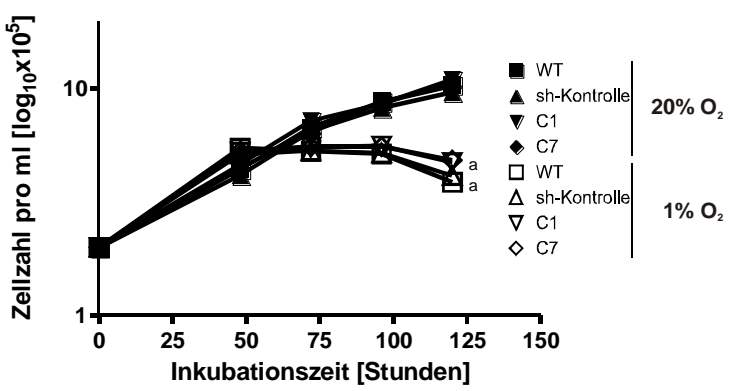

B

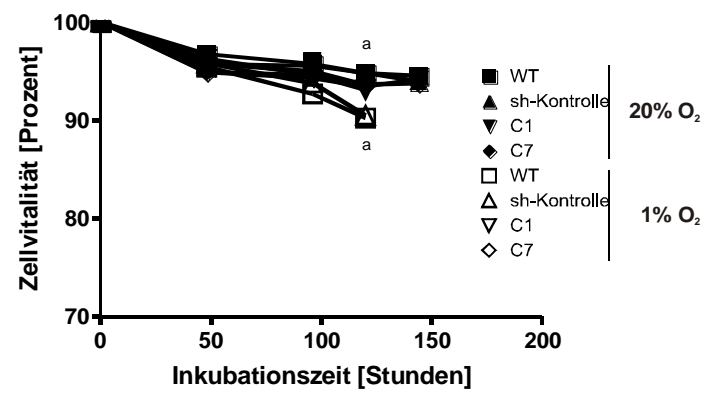

Abbildung 7: Der PHD2-knock-down in den MCF7-Zellen hat einen geringen Einfluss auf die Zellproliferation (A) und -vitalität (B) unter hypoxischen $\left(\mathbf{1 \%} \quad \mathrm{O}_{2}\right)$ Bedingungen. MCF7-Wildtyp- (WT), -sh-transfizierte Kontroll-Zellen (sh-Kontrolle) und die PHD2-knockdown-Klone $\mathrm{C} 1$ und $\mathrm{C} 7$ wurden mit der Zielkonzentration $2 \times 10^{5} / \mathrm{ml}$ in 6-cm-Schalen ausgesät. Anschließend ließ man die Zellen unter normoxischen $\left(20 \% \mathrm{O}_{2}\right)$ bzw. hypoxischen $\left(1 \% \mathrm{O}_{2}\right)$ Bedingungen inkubieren. $\mathrm{Zu}$ den angegebenen Zeitpunkten wurden die Zellkonzentrationen mit dem Cellometer (Nexcelom) (A) bzw. die Zellvitatalität mittels Trypanblau-Färbung (B) bestimmt. mean \pm SEM; $n=3$ biologische Replikate

Abb. 7A:

a: $\mathrm{C} 1$ und $\mathrm{C} 7$ jeweils signifikant gegenüber WT bei $1 \% \mathrm{O}_{2}(\mathrm{p}<0,05)$

Abb. 7B:

a: $\mathrm{C} 1$ und $\mathrm{C7}$ jeweils signifikant gegenüber WT $(\mathrm{p}<0,05)$ und sh-Kontrolle $(\mathrm{p}<0,01)$ bei $1 \% \mathrm{O}_{2}$

Es zeigte sich, vergleichbar mit den MDA-MB-231-Zellen, ein signifikanter Proliferationsvorteil der PHD2-knock-down-Klone C1 und C7 gegenüber den Wildtyp-Zellen unter hypoxischen Bedingungen ( $\left.1 \% \mathrm{O}_{2}\right)$ nach 120 Stunden (Abb. 7A). Dieser Befund spiegelt sich ebenfalls in dem Anteil der vitalen Zellen wider. Auch hier haben die PHD2knock-down-Klone einen signifikant größeren Anteil an vitalen Zellen, verglichen mit den Wildtyp- und den sh-transfizierten Kontroll-Zellen in Hypoxie $\left(1 \% \mathrm{O}_{2}\right)$ nach 144 Stunden (Abb. 7B). In Normoxie $\left(20 \% \mathrm{O}_{2}\right)$ ist kein signifikanter Unterschied in der Proliferation und Zellvitalität festzustellen.

Auch für die MCF7-Zellen wurden die Verdoppelungszeiten mit der Formel 3.2 errechnet. Als Intervallgrenzen wurden gewählt: $\mathrm{t}_{0}=0 \mathrm{~h} ; \mathrm{t}_{1}=48 \mathrm{~h}$ (Normoxie und Hypoxie) 
Tabelle 5: Auflistung von Verdoppelungszeiten (G) der MCF7-Wildtyp- (WT), -sh-transfizierten Kontroll-Zellen (sh-Kontrolle) und der beiden PHD2-knock-down-Klone (\#3 und \#4) unter normoxischen $\left(20 \% \mathrm{O}_{2}\right)$ bzw. hypoxischen $\left(1 \% \mathrm{O}_{2}\right)$ Bedingungen

\begin{tabular}{ccc}
\hline MCF7 & $\mathbf{O}_{2}$ & $\begin{array}{c}\text { Verdoppelungszeit G } \\
\text { [Stunden] }\end{array}$ \\
\hline WT & $20 \%$ & 42,00 \\
sh-Kontrolle & $20 \%$ & 45,44 \\
C1 & $20 \%$ & 39,37 \\
C7 & $20 \%$ & 41,14 \\
WT & $1 \%$ & 32,91 \\
sh-Kontrolle & $1 \%$ & 35,24 \\
C1 & $1 \%$ & 34,40 \\
C7 & $1 \%$ & 34,00 \\
\hline
\end{tabular}

Wie bei den MDA-MB-231-Zellen zeigte sich auch in den MCF7-Zellen ein unterschiedliches Wachstumsmuster, abhängig von der Dauer der Inkubation. So konnte nach längerer Inkubation ein Proliferationsvorteil der PHD2-knock-down-Klone C1 und C7 unter hypoxischen Bedingungen $\left(1 \% \mathrm{O}_{2}\right)$ beobachtet werden (Abb. 7A). Dieser Befund ist in der früheren, exponentiellen Wachstumsphase nicht zu bestätigen. Dort zeigt sich ein ähnliches Wachstumsverhalten zwischen Wildtyp-, sh-transfizierten Kontroll-Zellen und den beiden PHD2-knock-down-Klonen C1 und C7 (Tab. 5). Demnach scheint sich, analog zu den MDAMB-231-Zellen, der PHD2-knock-down unterschiedlich, abhängig von der Inkubationszeit, auf das Wachstumsverhalten auszuwirken.

Außerdem sorgt die Inkubation in Hypoxie für eine deutlich gesteigerte Wachstumsgeschwindigkeit während der exponentiellen, frühen Wachstumsphase in den MCF7-Zellen (Tab. 5). Nach ca. 50 Stunden hypoxischer Inkubation stagniert das Wachstum jedoch und es stellt sich ein negatives Wachstum ein. Dieser Befund ist in den unter normoxischen Bedingungen inkubierten Zellen nicht $\mathrm{zu}$ bestätigen (Abb. 7). Diese Beobachtungen verdeutlichen die Abhängigkeit des Wachstumsverhaltens von der Inkubationszeit und den Inkubationsbedingungen in den untersuchten Zellen.

\subsection{Der PHD2-knock-down bewirkt in vitro eine verminderte Adhäsion unterschiedlicher Tumorzellreihen an die extrazelluläre Matrix (ECM)}

\subsubsection{Etablierung des Adhäsions-Assays und Untersuchung der HeLa- Zellen auf ihr Adhäsionsverhalten}

Die Adhäsion von Tumorzellen an Bestandteile der ECM spielt eine wichtige Rolle bei dem Prozess der Tumormetastasierung. Die Malignität verschiedener Tumorentitäten hängt 
von der Neigung zur Metastasenbildung ab. Der grundlegende Prozess der Metastasierung wurde bereits vor vielen Jahren beobachtet und beschrieben. Er beinhaltet Schritte, wie die Invasion von Tumorzellen in das umliegende Gewebe, die Intravasation in benachbarte Lymph- und Blutgefäße, den Transport zu entfernten Geweben und die dortige Extravasation der Tumorzellen, gefolgt von der erneuten Invasion in das neue Gewebe mit anschließender Proliferation, was schließlich zur Bildung von Metastasen führt (Sato 1962). In den letzten Jahren wurde intensiv an den genauen Mechanismen der Metastasierung geforscht und neue Erkenntnisse gewonnen. So wurde zum Beispiel beschrieben, dass Tumorzellen nicht zwangsläufig mittels Extravasation in das umliegende Gewebe einbrechen müssen, sondern auch am Gefäßendothel haftend proliferieren können und auf diesem Weg zu Metastasen führen (Al-Mehdi et al. 2000). In all diesen Schritten ist die Adhäsionsfähigkeit der Zellen involviert.

Der Einfluss von PHD2 auf die Adhäsion von Tumorzellen an die ECM, genauer an Fibronektin, wurde mit Hilfe der vorher charakterisierten PHD2-knock-down-Zellen untersucht. Als Methode wurde dazu ein Adhäsions-Assay gewählt, bei dem die Adhäsionseigenschaften von Zellen an Bestandteile der ECM erfasst werden konnten. In diesem Fall diente Fibronektin als Beschichtungsmedium. Fibronektin wurde bereits 1978 als wichtiger Bestandteil der ECM im Zusammenhang mit der Adhäsion von Zellen beschrieben (Stenman und Vaheri 1978).

Zunächst musste hierfür ein Adhäsions-Assay etabliert werden. Dazu wurden die zu untersuchenden Zellen in 96-Loch-Platten ausgesät, welche mit Fibronektin beschichtet waren. Je nach Zelllinie wurden die Zellen anschließend für ca. 25-50 Minuten inkubiert und daraufhin die stabil adhärierten Zellen mit Kristallviolett gefärbt. Die dann bei einer Wellenlänge von 595 nm gemessene OD gab Auskunft über die Anzahl der adhärierten Zellen und damit das jeweilige zelluläre Adhäsionsverhalten

Zur Überprüfung der Aussagekraft des Assays wurde anfangs die Adhäsionsfähigkeit von HeLa-sh-transfizierten Kontroll-Zellen (sh-Kontr.) auf Fibronektin mit der auf einem unbeschichteten Untergrund verglichen (Abb. 8). 


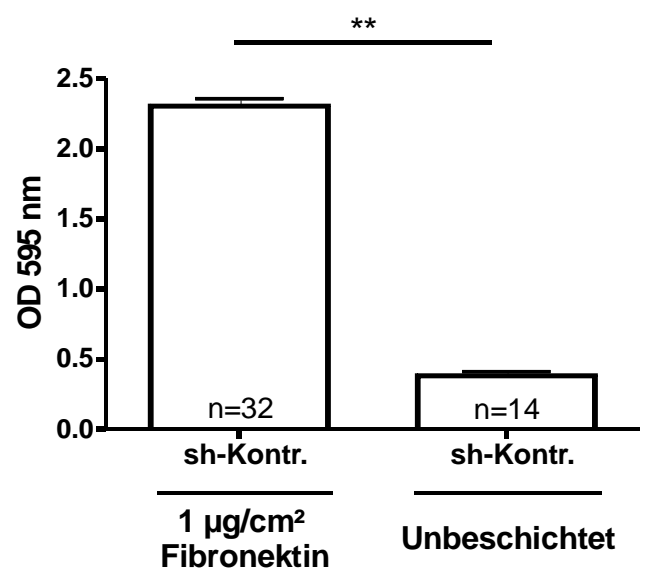

Abbildung 8: Der Adhäsions-Assay eignet sich zur Beurteilung des zellulären Adhäsionsverhaltens.

HeLa-sh-transfizierte Kontroll-Zellen (sh-Kontr.) wurden in 96-Loch-Platten mit der Zielkonzentration $2 \times 10^{5} / \mathrm{ml}$ ausgesät (50 $\mu \mathrm{l} /$ Vertiefung). Die Vertiefungen lagen entweder Fibronektin-beschichtet oder unbeschichtet vor. Nach 50-minütiger Inkubation wurden die stabil adhärierten Zellen mit Kristallviolett gefärbt und anschließend die Lichtabsorption im BioRad Reader bei einer Wellenlänge von $595 \mathrm{~nm}$ bestimmt. mean $\pm \mathrm{SEM}$; n=Anzahl untersuchter unabhängiger Vertiefungen einer 96-Loch-Platte; ** $\mathrm{p}<0,01$

Der Assay ist in der Lage, die Adhäsionsfähigkeit von Zellen zu beurteilen, da erwartungsgemäß die Adhäsion der sh-kontroll-transfizierten HeLa-Zellen auf einer ECMBeschichtung (Fibronektin) signifikant gesteigert war, verglichen mit der auf einem nichtbeschichteten Untergrund. Dort betrug die OD bei $595 \mathrm{~nm}$ nahezu null.

Um nun den Einfluss von PHD2 auf die Adhäsion von Tumorzellen an die ECM zu beschreiben, wurden die Wildtyp-, die sh-transfizierten Kontroll- und die PHD2-knock-downZellen der Klone 1B6 und 3B7 auf ihre Adhäsion an Fibronektin untersucht (Abb. 9). Die shtransfizierten Kontroll-Zellen sollten dabei zum Ausschluss eines möglichen, durch die Transfektion bedingten unspezifischen Effekts dienen. 


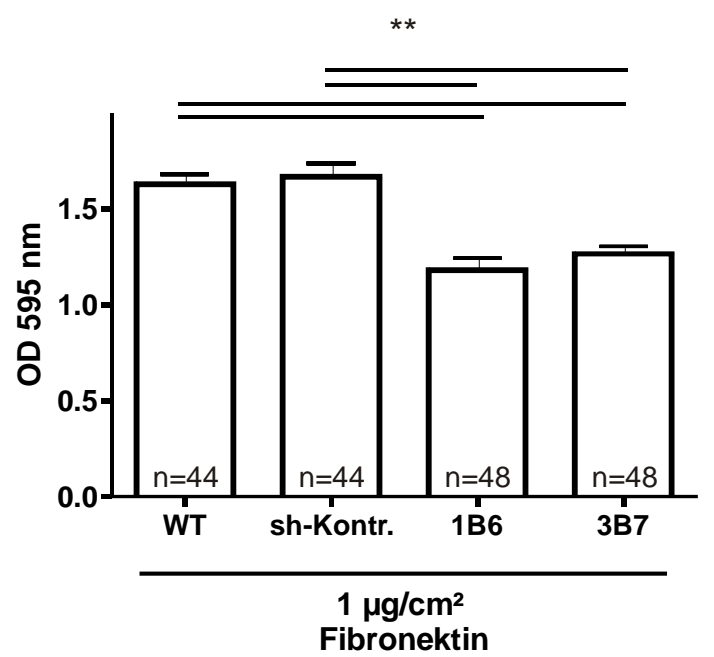

Abbildung 9: PHD2 beeinflusst die Adhäsion an Fibronektin von HeLa-Zellen.

HeLa-Wildtyp- (WT), -sh-transfizierte Kontroll-Zellen (sh-Kontr.) und die beiden PHD2knock-down-Klone 1B6 und 3B7 wurden jeweils in 96-Loch-Platten mit der Zielkonzentration $2 \times 10^{5} / \mathrm{ml}$ ausgesät (50 $\mu \mathrm{l} /$ Vertiefung). Die Vertiefungen waren mit Fibronektin beschichtet. Nach 40-minütiger Inkubation wurden die stabil adhärierten Zellen mit Kristallviolett gefärbt und anschließend die OD bei einer Wellenlänge von $595 \mathrm{~nm}$ gemessen. mean \pm SEM; $\mathrm{n}=$ Anzahl untersuchter unabhängiger Vertiefungen einer 96-Loch-Platte; $* * \mathrm{p}<0,01$

Es zeigte sich, dass die beiden PHD2-knock-down-Klone 1B6 und 3B7 eine im Vergleich zu den Wildtyp-Zellen hochsignifikant reduzierte Adhäsion an Fibronektin aufwiesen. Da sich die sh-transfizierten Kontroll-Zellen in Bezug auf das Adhäsionsverhalten wie die Wildtyp-Zellen verhielten, konnte ausgeschlossen werden, dass der beobachtete Effekt unspezifisch Transfektions-bedingt war.

\subsubsection{Adhäsionsverhalten der MDA-MB-231-Zellen}

Um einen Zell-spezifischen, PHD2-unabhängigen Adhäsionseffekt auszuschließen, wurden die Adhäsionsversuche ebenfalls mit den Wildtyp-, den sh-transfizierten KontrollZellen und den beiden PHD2-knock-down-Klonen \#3 und \#4 der MDA-MB-231-Zellen durchgeführt. 


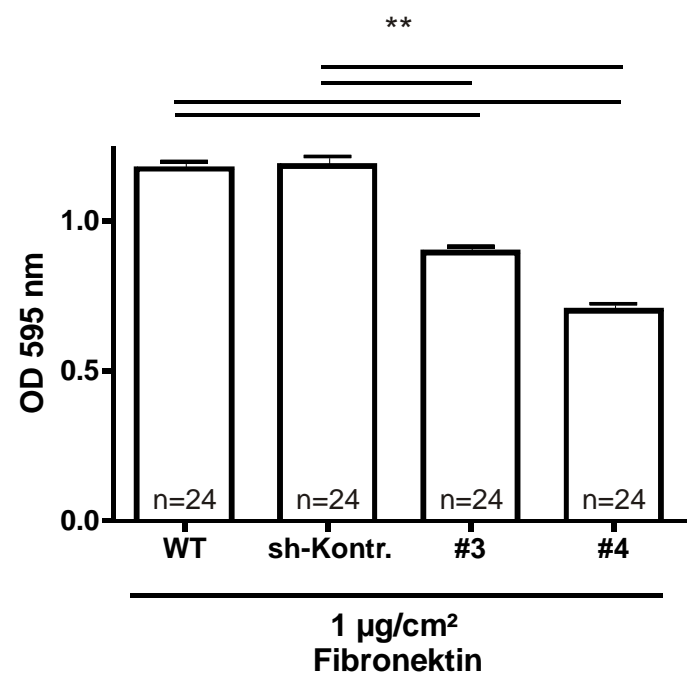

Abbildung 10: PHD2 beeinflusst die Adhäsion an Fibronektin in MDA-MB-231-Zellen.

Wildtyp- (WT), sh-transfizierte Kontroll-Zellen (sh-Kontr.) und die beiden PHD2-knockdown-Klone \#3 und \#4 der MDA-MB-231-Zellen wurden in 96-Loch-Platten jeweils mit der Zielkonzentration $2 \times 10^{5} / \mathrm{ml}$ ausgesät $(50 \mu \mathrm{l} /$ Vertiefung). Die Vertiefungen waren mit Fibronektin beschichtet. Nach 40-minütiger Inkubation wurden die stabil adhärierten Zellen mit Kristallviolett gefärbt und anschließend die OD bei einer Wellenlänge von $595 \mathrm{~nm}$ bestimmt. mean \pm SEM; n=Anzahl untersuchter unabhängiger Vertiefungen einer 96-LochPlatte; ** $\mathrm{p}<0,01$

Auch hier zeigte sich eine signifikant reduzierte Adhäsion der PHD2-knock-down-Klone \#3 und \#4 auf Fibronektin (Abb. 10). Der Adhäsions-fördernde Effekt von PHD2 scheint demnach nicht Zell-spezifisch zu sein.

\subsubsection{Adhäsionsverhalten der T-REx-HeLa-Zellen/P2.1.1-16-Zellen}

Um den beschriebenen Effekt weiter $\mathrm{zu}$ untermauern und $\mathrm{zu}$ überprüfen, ob eine langfristige PHD2-Herunterregulation nötig ist, wurde der Adhäsions-Assay mit den T-RExHeLa-Zellen durchgeführt. In dem von Frau Dr. med. S. Le Huu in der Abteilung für Herzund Kreislaufphysiologie der Universität Göttingen etablierten Klon P2.1.1-16 kann Tetrazyklin-abhängig ein PHD2-knock-down in den T-REx-HeLa-Zellen erreicht werden (Brökers et al. 2009). 
A

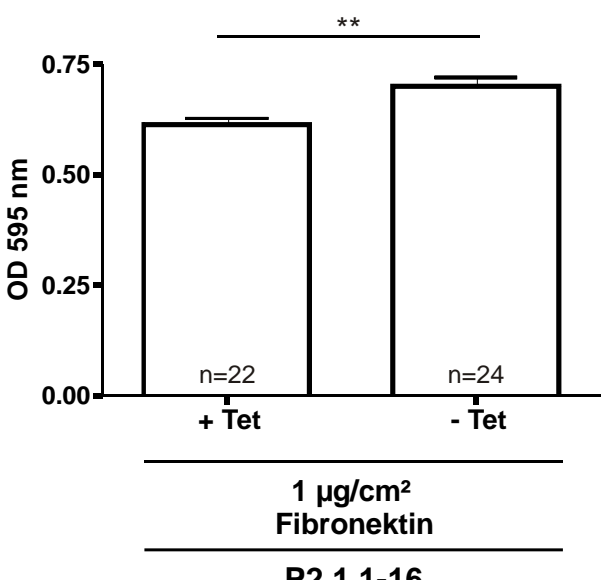

B

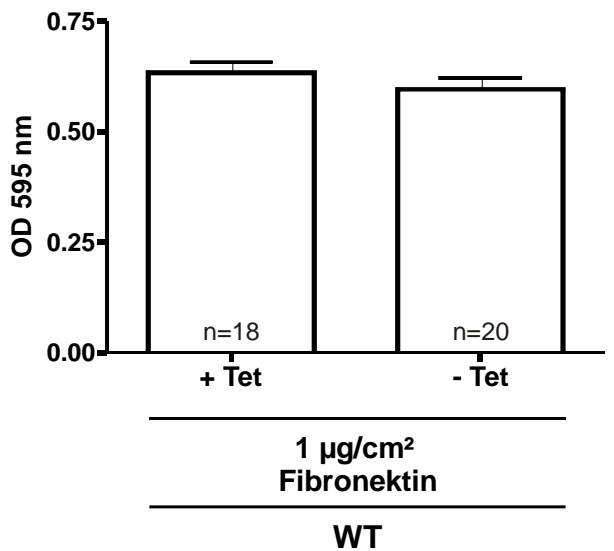

Abbildung 11: Der durch Tetrazyklin induzierbare PHD2-knock-down in den P2.1.1-16-Zellen führt zu einer reduzierten Zelladhäsion.

Sowohl P2.1.1-16- (A) als auch Wildtyp-T-REx-HeLa-Zellen (WT) (B) wurden jeweils unbehandelt (-Tet) bzw. nach 96-stündiger Inkubation mit Tetrazyklin $(10 \mu \mathrm{g} / \mathrm{ml}$, +Tet $)$ mit der Zielkonzentration $2 \times 10^{5} / \mathrm{ml}$ in Fibronektin-beschichtete 96-Loch-Platten ausgesät (50 $\mu 1 /$ Vertiefung). Nach 40-minütiger Inkubation wurden die stabil adhärierten Zellen mit Kristalviolett gefärbt. Anschließend wurde die OD bei einer Wellenlänge von $595 \mathrm{~nm}$ bestimmt. mean \pm SEM; $n=$ Anzahl untersuchter unabhängiger Vertiefungen einer 96-LochPlatte; ** $\mathrm{p}<0,01$

In diesen Zellen zeigte sich durch Zugabe von Tetrazyklin (+ Tet) bei der Durchführung des Adhäsions-Assays eine verminderte Adhäsion des Klons P2.1.1-16 im Vergleich zu unbehandelten Zellen (Abb. 11A). Dieser Befund lässt sich durch den Tetrazyklin induzierten PHD2-knock-down erklären, da eine Tetrazyklin-Zugabe zu den T-REx-HeLa-Kontroll-Zellen keinen Einfluss auf die Adhäsion hatte (Abb. 11B).

\subsubsection{Adhäsion auf Laminin}

Da Fibronektin nur ein möglicher Bestandteil der extrazellulären Matrix ist, wurde das Adhäsionsverhalten der MDA-MB-231-Zellen auch in Laminin-beschichteten Platten untersucht. Laminin ist ebenfalls ein Bestandteil der ECM und wurde 1979 erstmals als wichtiger Bestandteil der Basalmembran beschrieben (Timpl et al. 1979). 


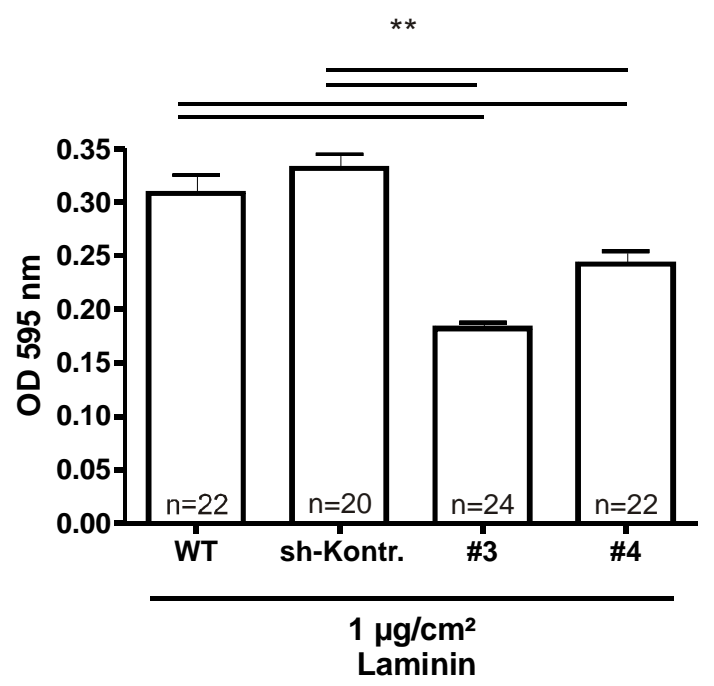

Abbildung 12: PHD2 beeinflusst die Adhäsion an Laminin in MDA-MB-231-Zellen.

Wildtyp- (WT), sh-transfizierte Kontroll-Zellen (sh-Kontr.) und die beiden PHD2-knockdown-Klone \#3 und \#4 der MDA-MB-231-Zellen wurden jeweils in 96-Loch-Platten mit der Zielkonzentration $2 \times 10^{5} / \mathrm{ml}$ ausgesät ( $50 \mu \mathrm{l} /$ Vertiefung). Die Vertiefungen waren mit Laminin beschichtet. Nach 40-minütiger Inkubation wurden die stabil adhärierten Zellen mit Kristallviolett gefärbt und anschließend die OD bei einer Wellenlänge von $595 \mathrm{~nm}$ gemessen. mean \pm SEM; $n=$ Anzahl untersuchter unabhängiger Vertiefungen einer 96-Loch-Platte; $* * \mathrm{p}<0,01$

Auch auf Laminin zeigte sich eine signifikant verminderte Adhäsion der PHD2-knockdown-Klone \#3 und \#4 (Abb. 12). Somit ist der Effekt der reduzierten Adhäsion der PHD2knock-down-Zellen weder Zell-, noch Fibronektin-spezifisch. Allerdings ist zu berücksichtigen, dass das Adhäsionslevel auf Laminin insgesamt deutlich geringer war, als es auf Fibronektin der Fall war. Dieser Befund lässt sich über eine vermutlich geringere Ausbildung der Lamininrezeptoren auf den Zelllinien erklären.

\subsection{Das Fehlen von PHD2 in den PHD2-knock-down-Klonen ist für die verminderte Adhäsion an die ECM verantwortlich}

\subsection{1}

\section{MDA-MB-231-Zellen}

Nachdem der Befund der verminderten Adhäsion der PHD2-knock-down-Klone in verschiedenen Zelllinien und auf unterschiedlichen ECM-Bestandteilen reproduzierbar war, wurde im Folgenden untersucht, ob dieser Effekt tatsächlich auf die Abwesenheit von PHD2 zurückzuführen war. Dazu wurden sowohl die Wildtyp-Zellen als auch der PHD2-knockdown-Klon \#4 der MDA-MB-231-Zellen einerseits transient mit einem Kontroll-Plasmid (Kontrolle) und andererseits mit einem HA-PHD2-kodierenden Plasmid Lipofektaminvermittelt transfiziert. Die Transfektion mit dem Kontroll-Plasmid sollte auch hier erneut einen Transfektions-bedingten, unspezifischen Effekt ausschließen. Anschließend wurden die transfizierten Zellen in Bezug auf ihre Adhäsion auf Fibronektin untersucht. 

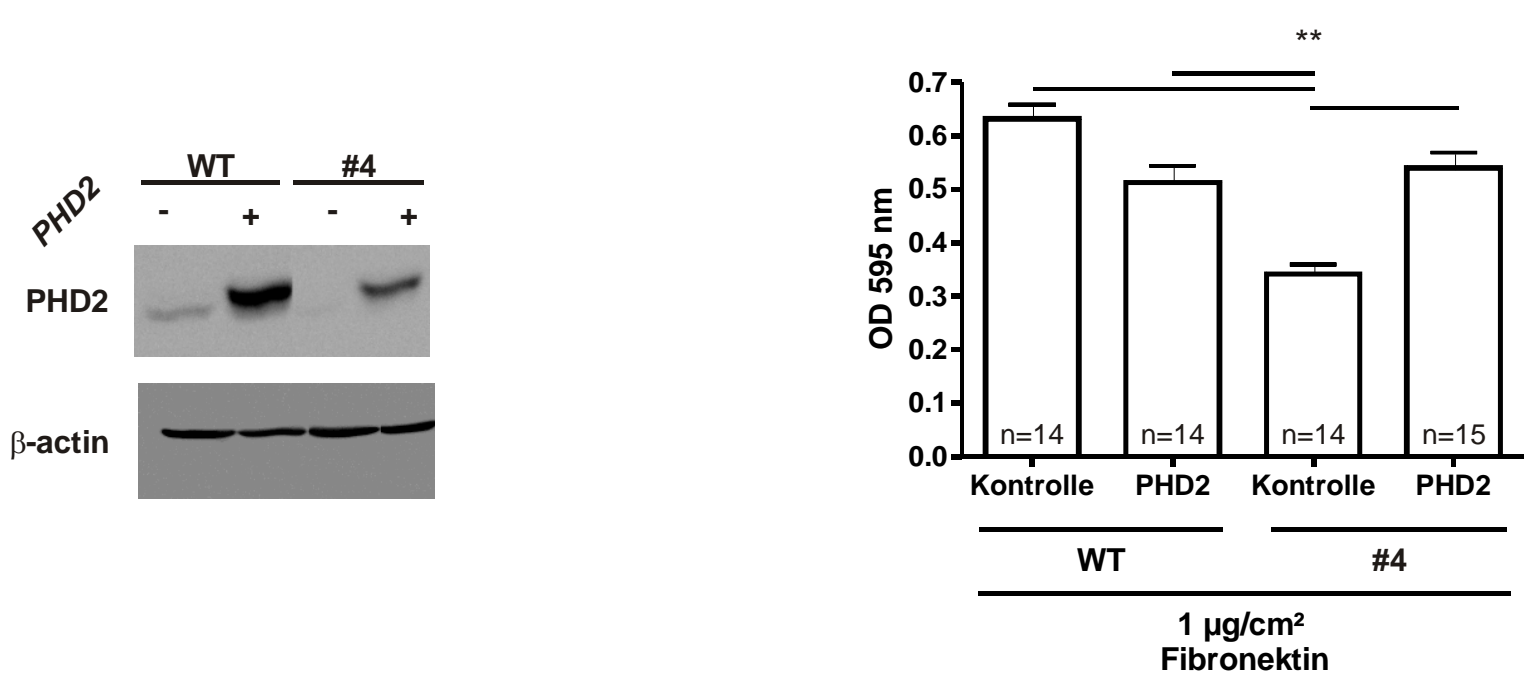

Abbildung 13: Die PHD2-Abwesenheit in MDA-MB-231-Zellen ist für die verminderte Adhäsion der PHD2-knock-down-Klone auf Fibronektin verantwortlich.

MDA-MB-231-Wildtyp- (WT) und -PHD2-knock-down-Zellen (\#4) wurden mit pcDNA3.1 (Kontrolle) oder pcDNA3.1-HA-PHD2 (PHD2) mittels Lipofektamin transient transfiziert. Die erfolgreiche Expression von PHD2 wurde mittels Western Blots überprüft (A). Nach 24 Stunden Inkubation wurden diese Zellen jeweils in 96-Loch-Platten mit der Zielkonzentration $2 \times 10^{5} / \mathrm{ml}$ ausgesät $(50 \mu \mathrm{l} /$ Vertiefung). Die Vertiefungen der 96 -Loch-Platte waren mit Fibronektin beschichtet. Nach weiterer 30-minütiger Inkubation wurden die stabil adhärierten Zellen mit Kristallviolett gefärbt und daraufhin die OD bei einer Wellenlänge von $595 \mathrm{~nm}$ gemessen (B). Die zughörigen Western Blots zeigen die PHD2-Proteinexpressionen in den kontroll-transfizierten (-PHD2) und PHD2-transfizierten (+PHD2) Wildtyp- (WT) bzw. PHD2-knock-down-Zellen (\#4) (A). mean \pm SEM; $n=$ Anzahl untersuchter unabhängiger Vertiefungen einer 96-Loch-Platte; $* * \mathrm{p}<0,01$

Abbildung 13A zeigt die deutlich erhöhte PHD2-Expression auf Proteinebene nach Transfektion des PHD2-Expressionsplasmides (+ PHD2), verglichen mit der KontrollTransfektion (- PHD2) sowohl in den Wildtyp-Zellen wie auch im PHD2-knock-down-Klon \#4. Durch die Rekonstitution von PHD2 ist die Adhäsion des PHD2-knock-down-Klons \#4 auf Fibronektin signifikant gesteigert und kann sogar das Ausmaß der Wildtyp-Zellen erreichen (Abb. 13B). Dieser Befund untermauert, dass die verminderte Adhäsion der PHD2knock-down-Klone tatsächlich auf das Fehlen von PHD2 zurückzuführen ist.

\subsection{2}

MCF7-Zellen

Um auch in diesem Zusammenhang einen Zell-spezifischen Effekt auszuschließen, wurde der Versuch mit den MCF7-Zellen wiederholt. Dazu wurde in der Arbeitsgruppe von Herrn Prof. Dr. Wenger an der Universität Zürich der stabil PHD2-retransfizierte, ursprüngliche PHD2-knock-down-Klon V5PHD2\#2 etabliert. 


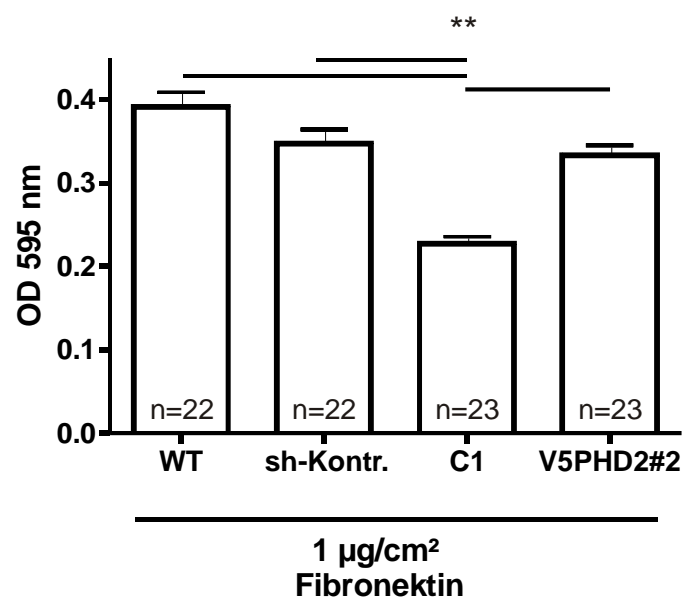

Abbildung 14: Die PHD2-Abwesenheit in MCF7-Zellen ist für die verminderte Adhäsion der PHD2knock-down-Klone auf Fibronektin verantwortlich.

MCF7-Wildtyp- (WT), -sh-transfizierte Kontroll- (sh-Kontr.), PHD2-knock-down- (C1) und stabil PHD2-retransfizierte PHD2-knock-down-Zellen (V5PHD2\#2) wurden jeweils mit der Zielkonzentration $2 \times 10^{5} / \mathrm{ml}$ in 96 -Loch-Platten ausgesät (50 $\mu \mathrm{l} /$ Vertiefung). Die Vertiefungen waren mit Fibronektin beschichtet. Nach 30-minütiger Inkubation wurden die stabil adhärierten Zellen mit Kristallviolett gefärbt und anschließend die OD bei einer Wellenlänge von $595 \mathrm{~nm}$ bestimmt. mean \pm SEM; $\mathrm{n}=$ Anzahl untersuchter unabhängiger Vertiefungen einer 96-Loch-Platte; $* *$ p $<0,01$

Der Klon V5PHD2\#2 zeigte eine signifikant gesteigerte Adhäsion auf Fibronektin im Vergleich mit dem PHD2-knock-down-Klon C1 (Abb. 14). Auch hier wurde durch die PHD2Re-Transfektion, welche in diesem Fall stabil erfolgte, beinahe das Adhäsionslevel der Wildtyp-Zellen erreicht. Es wird also der Befund aus den MDA-MB-231-Zellen, dass tatsächlich das Fehlen von PHD2 für die signifikant reduzierte Adhäsionsfähigkeit verantwortlich ist, in den MCF7-Zellen bestätigt.

Zusammenfassend scheint PHD2 somit einen positiven Effekt auf die Adhäsion von Tumorzellen an die ECM zu haben.

\subsubsection{PHD2 beeinflusst die Adhäsion von Zellen an die ECM HIF-1 $\alpha$ - unabhängig}

Da PHD2 an der Regulation von HIF-1 $\alpha$ maßgeblich beteiligt ist, wurde im Rahmen dieser Arbeit untersucht, ob die verminderte Adhäsion an die ECM der PHD2-knock-downZellen auf die erhöhten Proteinlevel von HIF-1 $\alpha$ zurückzuführen sind. Dazu wurden aus HIF1 $\alpha$-knock-out-Mäusen gewonnene Maus-embryonale Fibroblasten (MEF) verwendet, um den Einfluss von HIF-1 $\alpha$ auf die Zelladhäsion an die ECM zu analysieren (Abb. 15). Es wurden jeweils zwei unterschiedliche, kontroll-transfizierte HIF-1 $\alpha^{+/+}$(CC8B4, CC8D3)- und HIF$1 \alpha^{-/-}$-Klone (CE8C3, CE11B5) in Bezug auf ihr Wachstumsverhalten auf Fibronektin untersucht, um einen Transfektions-bedingten Effekt auszuschließen. 


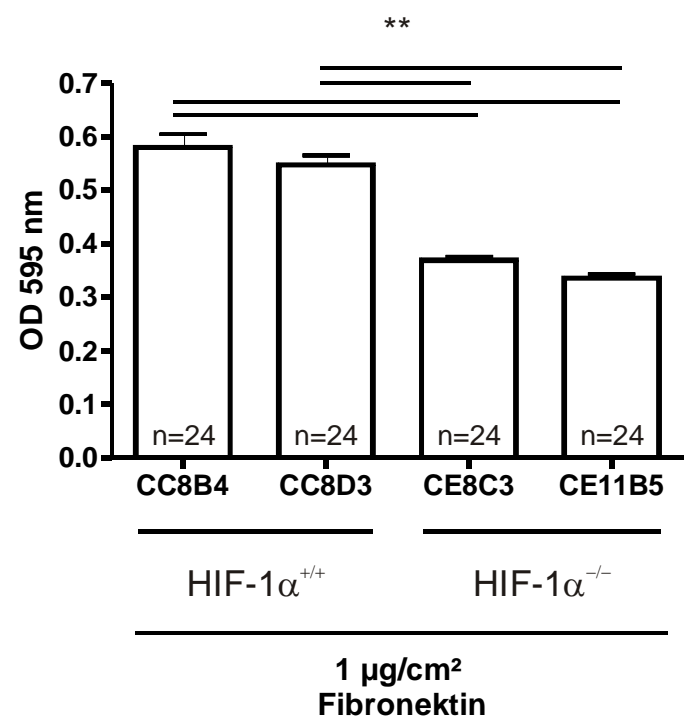

Abbildung 15: HIF-1 $\alpha$ beeinflusst die Zelladhäsion.

Sowohl die sh-kontroll-transfizierten MEF-HIF-1 $\alpha^{+/+}-(\mathrm{CC} 8 \mathrm{~B} 4, \mathrm{CC} 8 \mathrm{D} 3)$ als auch die shkontroll-transfizierten MEF-HIF-1 $\alpha^{-/-}$-Zellen (CE8C3, CE11B5) wurden mit einer Zielkonzentration von $2 \times 10^{5} / \mathrm{ml}$ in 96-Loch-Platten ausgesät $(50 \mu \mathrm{l} /$ Vertiefung $)$. Die Vertiefungen waren mit Fibronektin beschichtet. Nach 30-minütiger Inkubation wurden die stabil adhärierten Zellen mit Kristallviolett gefärbt und anschließend die OD bei $595 \mathrm{~nm}$ gemessen. mean \pm SEM; n=Anzahl untersuchter unabhängiger Vertiefungen einer 96-LochPlatte; ** $\mathrm{p}<0,01$

Es zeigte sich, verglichen mit den HIF- $1 \alpha^{+/+}-\mathrm{MEF}-Z$ Zllen, eine signifikant verminderte Adhäsion der HIF-1 $\alpha$-defizienten MEF-Zellen auf Fibronektin. Dieser Befund verdeutlicht eine positive Beeinflussung der Zelladhäsion durch den Transkriptionsfaktor HIF-1 $\alpha$.

Der nächste Schritt bestand darin, zu untersuchen, ob die reduzierte Adhäsion durch das Fehlen von PHD2 durch das dadurch regulatorisch vermehrte Vorkommen von HIF-1 $\alpha$ bedingt war. Dazu wurden von Frau Dr. rer. nat. Anke Zieseniss in der Abteilung für Herzund Kreislaufphysiologie der Universität Göttingen aus den HIF-1 $\alpha^{+/+}$- und den HIF- $1 \alpha^{-/{ }_{-}}$ MEF-Zellen jeweils PHD2-knock-down-Zellen generiert und in der vorliegenden Arbeit auf ihre Adhäsion an Fibronektin überprüft (Abb. 16). 

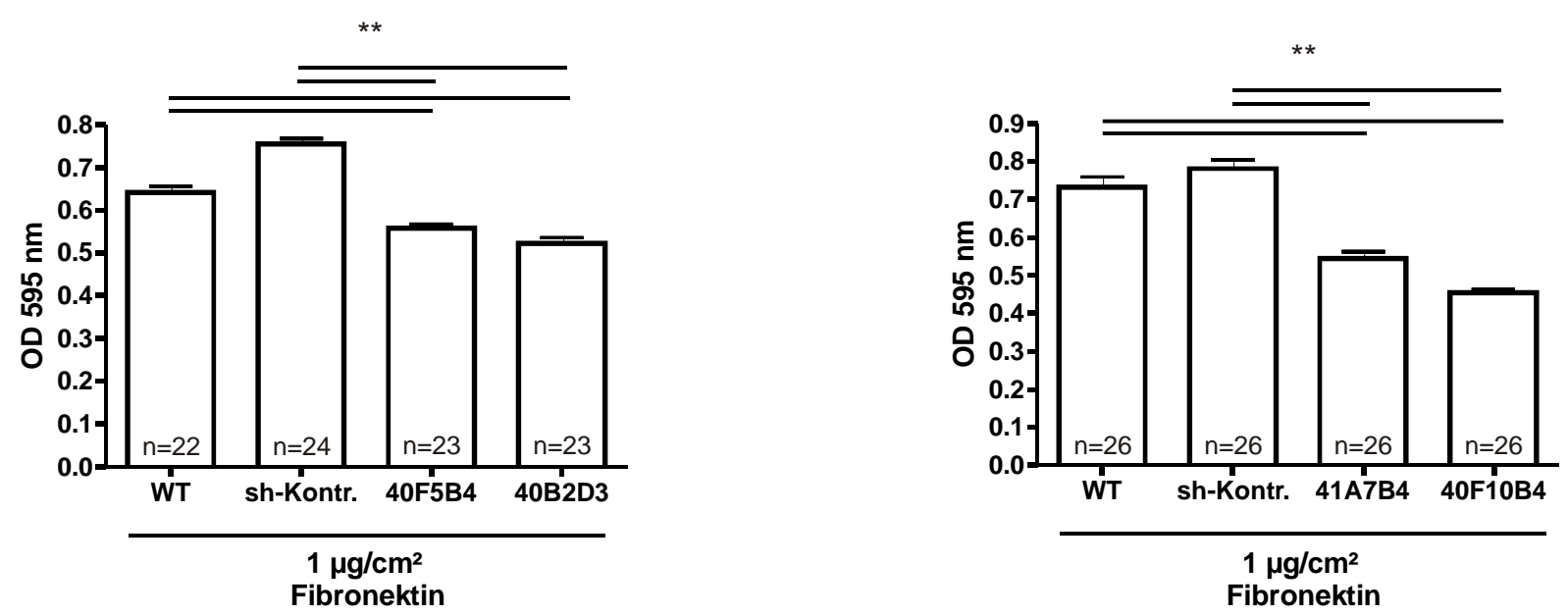

Abbildung 16: PHD2 beeinflusst die Zelladhäsion HIF-1 $\alpha$-unabhängig.

Wildtyp- (WT), sh-transfizierte Kontroll-Zellen (sh-Kontr.) und die jeweiligen PHD2-knockdown-Klone der MEF-HIF-1 $\alpha^{+/+}-(40 F 5 B 4,40 B 2 D 3)$ (A) und der MEF-HIF-1 $\alpha^{-/-}$-Zellen (41A7B4, 40F10B4) (B) wurden je in 96-Loch-Platten mit der Zielkonzentration 2x10 $/ \mathrm{ml}$ ausgesät $(50 \mu \mathrm{l} / \mathrm{Vertiefung})$. Die Vertiefungen waren mit Fibronektin beschichtet. Nach 30minütiger (A) bzw. 45-minütiger Inkubation (B) wurden die stabil adhärierten Zellen mit Kristalviolett gefärbt und anschließend die OD bei einer Wellenlänge von $595 \mathrm{~nm}$ bestimmt. mean \pm SEM; $n=$ Anzahl untersuchter unabhängiger Vertiefungen einer 96-Loch-Platte; $* * \mathrm{p}<0,01$

Sowohl bei den HIF-1 $\alpha^{+/+}$- (Abb. 16A) wie auch bei den HIF-1 $\alpha^{-/-}$-Zellen (Abb. 16B) war eine signifikant geringere Adhäsion der PHD2-knock-down-Klone (40F5B4 und 40B2D3 bzw. 41A7B4 und 40F10B4) auf Fibronektin zu beobachten. Da das Fehlen von PHD2 auch in den HIF-1 $\alpha$-defizienten Zellen zu einer reduzierten Adhäsion führt, scheint PHD2 die Zelladhäsion HIF-1 $\alpha$-unabhängig zu regulieren. Auf welche Weise PHD2 einen Einfluss auf die Zelladhäsion nimmt, muss weiter untersucht werden.

\subsubsection{Durch Inhibition der Rho-associated kinase (ROCK) kann die Adhäsion der HeLa-PHD2-knock-down-Zellen gesteigert werden}

Der Rho-ROCK-Lim-Kinase-Signalweg spielt eine wichtige Rolle im Zusammenhang mit der Inaktivierung von Cofilin, einem Regulator des intrazellulären Aktinumbaus. Dabei aktiviert die GTPase Rho die Kinase ROCK (rho-associated, coiled-coil-forming protein kinase), welche dann wiederum die Lim-Kinase mittels Phosphorylierung aktiviert. Die LimKinase phosphoryliert nun Cofilin, welches daraufhin inaktiv wird und nicht mehr am Umbau des Aktingerüsts mitwirken kann (Arber et al. 1998, Sumi et al. 1999, Yang N et al. 1998, Maekawa et al. 1999). Es konnte kürzlich gezeigt werden, dass auch PHD2 in die Regulation 
von Cofilin eingreift. So führte ein PHD2-knock-down zu einer vermehrten Phosphorylierung und somit Inaktivierung von Cofilin (Vogel et al. 2010).

Daher wurde der Einfluss dieses Signalweges auf die PHD2-abhängige Zelladhäsion näher untersucht (Abb. 17). Dazu wurden sowohl die HeLa-Wildtyp-Zellen als auch der PHD2-knock-down-Klon 3B7 jeweils mit und ohne Y27632, einem zellgängigen Inhibitor von ROCK, behandelt. Anschließend wurde die Adhäsion dieser Zellen auf Fibronektin untersucht.

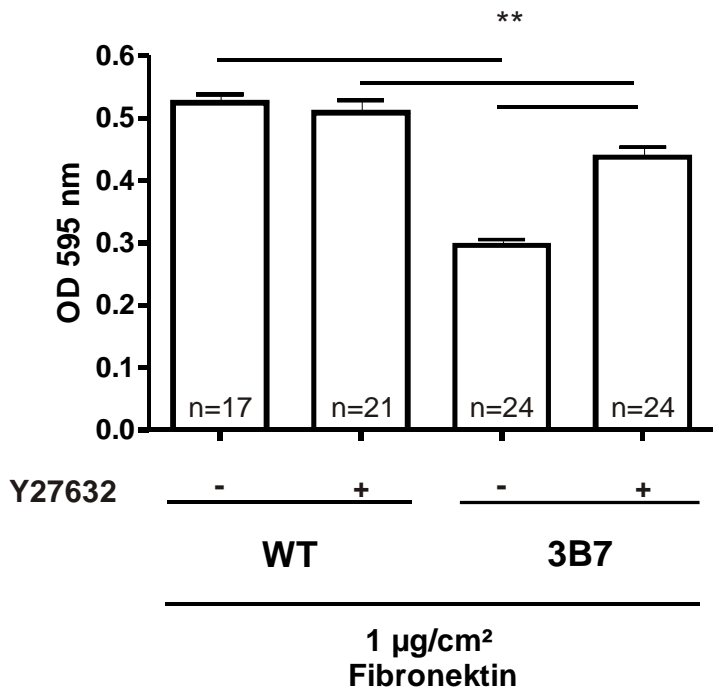

Abbildung 17: Durch den ROCK-Inhibitor Y27632 kann die Adhäsion auf Fibronektin im PHD2-knockdown-Klon $3 B 7$ der HeLa-Zellen signifikant gesteigert werden.

HeLa-Wildtyp- (WT) und -PHD2-knock-down-Zellen (3B7) wurden jeweils unbehandelt (Y27632) bzw. nach 100-minütiger Inkubation mit dem ROCK-Inhibitor Y27632 (10 $\mu \mathrm{M})$ (+Y27632) in 96-Loch-Platten mit der Zielkonzentration $2 \times 10^{5} / \mathrm{ml}$ ausgesät ( $50 \mu 1 /$ Vertiefung). Die Vertiefungen waren mit Fibronektin beschichtet. Nach 30-minütiger Inkubation wurden die stabil adhärierten Zellen mit Kristallviolett gefärbt und anschließend die OD bei einer Wellenlänge von $595 \mathrm{~nm}$ gemessen. mean \pm SEM; n=Anzahl untersuchter unabhängiger Vertiefungen einer 96-Loch-Platte; $* * \mathrm{p}<0,01$

Als Folge einer 100-minütigen Behandlung der Zellen mit $10 \mu \mathrm{M}$ Y27632 zeigte sich eine signifikante Steigerung der Zelladhäsion des HeLa-PHD2-knock-down-Klons 3B7. Durch Inhibition von ROCK wird Cofilin vermindert phosphoryliert und liegt damit vermehrt aktiv vor. Die Folge davon ist ein effektiverer Umbau des Aktingerüstes (McGough et al. 1997). Auf das Adhäsionsverhalten der Wildtyp-Zellen hat der ROCK-Inhibitor keinen Einfluss.

\subsection{PHD2 hat keinen Einfluss auf die Ausbildung und Verteilung fokaler Adhäsionen in MDA-MB-231- und MCF7-Zellen}

Um mögliche Ursachen für die verminderte Adhäsion der PHD2-knock-down-Zellen zu untersuchen, wurden mittels Fluoreszenzmikroskopie die fokalen Kontakte der Zellen dargestellt. Hierfür wurde die Lokalisation des Fokalkontaktproteins Vinculin (Geiger et al. 
1980) mittels Immunfluoreszenz untersucht (Abb. 18A) und die Anzahl der Fokalkontakte manuell ausgezählt (Abb. 18B).

A

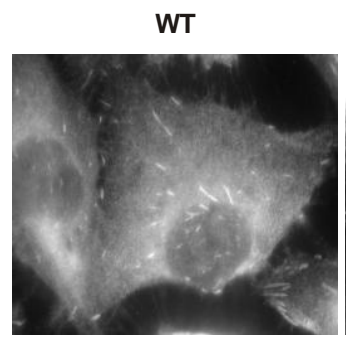

\#3

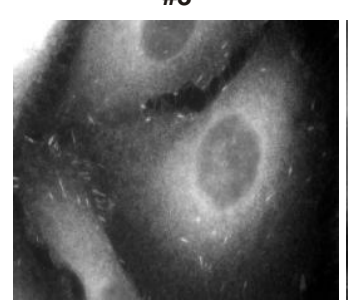

B

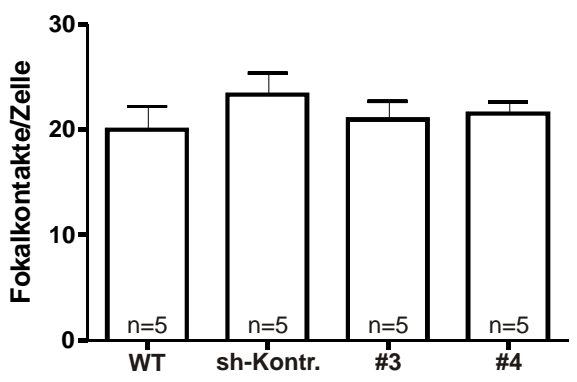

Abbildung 18: Der PHD2-knock-down der MDA-MB-231-Zellen verändert weder die Anzahl, noch die Verteilung der Fokalkontakte.

Es werden die Fokalkontakte der MDA-MB-231-Wildtyp- (WT), der -sh-transfizierten Kontroll-Zellen (sh-Kontr.) und der beiden PHD2-knock-down-Klone \#3 und \#4 mittels Immunfluoreszenz dargestellt (A). Dazu wurden die Zellen fixiert und permeabilisiert. Die Fokalkontakte wurden mittels eines spezifischen, primären anti-Vinculin-Antikörpers und eines Texas Red gekoppelten Sekundärantikörpers gefärbt und fluoreszenzmikroskopisch analysiert. Die Zellkerne wurden mit 4',6-Diamidin-2-phenylindol (DAPI) gefärbt. Die dargestellten Fokalkontakte wurden manuell in 5 Gesichtsfeldern je Zelltyp ausgezählt und durch die Anzahl der beobachteten Zellen dividiert (B). mean \pm SEM; n=Anzahl technischer Replikate

Es waren keine Unterschiede in der Ausbildung oder Verteilung der fokalen Kontakte festzustellen. Nach Auszählen der fokalen Kontakte je Zelle in jeweils fünf Gesichtsfeldern konnte dieser optische Eindruck bestätigt werden. Es zeigte sich keine signifikante Veränderung in der Anzahl der fokalen Kontakte durch den PHD2-knock-down in den MDAMB-231-Zellen.

Um erneut einen Zell-spezifischen Effekt auszuschließen, wurden in gleicher Weise die fokalen Kontakte der MCF7-Zellen dargestellt und manuell quantitativ bestimmt. 


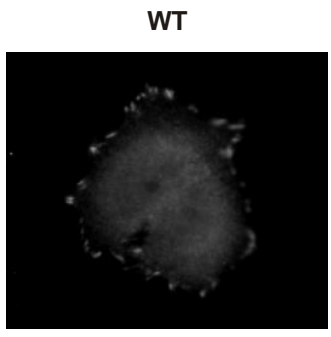

C1

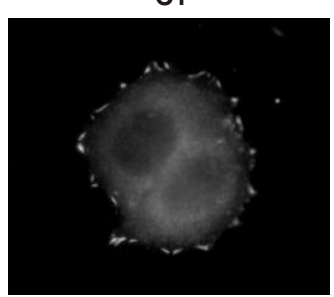

sh-Kontrolle

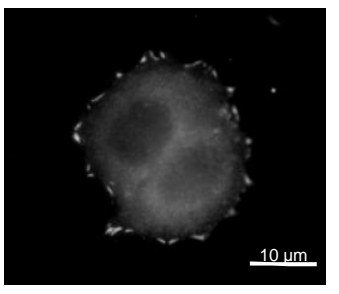

C7

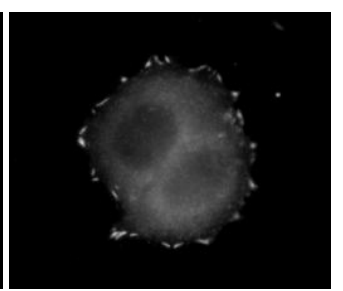

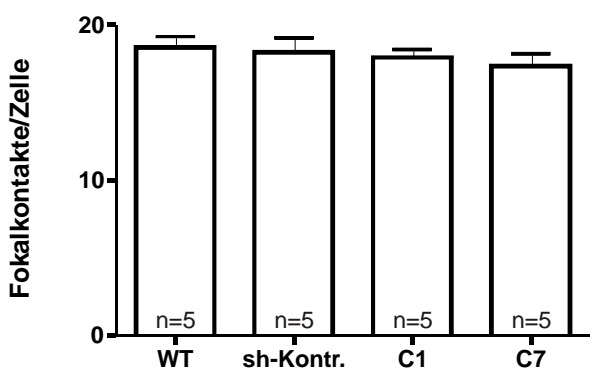

Abbildung 19: Der PHD2-knock-down der MCF7-Zellen verändert weder die Anzahl, noch die Verteilung der Fokalkontakte.

Es werden die Fokalkontakte der MCF7-Wildtyp- (WT), der -sh-transfizierten Kontroll-Zellen (sh-Kontr.) und der beiden PHD2-knock-down-Klone C1 und C7 mittels Immunfluoreszenz dargestellt (A). Die Durchführung war analog zu den MDA-MB-231-Zellen (Abb. 18). Die dargestellten Fokalkontakte wurden ebenfalls manuell in 5 Gesichtsfeldern je Zelltyp ausgezählt und durch die Anzahl der beobachteten Zellen dividiert (B). mean \pm SEM; $\mathrm{n}=$ Anzahl technischer Replikate

Auch bei den MCF7-Zellen zeigte sich keine Veränderung in der Anzahl und Verteilung der fokalen Kontakte in den PHD2-knock-down-Klonen C1 und C7. Die Anzahl der bestimmten fokalen Kontakte je Zelle deckte sich mit denen der MDA-MB-231-Zellen (Abb. 18). Zusammenfassend lässt sich sagen, dass PHD2 keinen Einfluss auf die Anzahl und Verteilung von fokalen Kontakten zu haben scheint.

\subsection{SPARC und SPP1 als mögliche Kandidatengene, die PHD2- reguliert Einfluss auf die Zelladhäsion nehmen}

Nachdem eine PHD2-vermittelte Regulation der fokalen Kontakte als Ursache für das verminderte Adhäsionsverhalten verschiedener PHD2-knock-down-Klone ausgeschlossen werden konnte, wurde im Folgenden die PHD2-abhängige Genexpression als mögliche Ursache genauer untersucht. Um mögliche Gene zu identifizieren, die für die verminderte Adhäsionsfähigkeit in PHD2-knock-down-Zellen verantwortlich sind, wurden die WildtypZellen und der PHD2-knock-down-Klon 3B7 der HeLa-Zellen mittels qRT-PCR auf die Expression unterschiedlicher Gene untersucht. Mithilfe des RT Profiler ${ }^{T M}$ PCR Array (SABiosciences, Frederick, USA) konnte die Expression der Zellen auf 84, im Zusammenhang mit Zelladhäsion stehenden Gene untersucht werden. In diesem Array fielen 12 Gene auf, die im PHD2-knock-down-Klon 3B7 ein deutlich verändertes Expressionsmuster 


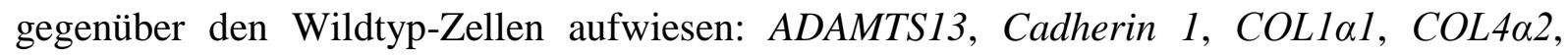
COL6a1, Integrin 32, MMP7, Sarcoglycan, SPARC, SPP1, Thrombospondin 3, Vitronectin. Nachfolgend wurden HeLa-, MDA-MB-231- und MCF7-Zellen auf die unterschiedlichen Expressionen dieser Gene in den jeweiligen PHD2-knock-down-Klonen mittels qRT-PCR überprüft. Ferner wurde die Anzahl der biologischen Replikate von $n=1$ im Array auf n=6 gesteigert.

Der fold up (Heraufregulierung des Gens im PHD2-knock-down-Klon bezogen auf die Wildtyp-Zellen) bzw. der fold down (Herunterregulation des Gens im PHD2-knock-downKlon bezogen auf die Wildtyp-Zellen) wurde anhand der Formel 3.1 berechnet. Es ist erneut zu berücksichtigen, dass ein Wert $<1$ und $>0$ eine Herunterregulation des Gens bedeutete und aus diesem Grund noch durch -1 dividiert wurde. Diese errechneten fold ups bzw. fold downs der jeweiligen Gene sind zusammen mit den $\Delta \mathrm{C}_{\mathrm{t}}$-Werten $\left(\mathrm{C}_{\mathrm{t}^{-}}-\right.$Wert gene of interest $-\mathrm{C}_{\mathrm{t}^{-}}$

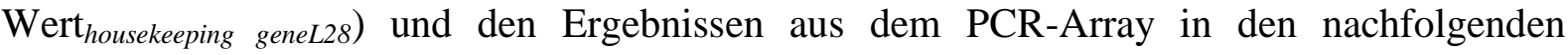
Tabellen für die HeLa- (Tab. 6), MDA-MB-231- (Tab. 7) und MCF7-Zellen (Tab. 8) dargestellt.

Zur übersichtlichen Darstellung werden die Ergebnisse aus dem RT Profiler ${ }^{T M}$ PCR Array in Form einer heat-map dargestellt (Abb. 20).

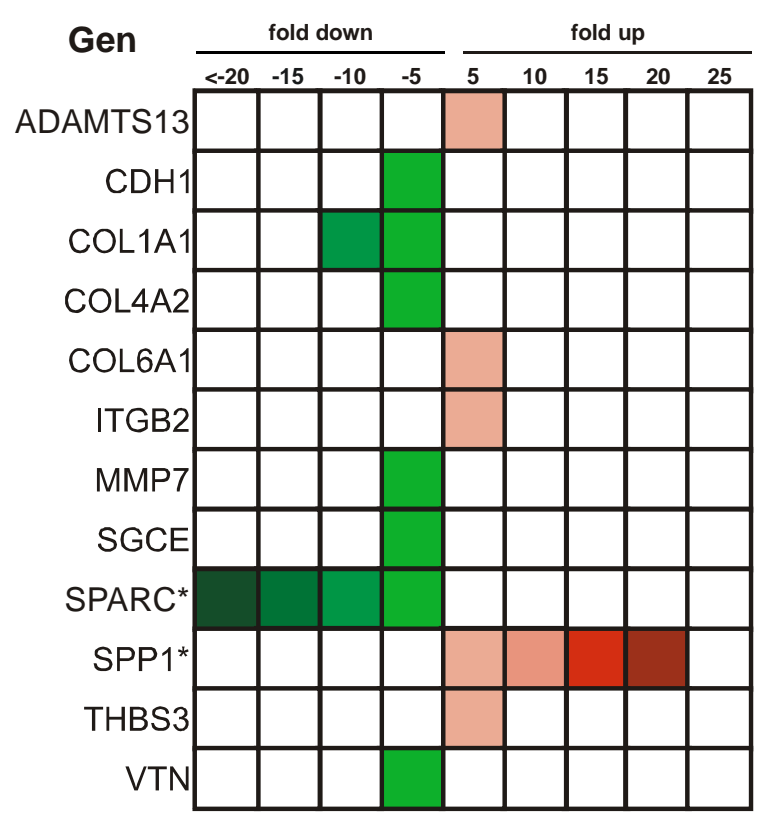

Abbildung 20: Heat-map der Ergebnisse aus dem mit den HeLa-Zellen durchgeführten RT Profiler $^{T M}$ PCR Array.

Dargestellt sind die Herauf- (fold up) bzw. Herunterregulationen (fold down) der jeweiligen Gene in dem HeLa-PHD2-knock-down-Klon 3B7, verglichen mit den Wildtyp-Zellen. Diese Werte wurden mittels der Formel 3.1 errechnet und einer Farbintensität zugeordnet. Die Intensität der Farbe rot ist gesteigert dargestellt bei steigender Heraufregulation des Gens im PHD2-knock-down-Klon, die der Farbe grün bei steigender Herunterregulation des Gens. Das Symbol * bedeutet, dass diese gekennzeichneten Gene auch einer starke Veränderung der Expression in den PHD2-knock-down-Klonen der MDA-MB-231-Zellen aufweisen. 
Unterschiedliche Genexpressionen in den HeLa-Wildtyp- (WT), -sh-transfizierten Kontroll-Zellen (shK) und den beiden PHD2-knock-down-Klonen $1 B 6$ und 3B7. Nach RNA-Isolation und deren Umschreibung in cDNA wurden die $\mathrm{C}_{\mathrm{t}}$-Werte der zu untersuchenden Gene mittels qRT-PCR bestimmt. In der Tabelle sind die Daten aus dem PCR-Array (SABiosciences) und die durchschnittlichen $\Delta \mathrm{C}_{\mathrm{t}}-\mathrm{Werte}\left(\mathrm{C}_{\mathrm{t}}\right.$-Wert gene of interest $-\mathrm{C}_{\mathrm{t}}-\mathrm{Wert}$ housekeeping geneL28 $)$ aufgelistet. Außerdem ist der fold up bzw. fold down des jeweiligen Gens im PHD2-knock-down-Klon bezogen auf die Wildtyp-Zellen über die Formel 3.1 errechnet worden und dargestellt. Ein fold up wird in den Tabellen jeweils mit der Farbe rot, ein fold down mit der Farbe grün und eine annähernd gleiche Expression in PHD2-knock-down-Klon und Wildtyp-Zellen mit der Farbe blau symbolisiert. mean \pm SD; n=6 biologische Replikate; ** $\mathrm{p}<0,01, * \mathrm{p}<0,05$

\begin{tabular}{|c|c|c|c|c|c|c|c|c|c|c|}
\hline \multirow{3}{*}{ Gen } & \multirow{3}{*}{ Symbol } & \multicolumn{3}{|c|}{ PCR-Array } & \multicolumn{6}{|c|}{ HeLa } \\
\hline & & \multicolumn{2}{|c|}{$\begin{array}{c}\text { AVG } \Delta \mathrm{C}_{\mathrm{t}} \\
(\mathrm{Ct}(\mathrm{GOI})-\text { Ave Ct }(\mathrm{HKG}))\end{array}$} & \multirow{2}{*}{$\begin{array}{c}\begin{array}{c}\text { Fold Up- oder } \\
\text { Down-Regulation }\end{array} \\
\text { 3B7 Sample /WT } \\
\text { Sample }\end{array}$} & \multicolumn{4}{|c|}{$\begin{array}{c}\text { AVG } \Delta \mathrm{C}_{\mathrm{t}} \\
(\mathrm{Ct}(\mathrm{GOI})-\text { Ave Ct }(\mathrm{HKG}))\end{array}$} & \multicolumn{2}{|c|}{$\begin{array}{l}\text { Fold Up- oder Down- } \\
\text { Regulation }\end{array}$} \\
\hline & & 3B7 & WT & & WT & shK & $1 \mathrm{~B} 6$ & 3B7 & 1B6/WT & \#3B7/WT \\
\hline ADAM metallopeptidase & ADAMTS13 & 12,71 & 13,94 & 2,36 & $\begin{array}{c}22,3 \pm \\
1,43 \\
\end{array}$ & $\begin{array}{c}21,4 \pm \\
1,35\end{array}$ & $\begin{array}{c}14,7 \pm \\
1,67\end{array}$ & $\begin{array}{c}18,6 \pm \\
0,76\end{array}$ & $\begin{array}{l}293,2 \pm \\
298,1 *\end{array}$ & $\begin{array}{r}13,8 \pm \\
6,4 \text { ** }\end{array}$ \\
\hline Cadherin 1 & $\mathrm{CDH} 1$ & 14,57 & 12,45 & $-4,32$ & \multicolumn{6}{|c|}{ Expressionslevel zu gering } \\
\hline Collagen, type I alpha1 & COL1A1 & 7,62 & 5,11 & $-5,66$ & \begin{tabular}{|c|}
$7,00 \pm$ \\
0,28
\end{tabular} & $\begin{array}{c}6,78 \pm \\
0,45\end{array}$ & $\begin{array}{c}6,46 \pm \\
0,31\end{array}$ & $\begin{array}{c}5,98 \pm \\
0,83\end{array}$ & $\begin{array}{l}1,48 \pm \\
0,32 * *\end{array}$ & $\begin{array}{l}2,24 \pm \\
1,11^{*}\end{array}$ \\
\hline Collagen, type IV alpha2 & COL4A2 & 4,39 & 2,27 & $-4,32$ & $\begin{array}{c}10,9 \pm \\
0,61 \\
\end{array}$ & $\begin{array}{c}11,5 \pm \\
0,5\end{array}$ & $\begin{array}{c}10,0 \pm \\
0,84\end{array}$ & $\begin{array}{c}9,85 \pm \\
1,38 \\
\end{array}$ & $\begin{array}{l}2,05 \pm \\
0,54 * \star\end{array}$ & $\begin{array}{l}3,87 \pm \\
1,15 * \star\end{array}$ \\
\hline Collagen, type VI alpha1 & COL6A1 & 8,27 & 10,12 & 3,63 & $\begin{array}{c}19,8 \pm \\
1,1\end{array}$ & $\begin{array}{c}20,6 \pm \\
0,57\end{array}$ & $\begin{array}{c}14,5 \pm \\
2,11\end{array}$ & $\begin{array}{c}18,9 \pm \\
0,93\end{array}$ & $\begin{array}{l}20,8 \pm \\
10,6 \text { ** }\end{array}$ & $\begin{array}{l}2,41 \pm \\
1,29 *\end{array}$ \\
\hline $\begin{array}{c}\text { Integrin, beta } 2 \\
\text { Matrix metallo peptidase7 }\end{array}$ & $\begin{array}{l}\text { ITGB2 } \\
\text { MMP7 }\end{array}$ & $\begin{array}{c}8,87 \\
12,14\end{array}$ & $\begin{array}{l}10,67 \\
10,75\end{array}$ & \begin{tabular}{r|}
3,50 \\
$-2,61$
\end{tabular} & \multicolumn{6}{|c|}{ Expressionslevel zu gering } \\
\hline Sarcoglycan, epsilon & SGCE & 8,53 & 6,77 & $-3,37$ & \begin{tabular}{|c|}
$7,23 \pm$ \\
0,22
\end{tabular} & $\begin{array}{l}7,5 \pm \\
0,18\end{array}$ & $\begin{array}{c}6,76 \pm \\
0,46\end{array}$ & $\begin{array}{c}7,4 \pm \\
0,68\end{array}$ & $\begin{array}{c}1,45 \pm \\
0,53\end{array}$ & $\begin{array}{c}-1,03 \pm \\
0,44\end{array}$ \\
\hline $\begin{array}{l}\text { Secreted protein, acidic, Cystein- } \\
\text { reich; Osteonectin }\end{array}$ & SPARC & 14,57 & 7,29 & $-154,56$ & $\begin{array}{c}8,89 \pm \\
0,44\end{array}$ & $\begin{array}{c}17,0 \pm \\
0,3\end{array}$ & $\begin{array}{c}17,8 \pm \\
1,48\end{array}$ & $\begin{array}{c}18,6 \pm \\
0,92\end{array}$ & $\begin{array}{c}-738,4 \pm \\
688,1 *\end{array}$ & $\begin{array}{l}-959,9 \pm \\
556,6^{* *}\end{array}$ \\
\hline \multirow[t]{4}{*}{ Secreted protein 1, Osteopontin } & SPP1 & 8,37 & 12,88 & 22,91 & $\begin{array}{c}14,4 \pm \\
0,35\end{array}$ & $\begin{array}{c}15,4 \pm \\
0,56\end{array}$ & $\begin{array}{c}12,7 \pm \\
0,92\end{array}$ & $\begin{array}{c}10,1 \pm \\
0,76\end{array}$ & $\begin{array}{l}4,33 \pm \\
1,95^{\star *}\end{array}$ & $\begin{array}{l}22,1 \pm \\
10,8^{* \star}\end{array}$ \\
\hline & SPP1 a & & & & $\begin{array}{c}13,9 \pm \\
0,22\end{array}$ & $\begin{array}{c}15,1 \pm \\
0,38\end{array}$ & $\begin{array}{c}12,9 \pm \\
0,64\end{array}$ & $\begin{array}{c}9,44 \pm \\
0,81\end{array}$ & $\begin{array}{l}2,09 \pm \\
0,76 *\end{array}$ & $\begin{array}{l}24,5 \pm \\
11,4 * \star\end{array}$ \\
\hline & SPP1 b & & & & $\begin{array}{c}14,3 \pm \\
0,24\end{array}$ & $\begin{array}{c}15,4 \pm \\
0,5\end{array}$ & $\begin{array}{c}12,6 \pm \\
0,95\end{array}$ & $\begin{array}{l}9,8 \pm \\
0,77\end{array}$ & $\begin{array}{l}3,74 \pm \\
1,97^{*}\end{array}$ & $\begin{array}{l}25,5 \pm \\
12,0 * *\end{array}$ \\
\hline & SPP1 c & & & & \begin{tabular}{|c|}
$18,3 \pm$ \\
0,26 \\
\end{tabular} & $\begin{array}{c}19,5 \pm \\
0,34 \\
\end{array}$ & $\begin{array}{c}16,9 \pm \\
1,32 \\
\end{array}$ & $\begin{array}{c}13,8 \pm \\
0,75 \\
\end{array}$ & $\begin{array}{l}3,49 \pm \\
2,05 * \\
\end{array}$ & $\begin{array}{l}24,45 \pm \\
10,7 \text { ** }\end{array}$ \\
\hline Thrombospondin 3 & THBS3 & 9,09 & 10,23 & 2,22 & \multicolumn{6}{|c|}{ Expressionslevel zu gering } \\
\hline Vitronectin & VTN & 5,98 & 4,55 & $-2,68$ & $\begin{array}{c}7,83 \pm \\
0,38\end{array}$ & $\begin{array}{c}10,6 \pm \\
0,19\end{array}$ & $\begin{array}{c}11,9 \pm \\
0.85\end{array}$ & $\begin{array}{l}9,7 \pm \\
0.86\end{array}$ & $\begin{array}{l}-19,3 \pm \\
0,041 * *\end{array}$ & $\begin{array}{c}-4,13 \pm \\
0,17 *\end{array}$ \\
\hline
\end{tabular}




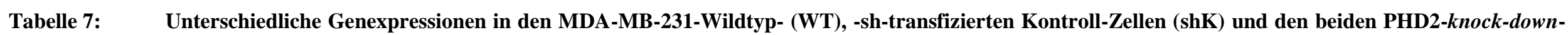
Klonen \#3 und \#4. Nach RNA-Isolation und deren Umschreibung in cDNA wurden die $\mathrm{C}_{\mathrm{t}}$-Werte der zu untersuchenden Gene mittels qRT-PCR bestimmt In der Tabelle sind die Daten aus dem PCR-Array (SABiosciences) und die durchschnittlichen $\Delta \mathrm{C}_{\mathrm{t}}-\mathrm{Werte}\left(\mathrm{C}_{\mathrm{t}}-\mathrm{Wert}_{\text {gene of interest }}-\mathrm{C}_{\mathrm{t}}\right.$-Wert $\left.{ }_{\text {housekeeping geneL28 }}\right)$ aufgelistet. Außerdem ist der fold up bzw. fold down des jeweiligen Gens im PHD2-knock-down-Klon bezogen auf die Wildtyp-Zellen über die Formel 3.1 errechnet worden und hier dargestellt. Ein relevanter fold up wird mit der Farbe rot, ein fold down mit der Farbe grün und eine annähernd gleiche Expression in PHD2knock-down-Klon und Wildtyp-Zellen mit der Farbe blau symbolisiert. mean \pm SD; $\mathrm{n}=6$ biologische Replikate; ** $\mathrm{p}<0,01, * \mathrm{p}<0,05$

\begin{tabular}{|c|c|c|c|c|c|c|c|c|c|c|c|c|c|c|c|c|}
\hline \multirow{3}{*}{ Gen } & \multirow{3}{*}{ Symbol } & \multicolumn{3}{|c|}{ PCR-Array } & \multicolumn{6}{|c|}{$\begin{array}{l}\text { MDA-MB-231 } \\
\text { ohne Östrogen }\end{array}$} & \multicolumn{6}{|c|}{$\begin{array}{l}\text { MDA-MB-231 } \\
\text { mit Östrogen }\end{array}$} \\
\hline & & \multicolumn{2}{|c|}{$\begin{array}{c}\text { AVG } \Delta \mathrm{C}_{\mathrm{t}} \\
(\mathrm{Ct}(\mathrm{GOI})-\text { Ave } \\
\text { Ct (HKG)) }\end{array}$} & \multirow{2}{*}{$\begin{array}{c}\text { Fold Up- } \\
\text { oder Down- } \\
\text { Regulation } \\
\text { 3B7 Sample } \\
\text { /WT Sample }\end{array}$} & \multicolumn{4}{|c|}{$\begin{array}{c}\text { AVG } \Delta \mathrm{C}_{\mathrm{t}} \\
(\mathrm{Ct}(\mathrm{GOI})-\text { Ave Ct (HKG)) }\end{array}$} & \multicolumn{2}{|c|}{$\begin{array}{c}\text { Fold Up- oder } \\
\text { Down- } \\
\text { Regulation }\end{array}$} & \multicolumn{4}{|c|}{$\begin{array}{c}\text { AVG } \Delta \mathrm{C}_{\mathrm{t}} \\
\text { (Ct(GOI) - Ave Ct (HKG)) }\end{array}$} & \multicolumn{2}{|c|}{$\begin{array}{l}\text { Fold Up- oder } \\
\text { Down- } \\
\text { Regulation }\end{array}$} \\
\hline & & 3B7 & WT & & WT & shK & \#3 & \#4 & \#3/WT & \#4/WT & WT & shK & \#3 & \#4 & \#3/WT & \#4/WT \\
\hline $\begin{array}{c}\text { ADAM } \\
\text { metallopeptidase }\end{array}$ & ADAMTS13 & 12,71 & 13,94 & 2,36 & \multicolumn{12}{|c|}{ Expressionslevel zu gering } \\
\hline Cadherin 1 & $\mathrm{CDH} 1$ & 14,57 & 12,45 & $-4,32$ & \begin{tabular}{|c|}
$2,29 \pm$ \\
0,30 \\
\end{tabular} & \begin{tabular}{|c|}
$3,82 \pm$ \\
0,67 \\
\end{tabular} & \begin{tabular}{|c|}
$4,06 \pm$ \\
0,33 \\
\end{tabular} & \begin{tabular}{|c|}
$3,90 \pm$ \\
0,56 \\
\end{tabular} & \begin{tabular}{|l|}
$-3,36 \pm$ \\
0,06 ** \\
\end{tabular} & $\begin{array}{l}-2,88 \pm \\
0,14 \text { ** }\end{array}$ & $\begin{array}{c}3,87 \pm \\
0,7 \\
\end{array}$ & $\begin{array}{c}4,92 \pm \\
0,51 \\
\end{array}$ & \begin{tabular}{|c|}
$4,97 \pm$ \\
0,89 \\
\end{tabular} & \begin{tabular}{|c|}
$3,92 \pm$ \\
0,61 \\
\end{tabular} & \begin{tabular}{|c|}
$-1,27 \pm$ \\
0,27 \\
\end{tabular} & $\begin{array}{c}1,04 \pm \\
0,48 \\
\end{array}$ \\
\hline $\begin{array}{c}\text { Collagen, type I } \\
\text { alpha1 }\end{array}$ & COL1A1 & 7,62 & 5,11 & $-5,66$ & \begin{tabular}{|c|}
$7,72 \pm$ \\
0,77
\end{tabular} & \begin{tabular}{|c|}
$8,23 \pm$ \\
0,79 \\
\end{tabular} & $\begin{array}{c}6,01 \pm \\
0,10\end{array}$ & $\begin{array}{c}6,06 \pm \\
0,33\end{array}$ & $\begin{array}{l}3,27 \pm \\
0,23 \text { ** }\end{array}$ & $\begin{array}{c}3,22 \pm \\
0,7 * *\end{array}$ & $\begin{array}{c}7,86 \pm \\
0,52\end{array}$ & $\begin{array}{c}8,58 \pm \\
0,67\end{array}$ & \begin{tabular}{|c|}
$7,39 \pm$ \\
1,29 \\
\end{tabular} & $\begin{array}{c}6,28 \pm \\
0,23\end{array}$ & $\begin{array}{l}1,77 \pm \\
1,08\end{array}$ & $\begin{array}{l}2,91 \pm \\
0,14 \text { ** }\end{array}$ \\
\hline $\begin{array}{c}\text { Collagen, type IV } \\
\text { alpha2 }\end{array}$ & COL4A2 & 4,39 & 2,27 & $-4,32$ & \multirow{4}{*}{\multicolumn{12}{|c|}{ Expressionslevel zu gering }} \\
\hline $\begin{array}{c}\text { Collagen, type VI } \\
\text { alpha1 }\end{array}$ & COL6A1 & 8,27 & 10,12 & 3,63 & & & & & & & & & & & & \\
\hline Integrin, beta 2 & ITGB2 & 8,87 & 10,67 & 3,50 & & & & & & & & & & & & \\
\hline $\begin{array}{l}\text { Matrix metallo } \\
\text { peptidase7 }\end{array}$ & MMP7 & 12,14 & 10,75 & $-2,61$ & & & & & & & & & & & & \\
\hline $\begin{array}{c}\text { Sarcoglycan, } \\
\text { epsilon }\end{array}$ & SGCE & 8,53 & 6,77 & $-3,37$ & \begin{tabular}{|l|}
$5,05 \pm$ \\
0,25 \\
\end{tabular} & \begin{tabular}{|c|}
$4,41 \pm$ \\
0,64 \\
\end{tabular} & \begin{tabular}{|c|}
$4,58 \pm$ \\
0,25 \\
\end{tabular} & \begin{tabular}{|c|}
$5,43 \pm$ \\
0,28 \\
\end{tabular} & $\begin{array}{l}1,31 \pm \\
0,15 * *\end{array}$ & $\begin{array}{r}-1,22 \pm \\
0,11 * \\
\end{array}$ & $\begin{array}{c}5,10 \pm \\
0,35 \\
\end{array}$ & \begin{tabular}{|l|}
$3,99 \pm$ \\
0,23 \\
\end{tabular} & \begin{tabular}{|c|}
$4,94 \pm$ \\
0,33 \\
\end{tabular} & $\begin{array}{l}5,5 \pm \\
0,22 \\
\end{array}$ & $\begin{array}{c}1,06 \pm \\
0,21 \\
\end{array}$ & $\begin{array}{l}-1,30 \pm \\
0,11^{\star \star} \\
\end{array}$ \\
\hline $\begin{array}{l}\text { Secreted protein, } \\
\text { acidic, Cystein- } \\
\text { reich; Osteonectin }\end{array}$ & SPARC & 14,57 & 7,29 & $-154,56$ & $\begin{array}{c}3,44 \pm \\
0,44\end{array}$ & $\begin{array}{c}5,46 \pm \\
0,46\end{array}$ & $\begin{array}{c}6,94 \pm \\
0,55\end{array}$ & $\begin{array}{c}7,57 \pm \\
0,54\end{array}$ & $\begin{array}{l}-12,5 \pm \\
0,03 \text { ** }\end{array}$ & $\begin{array}{l}-16,7 \pm \\
0,02 * *\end{array}$ & $\begin{array}{c}6,67 \pm \\
0,72\end{array}$ & $\begin{array}{c}7,47 \pm \\
0,78\end{array}$ & $\begin{array}{c}7,26 \pm \\
0,81\end{array}$ & $\begin{array}{c}7,59 \pm \\
0,78\end{array}$ & $\begin{array}{c}-1,67 \pm \\
0,29 *\end{array}$ & $\begin{array}{l}-1,72 \pm \\
0,25 *\end{array}$ \\
\hline \multirow[t]{4}{*}{$\begin{array}{l}\text { Secreted protein } 1, \\
\text { Osteopontin }\end{array}$} & SPP1 & 8,37 & 12,88 & 22,91 & $\begin{array}{c}9,23 \pm \\
0,69\end{array}$ & \begin{tabular}{|c|}
$13,9 \pm$ \\
0,71 \\
\end{tabular} & $\begin{array}{c}11,6 \pm \\
0,30 \\
\end{array}$ & $\begin{array}{c}12,7 \pm \\
0,52\end{array}$ & $\begin{array}{l}-5,00 \pm \\
0,04 \text { ** }\end{array}$ & $\begin{array}{l}-8,33 \pm \\
0,01 \text { ** }\end{array}$ & $\begin{array}{c}9,45 \pm \\
0,45\end{array}$ & $\begin{array}{c}13,8 \pm \\
0,43\end{array}$ & $\begin{array}{c}12,1 \pm \\
0,22 \\
\end{array}$ & $\begin{array}{c}12,8 \pm \\
0,33\end{array}$ & $\begin{array}{l}-6,25 \pm \\
0,03^{* *}\end{array}$ & $\begin{array}{l}-10,0 \pm \\
0,02 \text { ** }\end{array}$ \\
\hline & SPP1 a & & & & \begin{tabular}{|c|}
$7,28 \pm$ \\
0,59 \\
\end{tabular} & \begin{tabular}{|c|}
$13,0 \pm$ \\
0,94 \\
\end{tabular} & \begin{tabular}{c|}
$10,0 \pm$ \\
0,28 \\
\end{tabular} & \begin{tabular}{|c|}
$11,8 \pm$ \\
0,58 \\
\end{tabular} & $\begin{array}{l}-6,67 \pm \\
0,03 \text { ** }\end{array}$ & $\begin{array}{l}-20,0 \pm \\
0,01 * \star\end{array}$ & $\begin{array}{c}8,38 \pm \\
0,42 \\
\end{array}$ & $\begin{array}{c}13,2 \pm \\
0,34 \\
\end{array}$ & \begin{tabular}{|c|}
$10,8 \pm$ \\
0,23 \\
\end{tabular} & $\begin{array}{c}11,8 \pm \\
0,32 \\
\end{array}$ & \begin{tabular}{|l|}
$-5,26 \pm$ \\
0,03 ** \\
\end{tabular} & $\begin{array}{c}-10,00 \pm \\
0,02\end{array}$ ** \\
\hline & SPP1 b & & & & $\begin{array}{c}8,37 \pm \\
0,59\end{array}$ & $\begin{array}{c}14,0 \pm \\
0,74\end{array}$ & $\begin{array}{c}11,6 \pm \\
0,23\end{array}$ & $\begin{array}{c}12,8 \pm \\
0,35\end{array}$ & $\begin{array}{c}-9,1 \pm \\
0,02 \text { ** }\end{array}$ & $\begin{array}{l}-20,0 \pm \\
0,01\end{array}$ & $\begin{array}{c}9,37 \pm \\
0,40\end{array}$ & $\begin{array}{c}14,1 \pm \\
0,62\end{array}$ & \begin{tabular}{|c|}
$12,2 \pm$ \\
0,16 \\
\end{tabular} & $\begin{array}{c}13,3 \pm \\
0,51\end{array}$ & $\begin{array}{c}-7,14 \pm \\
0,02\end{array}$ ** & $\begin{array}{c}-16,67 \pm \\
0,02 \text { ** }\end{array}$ \\
\hline & SPP1 c & & & & $\begin{array}{c}11,9 \pm \\
0,70 \\
\end{array}$ & $\begin{array}{c}18,3 \pm \\
0,85 \\
\end{array}$ & $\begin{array}{c}14,8 \pm \\
0,52 \\
\end{array}$ & $\begin{array}{c}16,5 \pm \\
0,70 \\
\end{array}$ & $\begin{array}{l}-7,14 \pm \\
0,05 \text { ** }\end{array}$ & $\begin{array}{l}-25,0 \pm \\
0,01 * *\end{array}$ & $\begin{array}{c}13,2 \pm \\
0,62\end{array}$ & $\begin{array}{c}18,3 \pm \\
0,73 \\
\end{array}$ & \begin{tabular}{|c|}
$15,4 \pm$ \\
0,29 \\
\end{tabular} & \begin{tabular}{|c}
$16,7 \pm$ \\
0,29 \\
\end{tabular} & $\begin{array}{l}-4,55 \pm \\
0,05 \text { ** }\end{array}$ & $\begin{array}{r}-10,00 \pm \\
0,02\end{array}$ ** \\
\hline Thrombospondin 3 & THBS3 & 9,09 & 10,23 & 2,22 & \multicolumn{12}{|c|}{ Expressionslevel zu gering } \\
\hline Vitronectin & VTN & 5,98 & 4,55 & $-2,68$ & \begin{tabular}{|c|}
$13,8 \pm$ \\
0,50 \\
\end{tabular} & \begin{tabular}{|c|}
$13,9 \pm$ \\
0,88 \\
\end{tabular} & \begin{tabular}{|c|}
$13,2 \pm$ \\
0,69 \\
\end{tabular} & \begin{tabular}{|c|}
$13,4 \pm$ \\
0,45 \\
\end{tabular} & $\begin{array}{c}1,27 \pm \\
0,44 \\
\end{array}$ & $\begin{array}{c}1,27 \pm \\
0,37 \\
\end{array}$ & $\begin{array}{c}14,2 \pm \\
0,11\end{array}$ & $\begin{array}{c}13,5 \pm \\
0,52 \\
\end{array}$ & \begin{tabular}{|c|}
$13,6 \pm$ \\
0,47 \\
\end{tabular} & \begin{tabular}{|c|}
$13,8 \pm$ \\
0,22 \\
\end{tabular} & $\begin{array}{c}1,26 \pm \\
0,3 \\
\end{array}$ & $\begin{array}{l}1,33 \pm \\
0,29 * \star\end{array}$ \\
\hline
\end{tabular}




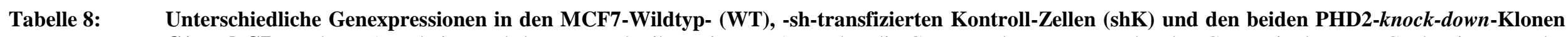
C1 und C7. Nach RNA-Isolation und deren Umschreibung in cDNA wurden die $\mathrm{C}_{\mathrm{t}}$-Werte der zu untersuchenden Gene mittels qRT-PCR bestimmt In der

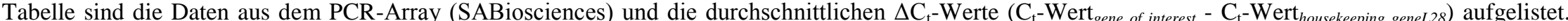
Außerdem ist der fold up bzw. fold down des jeweiligen Gens im PHD2-knock-down-Klon bezogen auf die Wildtyp-Zellen über die Formel 3.1 errechnet worden und hier dargestellt. Ein relevanter fold up wird in den Tabellen jeweils mit der Farbe rot, ein fold down mit der Farbe grün und eine annähernd gleiche Expression in PHD2-knock-down-Klon und Wildtyp-Zellen mit der Farbe blau symbolisiert. mean \pm SD; $\mathrm{n}=6$ biologische Replikate; ** $\mathrm{p}<0,01$, * $\mathrm{p}<0,05$

\begin{tabular}{|c|c|c|c|c|c|c|c|c|c|c|c|c|c|c|c|c|}
\hline \multirow{3}{*}{ Gen } & \multirow{3}{*}{ Symbol } & \multicolumn{3}{|c|}{ PCR-Array } & \multicolumn{6}{|c|}{$\begin{array}{c}\text { MCF7 } \\
\text { ohne Östrogen }\end{array}$} & \multicolumn{6}{|c|}{$\begin{array}{c}\text { MCF7 } \\
\text { mit Östrogen }\end{array}$} \\
\hline & & \multicolumn{2}{|c|}{$\begin{array}{c}\text { AVG } \Delta \mathrm{C}_{\mathrm{t}} \\
(\mathrm{Ct}(\mathrm{GOI})-\mathrm{Ave} \\
\mathrm{Ct}(\mathrm{HKG}))\end{array}$} & \multirow{2}{*}{$\begin{array}{c}\text { Fold Up- } \\
\text { oder Down- } \\
\text { Regulation } \\
\text { 3B7 Sample } \\
\text { /WT Sample }\end{array}$} & \multicolumn{4}{|c|}{$\begin{array}{c}\text { AVG } \Delta \mathrm{C}_{\mathrm{t}} \\
\text { (Ct(GOI) - Ave Ct (HKG)) }\end{array}$} & \multicolumn{2}{|c|}{$\begin{array}{c}\text { Fold Up- oder } \\
\text { Down- } \\
\text { Regulation }\end{array}$} & \multicolumn{4}{|c|}{$\begin{array}{c}\text { AVG } \Delta \mathrm{C}_{\mathrm{t}} \\
\text { (Ct(GOI) - Ave Ct (HKG)) }\end{array}$} & \multicolumn{2}{|c|}{$\begin{array}{c}\text { Fold Up- oder } \\
\text { Down- } \\
\text { Regulation }\end{array}$} \\
\hline & & 3B7 & WT & & WT & shK & C1 & C7 & C1/WT & C7/WT & WT & shK & C1 & C7 & C1/WT & C7/WT \\
\hline $\begin{array}{c}\text { ADAM } \\
\text { metallopeptidase }\end{array}$ & ADAMTS13 & 12,71 & 13,94 & 2,36 & $\begin{array}{c}18,7 \pm \\
0,25\end{array}$ & $\begin{array}{c}18,2 \pm \\
0,62\end{array}$ & $\begin{array}{c}17,1 \pm \\
0,63\end{array}$ & $\begin{array}{c}17,1 \pm \\
0,86\end{array}$ & $\begin{array}{l}3,7 \pm \\
0,73^{\star *}\end{array}$ & $\begin{array}{l}3,78 \pm \\
0,39 * *\end{array}$ & $\begin{array}{c}17,1 \pm \\
0,63\end{array}$ & $\begin{array}{c}17,1 \pm \\
0,33\end{array}$ & $\begin{array}{c}16,8 \pm \\
0,54\end{array}$ & $\begin{array}{c}17,0 \pm \\
0,48\end{array}$ & $\begin{array}{l}1,57 \pm \\
0,21 * \star\end{array}$ & $\begin{array}{c}1,00 \pm \\
0,18\end{array}$ \\
\hline Cadherin 1 & $\mathrm{CDH} 1$ & 14,57 & 12,45 & $-4,32$ & \begin{tabular}{|c|}
$12,0 \pm$ \\
0,94
\end{tabular} & $\begin{array}{c}12,3 \pm \\
0,73\end{array}$ & \begin{tabular}{|c|}
$12,2 \pm$ \\
0,29 \\
\end{tabular} & \begin{tabular}{|c|}
$12,2 \pm$ \\
0,37
\end{tabular} & $\begin{array}{c}1,13 \pm \\
0,23\end{array}$ & $\begin{array}{c}1,03 \pm \\
0,23 \\
\end{array}$ & $\begin{array}{c}11,9 \pm \\
0,51\end{array}$ & $\begin{array}{c}12,4 \pm \\
0,24\end{array}$ & $\begin{array}{c}12,1 \pm \\
0,43\end{array}$ & $\begin{array}{c}12,3 \pm \\
0,16\end{array}$ & $\begin{array}{c}-1,14 \pm \\
0,27 \\
\end{array}$ & $\begin{array}{l}-1,35 \pm \\
0,08 \text { ** }\end{array}$ \\
\hline $\begin{array}{c}\text { Collagen, type I } \\
\text { alpha1 }\end{array}$ & COL1A1 & 7,62 & 5,11 & $-5,66$ & $\begin{array}{c}8,18 \pm \\
0,58\end{array}$ & $\begin{array}{c}8,06 \pm \\
0,33\end{array}$ & \begin{tabular}{|c|}
$8,24 \pm$ \\
0,49 \\
\end{tabular} & $\begin{array}{c}7,63 \pm \\
0,52 \\
\end{array}$ & $\begin{array}{l}1,15 \pm \\
0,35 \\
\end{array}$ & $\begin{array}{l}1,35 \pm \\
0,35 *\end{array}$ & $\begin{array}{c}7,81 \pm \\
0,19\end{array}$ & $\begin{array}{c}7,97 \pm \\
0,44 \\
\end{array}$ & $\begin{array}{c}8,10 \pm \\
0,88\end{array}$ & $\begin{array}{c}7,35 \pm \\
0,29 \\
\end{array}$ & $\begin{array}{l}1,21 \pm \\
0,24 \\
\end{array}$ & $\begin{array}{l}1,40 \pm \\
0,28 \text { ** }\end{array}$ \\
\hline $\begin{array}{c}\text { Collagen, type IV } \\
\text { alpha2 }\end{array}$ & COL4A2 & 4,39 & 2,27 & $-4,32$ & \begin{tabular}{|c|}
$11,2 \pm$ \\
0,16 \\
\end{tabular} & $\begin{array}{c}10,1 \pm \\
0,72 \\
\end{array}$ & \begin{tabular}{|c|}
$10,8 \pm$ \\
0,39 \\
\end{tabular} & $\begin{array}{c}10,7 \pm \\
0,51 \\
\end{array}$ & $\begin{array}{l}1,39 \pm \\
0,38 \text { * }\end{array}$ & $\begin{array}{l}1,45 \pm \\
0,36 \text { * }\end{array}$ & $\begin{array}{c}10,9 \pm \\
0,52 \\
\end{array}$ & $\begin{array}{c}10,9 \pm \\
0,19 \\
\end{array}$ & $\begin{array}{c}10,8 \pm \\
0,47\end{array}$ & $\begin{array}{c}10,7 \pm \\
0,65\end{array}$ & $\begin{array}{c}1,02 \pm \\
0,29 \\
\end{array}$ & $\begin{array}{c}1,03 \pm \\
0,1 \\
\end{array}$ \\
\hline $\begin{array}{l}\text { Collagen, type VI } \\
\text { alpha1 }\end{array}$ & COL6A1 & 8,27 & 10,12 & 3,63 & \multirow{3}{*}{\multicolumn{12}{|c|}{ Expressionslevel zu gering }} \\
\hline Integrin, beta 2 & ITGB2 & 8,87 & 10,67 & 3,50 & & & & & & & & & & & & \\
\hline $\begin{array}{l}\text { Matrix metallo } \\
\text { peptidase } 7\end{array}$ & MMP7 & 12,14 & 10,75 & $-2,61$ & & & & & & & & & & & & \\
\hline $\begin{array}{c}\text { Sarcoglycan, } \\
\text { epsilon }\end{array}$ & SGCE & 8,53 & 6,77 & $-3,37$ & \begin{tabular}{|c|}
$12,2 \pm$ \\
0,24 \\
\end{tabular} & $\begin{array}{c}13,5 \pm \\
0,44 \\
\end{array}$ & \begin{tabular}{|c|}
$16,4 \pm$ \\
0,73 \\
\end{tabular} & \begin{tabular}{|c|}
$17,4 \pm$ \\
0,79 \\
\end{tabular} & $\begin{array}{l}-17,0 \pm \\
0,02 \text { ** } \\
\end{array}$ & $\begin{array}{l}-33,8 \pm \\
0,01 * * \\
\end{array}$ & $\begin{array}{c}11,7 \pm \\
0,35 \\
\end{array}$ & $\begin{array}{c}12,7 \pm \\
0,56 \\
\end{array}$ & \begin{tabular}{|c|}
$15,5 \pm$ \\
0,41 \\
\end{tabular} & $\begin{array}{c}16,1 \pm \\
0,55 \\
\end{array}$ & $\begin{array}{l}-14,1 \pm \\
0,02 \text { ** } \\
\end{array}$ & $\begin{array}{l}-19,9 \pm \\
0,02 \text { ** } \\
\end{array}$ \\
\hline $\begin{array}{l}\text { Secreted protein, } \\
\text { acidic, Cystein- } \\
\text { reich; Osteonectin }\end{array}$ & SPARC & 14,57 & 7,29 & $-154,56$ & $\begin{array}{c}15,1 \pm \\
0,58\end{array}$ & $\begin{array}{c}17,0 \pm \\
0,93\end{array}$ & $\mid \begin{array}{c}15,3 \pm \\
0,44\end{array}$ & $\begin{array}{c}16,2 \pm \\
0,21\end{array}$ & $\begin{array}{c}-1,05 \pm \\
0,28\end{array}$ & $\begin{array}{l}-2,03 \pm \\
0,07 * \star\end{array}$ & $\begin{array}{c}15,4 \pm \\
1,00\end{array}$ & $\begin{array}{c}17,9 \pm \\
1,03\end{array}$ & $\begin{array}{c}16,0 \pm \\
0,99\end{array}$ & $\begin{array}{c}18,1 \pm \\
1,02\end{array}$ & $\begin{array}{l}-2,10 \pm \\
0,16 *\end{array}$ & $\begin{array}{l}-3,49 \pm \\
0,08 \text { ** }\end{array}$ \\
\hline $\begin{array}{c}\text { Secreted protein 1, } \\
\text { Osteopontin }\end{array}$ & SPP1 & 8,37 & 12,88 & 22,91 & $\begin{array}{c}14,7 \pm \\
0,50 \\
\end{array}$ & $\begin{array}{c}14,6 \pm \\
0,63 \\
\end{array}$ & \begin{tabular}{|c|}
$14,6 \pm$ \\
0,53 \\
\end{tabular} & $\begin{array}{c}14,7 \pm \\
0,52 \\
\end{array}$ & $\begin{array}{l}1,29 \pm \\
0,05 * *\end{array}$ & $\begin{array}{c}1,16 \pm \\
0,30 \\
\end{array}$ & $\begin{array}{c}14,9 \pm \\
0,66\end{array}$ & $\begin{array}{c}15,0 \pm \\
0,38 \\
\end{array}$ & $\begin{array}{c}14,6 \pm \\
0,51 \\
\end{array}$ & $\begin{array}{c}14,7 \pm \\
0,88 \\
\end{array}$ & $\begin{array}{c}1,10 \pm \\
0,17 \\
\end{array}$ & $\begin{array}{c}1,05 \pm \\
0,27 \\
\end{array}$ \\
\hline & SPP1 a & & & & \multirow{4}{*}{\multicolumn{12}{|c|}{ Expressionslevel zu gering }} \\
\hline & SPP1 b & & & & & & & & & & & & & & & \\
\hline & SPP1 c & & & & & & & & & & & & & & & \\
\hline Thrombospondin 3 & THBS3 & 9,09 & 10,23 & 2,22 & & & & & & & & & & & & \\
\hline Vitronectin & VTN & 5,98 & 4,55 & $-2,68$ & $\begin{array}{c}13,7 \pm \\
0,51 \\
\end{array}$ & $\begin{array}{c}14,1 \pm \\
0,49 \\
\end{array}$ & \begin{tabular}{|c|}
$13,2 \pm$ \\
0,65 \\
\end{tabular} & \begin{tabular}{|c|}
$13,2 \pm$ \\
0,48 \\
\end{tabular} & $\begin{array}{l}1,72 \pm \\
0,58 \text { * }\end{array}$ & $\begin{array}{l}1,48 \pm \\
0,27 * * \\
\end{array}$ & $\begin{array}{c}13,7 \pm \\
0,59 \\
\end{array}$ & $\begin{array}{c}14,3 \pm \\
0,10 \\
\end{array}$ & \begin{tabular}{|c|}
$13,2 \pm$ \\
0,52 \\
\end{tabular} & $\begin{array}{c}13,1 \pm \\
0,54 \\
\end{array}$ & $\begin{array}{l}1,34 \pm \\
0,34 * \\
\end{array}$ & $\begin{array}{l}1,38 \pm \\
0,36 \text { * }\end{array}$ \\
\hline
\end{tabular}


Diverse Gene werden in den verschiedenen Zelllinien unterschiedlich stark exprimiert (Tab. 6, 7 und 8). Besonders auffällig ist jedoch die starke Herunterregulation der Gene SPARC (secreted protein acidic and rich in cysteine, osteonectin, BM-40) und SPP1 (secreted phosphoprotein 1, osteopontin) samt seiner drei unterschiedlichen Isoformen in den PHD2knock-down-Klonen \#3 und \#4 der MDA-MB-231-Zellen (Tab. 7). SPARC und SPP1 wurden bereits im Zusammenhang mit Hypoxie, Zelladhäsion und Tumorgenese in diversen Publikationen beschrieben und sind daher in dem vorliegenden Projekt von besonderem Interesse. 


\section{Diskussion}

HIF-1 ist ein heterodimerer Transkriptionsfaktor, der in der Zelle aktiviert wird, wenn das Sauerstoffangebot unter den Sauerstoffbedarf sinkt (Wang GL et al. 1995). Während HIF-1 $\beta$ als Untereinheit von HIF-1 konstitutiv im Nukleus exprimiert wird, ist die HIF-1 $\alpha$ Untereinheit in ihrer Stabilität Sauerstoff-abhängig. Im Rahmen der Tumorprogression und des Tumorwachstums spielt HIF-1 $\alpha$ eine entscheidende Rolle. Es wird von Zellen verschiedener, solider Tumoren vermehrt exprimiert. Zum Beispiel konnte in Geweben von Brust-, Kolon-, Lungen-, Ovarial-, Zervix- und Prostatakrebs eine verstärkte HIF-1 $\alpha$ Expression nachgewiesen werden (Zhong et al. 1999). Dieser Befund hat eine große klinische Relevanz, da das Ausmaß der HIF-1 $\alpha$-Expression im Tumorgewebe mit der Prognose des Patienten korreliert. Die gesteigerte HIF-1 $\alpha$-Expression eines Zervixkarzinoms korreliert beispielsweise mit der Patientenmortalität, die eines Ösophaguskarzinoms mit der Resistenz gegenüber einer möglichen Strahlentherapie (Birner et al. 2000, Koukourakis et al. 2001). Aus diesem Grund stellt HIF-1 $\alpha$ ein potentielles Zielmolekül in der Tumorbehandlung dar.

Auch die Wahrscheinlichkeit zur Metastasierung eines Tumors wird von HIF-1 beeinflusst. So sorgt HIF-1 für eine verminderte Expression von E-Cadherin, welches für Zell-Zell-Kontakte verantwortlich ist. Dies geschieht über die HIF-1-Zielgene Snail und SIP1, deren Proteinprodukte Repressorfunktion besitzen (Evans et al. 2007). Die Folge davon ist eine erhöhte Zellmobilität und eine Erhöhung der Wahrscheinlichkeit zur Metastasierung. Ferner beeinflusst HIF-1 die Expression der Lysyloxidase (LOX), eine Aminooxidase, welche die Entstehung stabiler Bindungen zwischen Kollagen und Elastin katalysiert. In Brustkrebszellen sorgt die vermehrte LOX-Expression für eine erhöhte Invasivität des Tumors und damit ebenfalls für eine gesteigerte Metastasierungswahrscheinlichkeit (Erler et al. 2006).

Im Rahmen der Tumorprogression und -metastasierung spielt neben der HIF-1-Aktivität bzw. der HIF-1 $\alpha$-Expression auch die zelluläre Adhäsionsfähigkeit an die extrazelluläre Matrix (ECM) eine wesentliche Rolle. Tumorzellen müssen sich im Zuge der Metastasierung erst von ihrem Ursprungsgewebe lösen, um nach dem Transport über die Lymphe oder das Blut am neuen Gewebe zu adhärieren und zu proliferieren. Einerseits müssen die Zellen also in der Lage sein, sich durch verminderte Adhäsion an die ECM von ihrem ursprünglichen Gewebe zu lösen, aber andererseits müssen sie am neuen Gewebe gut adhärieren können. So konnte gezeigt werden, dass ein knock-out von Vinculin, welches als intrazelluläres Protein die Zelle über Integrine an der ECM verankert, in Maus-embryonalen Fibroblasten (MEFs) zu einer rundlichen Zellform, einer im zweidimensionalen Raum mehr als zweifach erhöhten 
Migrationsgeschwindigkeit und schließlich zu einer verstärkten Metastasierung im Vergleich zum Wildtyp führte (Subauste et al. 2004, Coll et al. 1995). Es ergab sich daraus die Hypothese, dass eine verminderte Adhäsionsfähigkeit die Metastasierung von Tumorzellen fördere. Auf der anderen Seite wurde beschrieben, dass sich Tumorzellen, welche verstärkt Vinculin exprimieren, besser in dreidimensionalen Kollagenmatrices bewegen können, was wiederum die Wahrscheinlichkeit zur Metastasierung erhöhen kann. Es wurde in diesem Zusammenhang beobachtet, dass die Bewegungen der Vinculin-knock-out-MEF-Zellen durch ein dreidimensionales Kollagennetzwerk stark behindert wurden. Hier hatten die WildtypZellen einen erheblichen Vorteil (Mierke et al. 2008).

Darüber hinaus hat die Zelladhäsion einen Einfluss auf das Zellüberleben und die Zellproliferation. So werden nicht-dysplastisch veränderte Zellen bei einer verringerten Adhäsion an die ECM apoptotisch (Meredith et al. 1993). Tumorzellen sind jedoch im Verlauf der Metastasierung in der Lage, dieser Apoptose zu entgehen und auch ohne Adhäsion an die ECM zu überleben (Zhu $\mathrm{Z}$ et al. 2001). Dies geschieht über die Ausbildung spezieller Integrine und die EMT (epithelial to mesenchymal transition), was zur Folge hat, dass diese Tumorzellen ihren ursprünglich epithelialen Charakter durch einen mesenchymalen ersetzen. Es wird deutlich, dass der Zusammenhang zwischen der Fähigkeit von Zellen, zu adhärieren und der damit in Verbindung stehenden Metastasierungsaggressivität von Tumorzellen sehr komplex und noch lange nicht abschließend geklärt ist.

Im Rahmen dieser Arbeit wurde der Zusammenhang zwischen dem PHD2-HIF-1 $\alpha$ Signalweg und der Adhäsion von Tumorzellen an die ECM untersucht, um den Metastasierungsprozess bzw. das Wachstum von Tumorzellen näher charakterisieren zu können. Das langfristige Ziel dabei ist, durch den Einsatz spezifischer Substanzen diesen Signalweg zu modulieren und somit eine Tumormetastasierung zu verhindern.

Der PHD-HIF-1 $\alpha$-Signalweg ist bereits Gegenstand intensiver Forschung im Zuge der Herstellung von Substanzen zur Therapie einer durch EPO-Mangel bedingten Anämie. Diese Form der Anämie kann bei chronischer Niereninsuffizienz, Anti-Tumortherapie oder bei chronischen Entzündungsleiden auftreten. Die PHDs, über die die Aktivität von HIF-1 $\alpha$ reguliert werden kann, stehen dabei im Mittelpunkt des Interesses. Der Einsatz von PHDInhibitoren zur Behandlung einer durch EPO-Mangel bedingten Anämie wird bereits in Phase II Studien getestet. Durch die PHD-Inhibierung wird die HIF-1 $\alpha$-Aktivität sowohl in vitro als auch in vivo gesteigert, was zu einer vermehrten Expression des HIF-1-Zielgens EPO führt (Warnecke et al. 2003). 
In dieser Arbeit konnte mittels Adhäsions-Assays gezeigt werden, dass PHD2 in verschiedenen Zellen (HeLa, MDA-MB-231, MCF7, MEF, P2.1.1-16) einen positiven Einfluss auf die Zelladhäsion an die ECM hat. Die jeweiligen PHD2-knock-down-Klone wiesen im Vergleich zu den Wildtyp- und den sh-transfizierten Kontroll-Zellen eine hochsignifikant geringere Adhäsion auf Fibronektin auf (Abb. 9, 10, 14, 16 und 11, Seiten 38, 39, 43, 45 und 40). Dieser Befund wurde zusätzlich auf Laminin, einem weiteren Bestandteil der ECM, bestätigt und schloss somit eine Fibronektin-Spezifität aus (Abb. 12, Seite 41). Durch Re-Transfektion mit einem HA-PHD2-kodierenden Plasmid konnte dieser Effekt aufgehoben werden und die Adhäsion auf ein dem Wildtyp ähnliches Niveau gebracht werden (Abb. 13, Seite 42). Der Befund ist demnach PHD2-spezifisch.

Parallel wurden über Western-Blot-Untersuchungen die Proteinlevel von PHD2, HIF-1 $\alpha$ und dem HIF-1-Zielgen PHD3 in den HeLa-Zellen unter normoxischen $\left(20 \% \mathrm{O}_{2}\right)$ und hypoxischen $\left(1 \% \mathrm{O}_{2}\right)$ Bedingungen untersucht (Abb. 3, Seite 28). Es zeigte sich, dass in den PHD2-knock-down-Klonen 1B6 und 3B7 tatsächlich weniger PHD2 auf Proteinebene nachgewiesen werden kann. Dadurch wurde HIF-1 $\alpha$ stabilisiert und konnte auch unter 20\% $\mathrm{O}_{2}$ in den Klonen 1B6 und 3B7 verstärkt detektiert werden. Unter 1\% $\mathrm{O}_{2}$ stand PHD2 nicht genug $\mathrm{O}_{2}$ zur Verfügung, um HIF-1 $\alpha$ für den von-Hippel-Lindau-Tumorsuppressor (pVHL) zu markieren. Daher waren die Proteinmengen an HIF-1 $\alpha$ in allen Zellen hoch. Die Proteinexpression des HIF-1-Zielgens PHD3 verhielt sich unter den verschiedenen Bedingungen jeweils analog zur Menge an HIF-1 $\alpha$-Protein. In den MDA-MB-231-Zellen waren diese Regulationsvorgänge anhand der Proteinmengen nicht eindeutig nachzuvollziehen (Abb. 3, Seite 28). Der PHD2-knock-down war zwar im Western Blot erkennbar, jedoch ist die dadurch bedingte HIF-1 $\alpha$-Stabilisierung unter normoxischen Bedingungen $\left(20 \% \mathrm{O}_{2}\right)$ ausschließlich in dem Klon \#4 zu erahnen. Im Klon \#3 war keine HIF-1 $\alpha$-Stabilisierung auf Proteinebene festzustellen. Das könnte auf andere, PHD2unabhängige Regulationsmechanismen von HIF-1 $\alpha$ hinweisen. Es gibt zum Beispiel zwei weitere PHD-Isoformen, die in diesem Zusammenhang eine Rolle spielen könnten: PHD1, welches vor allem im Hoden nachgewiesen werden kann und PHD3, was überwiegend vom Herzmuskelgewebe exprimiert wird (Lieb et al. 2002, Cioffi et al. 2003). Dieses hauptsächlich Gewebe-spezifische Vorkommen der beiden anderen PHD-Isoformen schließt jedoch nicht aus, dass sie auch in anderen Zellen bei PHD2-Defizienz für die HIF-1 $\alpha$ Regulation verantwortlich sein können.

In der vorliegenden Arbeit konnte gezeigt werden, dass die verminderte Adhäsion der PHD2-knock-down-Klone nicht ausschließlich auf die dadurch vermehrte HIF-1 $\alpha$-Aktivität 
zurückzuführen ist, da der Effekt auch in HIF-1 $\alpha^{-/-}$-MEF-Zellen zu beobachten war (Abb. 16, Seite 45). PHD2 scheint somit einen HIF-1 $\alpha$-unabhängigen Einfluss auf die Zelladhäsion auszuüben. Passend zu diesem Befund wurden Daten veröffentlicht, die eine PHD2Abhängigkeit im Tumorwachstum zeigen, welche HIF-1 $\alpha$-unabhängig ist. So wurde ein gesteigertes Tumorwachstum von HCT116-Zellen (humane Kolorektalkarzinomzellen) nach kombiniertem HIF-1 $\alpha$ - und PHD2-knock-down gegenüber einem reinen HIF-1 $\alpha$-knock-down beobachtet (Chan et al. 2009). Außerdem wurde kürzlich eine indirekte Regulation von Amphiregulin durch PHD2 beschrieben. Auch dieser Zusammenhang ist HIF-1 $\alpha$-unabhängig. In MCF7-Zellen wurde nach PHD2-knock-down eine gesteigerte Expression von Amphiregulin beobachtet, welche auf die durch den PHD2-knock-down bedingte vermehrte Aktivität von HIF-2 $\alpha$ zurückgeführt werden konnte. Dieser Zusammenhang scheint in Verbindung mit dem Wachstum und der Progression von Brustkrebs zu stehen und impliziert eine Tumor-Suppressor-Funktion von PHD2 (Bordoli et al. 2011). PHD2 übernimmt demnach neben der Regulation von HIF-1 $\alpha$ auch entscheidende HIF-1 $\alpha$-unabhängige Aufgaben im Rahmen der Regulation von Zelladhäsion und Tumorwachstum. Dieser Befund verdeutlicht, dass weitere Einblicke und detailliertere Forschung auf diesem Gebiet nötig sind, um Tumorbiologie verständlicher und somit nutzbarer für die onkologische Therapie zu machen.

Ein möglicher Erklärungsansatz für die verminderte Adhäsion der PHD2-knock-downKlone diverser Zellen ist die Regulation von Cofilin durch den RhoA-ROCK-Lim-Signalweg. Wie in dieser Arbeit gezeigt werden konnte, sorgte die Inhibierung dieses Signalwegs und die damit verbundene Aktivitätssteigerung von nicht-phosphoryliertem Cofilin für eine Steigerung der Adhäsion des PHD2-knock-down-Klons 3B7 der HeLa-Zellen (Abb. 17, Seite 46). Es wurden bereits mehrfach Zusammenhänge zwischen Cofilin und Tumorprogression beschrieben. Die Expressionslevel von Cofilin und deren Regulatoren, wie zum Beispiel der Lim-Kinase, sind in invasiven Brustkrebszellen deutlich erhöht. Außerdem korreliert die Aktivität von Cofilin direkt mit der Invasion, Intravasation und Metastasierung von Tumorzellen (Wang J et al. 2004, Wang W et al. 2006). Cofilin und dessen Regulation spielen folglich eine wichtige Rolle im Rahmen des Tumorprogresses und der Metastasierung.

Von Corley et al. wurde 2005 der Einfluss von HIF-1 $\alpha$ auf die Adhäsion von glatten Muskelzellen der Aorta bzw. der Koronararterien an die ECM untersucht. Dabei zeigte sich eine signifikant verminderte Adhäsion der Zellen, die HIF-1 $\alpha$ überexprimierten. Dieser Befund passt auf der einen Seite zu den in dieser Arbeit gewonnen Daten: durch den PHD2knock-down wird HIF-1 $\alpha$ stabilisiert, was schließlich eine verminderte Adhäsionsfähigkeit zur Folge hat. Auf der anderen Seite zeigten in den vorliegenden Untersuchungen die MEF-HIF- 
$1 \alpha^{+/+}$-Zellen eine signifikant gesteigerte Adhäsion auf Fibronektin, verglichen mit den MEFHIF-1 $\alpha^{-/-}$-Zellen (Abb. 15, Seite 44). Trotzdem konnte ein zusätzlicher, HIF-unabhängiger Effekt von PHD2 auf die Zelladhäsion beobachtet werden (Abb. 16, Seite 45). Die verminderte Adhäsion der PHD2-knock-down-Zellen ist daher nicht ausschließlich auf eine vermehrte HIF-1 $\alpha$-Aktivität zurückzuführen, sondern auf alternative, PHD2-abhängige Signalwege oder Regulationsmechanismen. Auch ein direkter Einfluss von PHD2 wäre denkbar. Diese Möglichkeiten gilt es in Zukunft näher zu untersuchen.

Es wurden bislang unterschiedliche Daten erhoben, die den Einfluss von PHD2 auf Tumorprogression beschreiben. So wurde eine Steigerung der Tumorprogression durch PHD2 beschrieben. Diese beruhte laut den Autoren der Publikation auf der komplementären, additiven und Tumorwachstums-fördernden Regulation von HIF-1 $\alpha$ und NF- $\kappa$ B durch PHD2 (Chan et al. 2009). Jedoch konnten ebenfalls gegenteilige Effekte von PHD2 in Bezug auf das Tumorwachstum gezeigt werden. Zusätzlich zu den Beobachtungen von Bordoli et al., die eine Tumor-Suppressor-Funktion von PHD2 beschrieben, induziert PHD2 beispielsweise eine Seneszenz in Zellen eines Endometriumkarzinoms (Kato et al. 2006). Lee KA et al. fanden darüber hinaus den Zusammenhang, dass es vom PHD2-Expressionslevel abhängig ist, ob eine maligne Transformation gefördert oder inhibiert wird (Lee KA et al. 2008). Ein besseres und differenzierteres Wissen über den Einfluss von PHD2 auf das Tumorwachstum, die Tumorprogression und die Tumormetastasierung sind demnach von großem wissenschaftlichem und klinischem Interesse.

Daher wurden Wildtyp-, sh-transfizierte Kontroll-Zellen und die beiden PHD2-knockdown-Klone \#3 und \#4 (MDA-MB-231) bzw. C1 und C7 (MCF7) parallel zu den von mir durchgeführten Experimenten von Frau Priv.-Doz. Dr. med. C. Malz (Abteilung für Herz- und Kreislaufphysiologie, Universität Göttingen) und Frau Prof. Dr. med. F. Alves (Abeilung für Hämatologie/Onkologie, Universität Göttingen) in SCID (severe combined immunodeficiency)-Mäuse jeweils subkutan implantiert. Später wurden die Tumorlokalisationen und -größen mittels flat panel volume computer tomography genau erfasst und dargestellt. Dabei stellte sich heraus, dass nach der Implantation der PHD2-knockdown-Klone C1 und C7 der MCF7-Zellen im Vergleich zu den Wildtyp- und den shtranfizierten Kontroll-Zellen größere Tumore in einer kürzeren Zeitdauer entstanden. Dieser Befund wurde kürzlich ebenfalls von Bordoli et al. beschrieben (Bordoli et al. 2011). Das Gegenteil war nach Implantation der MDA-MB-231-Zellen zu beobachten. Dort entstanden deutlich größere Tumoren in kürzerer Zeit nach Implantation der Wildtyp- und der shtransfizierten Kontroll-Zellen im Vergleich $\mathrm{zu}$ den PHD2-knock-down-Klonen. Um 
auszuschließen, dass der beobachtete Effekt rein Zell-spezifisch und nicht PHD2-bedingt war, wurden parallel die beiden Zelllinien MDA-MB-231 und MCF7 von mir funktionell weiter charakterisiert. Dazu wurden in vitro die Zellproliferationen und -vitalitäten unter hypoxischen $\left(1 \% \mathrm{O}_{2}\right)$ und normoxischen $\left(20 \% \mathrm{O}_{2}\right)$ Bedingungen untersucht. Es spiegeln dabei die gewonnen Daten unter $1 \% \mathrm{O}_{2}$ die in-vivo-Bedingungen nach subkutaner Implantation der Zellen am genauesten wider. So herrschen in gesunder, humaner Haut physiologisch hypoxische Zustände, die eine hohe Expression und Aktivität von HIF-1 $\alpha$ bedingen. Am stärksten ist dieser Befund in den Hautanhangsgebilden $\mathrm{zu}$ beobachten (Rosenberger et al. 2007). In der exponentiellen Wachstumsphase zeigte sich kein signifikanter Unterschied in dem Wachstumsverhalten der jeweiligen Wildtyp- bzw- shtransfizierten Kontroll-Zellen, verglichen mit den PHD2-knock-down-Klonen der MDA-MB231- und MCF7-Zellen (Tab. 4 und 5, Seiten 33 und 35). Nach längerer Inkubation stellte sich jedoch unter hypoxischen Bedingungen $\left(1 \% \mathrm{O}_{2}\right)$ sowohl ein Proliferations- wie auch ein Vitalitätsvorteil der PHD2-knock-down-Klone \#3 und \#4 (MDA-MB-231) im Vergleich zu den Wildtyp- und den sh-transfizierten Kontroll-Zellen ein (Abb. 6, Seite 32). In den MCF7Zellen war der Effekt bei $1 \% \mathrm{O}_{2}$ ähnlich, jedoch ist der Proliferationsvorteil der PHD2-knockdown-Klone C1 und C7 nur in Bezug auf die Wildtyp-Zellen signifikant (Abb. 7, Seite 34). Diese Daten deuten auf ein unterschiedliches Proliferations- und Vitalitätsprofil der jeweiligen Wildtyp- und sh-transfizierten Kontroll-Zellen auf der einen Seite und den jeweiligen PHD2-knock-down-Klonen auf der anderen Seite hin. Da diese Unterschiede aber in MDA-MB-231- und MCF7-Zellen bei $1 \% \mathrm{O}_{2}$ ähnlich zu beobachten waren, kann davon ausgegangen werden, dass das Proliferations- und Vitalitätsverhalten der Zellen nicht allein für das unterschiedliche Wachstumsverhalten in vivo verantwortlich sind. Dennoch müssen diese Eigenschaften der Zellen berücksichtigt werden und sind im Zusammenhang mit dem Tumorwachstum von Bedeutung.

Ferner wiesen die MDA-MB-231-Zellen gegenüber den MCF7-Zellen eine gesteigerte und schnellere Proliferationsrate auf. Diese Daten decken sich mit früheren Beobachtungen, die eine erhöhte Proliferation und Invasivität der MDA-MB-231-Zellen bezogen auf die MCF7-Zellen beschreiben. Durch Behandlung mit Östrogenen konnte jedoch eine signifikante Steigerung der Bewegung durch die ECM und der Proliferation in MCF7-Zellen erreicht werden (Albini et al. 1986, Thompson et al. 1988). Welche Mechanismen den Proliferationsvorteil und die erhöhte Invasivität der MDA-MB-231-Zellen bedingen, wird intensiv erforscht. Ein Erklärungsansatz für einen möglichen Mechanismus wurde kürzlich publiziert. So ist in den MDA-MB-231-Zellen eine erhöhte Aktivität der phosphorylierten 
extracellularly regulated kinase1/2 (pERK1/2) gefunden worden, die positiv zur Zellproliferation und -migration beiträgt. In den MCF7-Zellen war keine erhöhte pERK1/2Aktivität festzustellen (You et al. 2009).

Fokale Kontakte spielen für die Adhäsion von Zellen an die ECM eine entscheidende Rolle. Integrine vermitteln dabei über intrazelluläre Proteine, wie zum Beispiel Vinculin, eine feste Verankerung der Zellen an Bestandteile der ECM, wie zum Beispiel Fibronektin oder Laminin. Um einen möglichen Einfluss von PHD2 auf die Ausbildung und Verteilung fokaler Kontakte zu detektieren, wurde das humane Vinculin der Zellen mittels ImmunfloureszenzMikroskopie dargestellt. Dabei stellte sich heraus, dass weder die Verteilung, noch die Anzahl der fokalen Kontakte PHD2-abhängig war (Abb. 18 und 19, Seiten 47 und 48). In den PHD2knock-down-Klonen, den Wildtyp- und den sh-transfizierten Kontroll-Zellen der MDA-MB231- bzw. der MCF7-Zellen waren keine Unterschiede festzustellen. Die Daten von Corley et al. unterstützen diesen Befund. Hier zeigte sich eine gleiche Anzahl und Verteilung der fokalen Kontakte zwischen HIF-1 $\alpha$-überexprimierenden und kontroll-transfizierten MEFZellen. Jedoch konnte ein Zusammenhang zwischen der HIF-1 $\alpha$-Expression und der Phosphorylierung der focal adhesion kinase (FAK) aufgezeigt werden. Die HIF-1 $\alpha-$ überexprimierenden MEF-Zellen wiesen eine geringere Phosphorylierung und damit eine verminderte Aktivität der FAK auf. Die FAK hat über Tyrosin-Phosphorylierungen diverser Proteine einen positiven Einfluss auf die Zelladhäsion. Dieser Einfluss blieb in diesem Fall aus, was die verminderte Adhäsion der HIF-1 $\alpha$-überexprimierenden MEF-Zellen erklärt (Corley et al. 2005, Panetti 2002). Im Rahmen dieser Arbeit wurde ebenfalls versucht, die Proteinlevel an phosphorylierter FAK in den MCF7- und den MDA-MB-231-Zellen zu bestimmen, um neben dem beschriebenen HIF-1 $\alpha$-Einfluss auch einen möglichen PHD2Einfluss auf die Phosphorylierung der FAK näher untersuchen zu können. Jedoch konnte im Western Blot mittels des polyklonalen-Kaninchen-IgG-Antikörpers (1:200; Santa Cruz Biotechnology), welcher die am $\mathrm{Tyr}^{397}$ phosphorylierte $\mathrm{FAK}$ bindet, kein Protein nachgewiesen werden. Vermutlich war der verwendete Antikörper nicht in der Lage, sein Antigen potent zu binden, da alle anderen Ursachen ausgeschlossen werden konnten. Dadurch war es nicht möglich festzustellen, ob PHD2 direkt einen Einfluss auf die Phosphorylierung der FAK hat und darüber die Adhäsionseigenschaften der Zellen reguliert.

Mittels quantitativer real-time-Polymerase-Ketten-Reaktion (qRT-PCR) wurden zwei Kandidatengene ermittelt, die ein reduziertes Expressionsmuster in den MDA-MB-231PHD2-knock-down-Zellen gegenüber den Wildtyp-Zellen aufweisen und in Verbindung mit Zelladhäsion und Tumorwachstum stehen. Es handelt sich dabei um die Gene SPARC 
(secreted protein acidic and rich in cysteine) bzw. Osteonectin und SPP1 (secreted phosphoprotein 1) bzw. Osteopontin (Tab. 7, Seite 51). Bei diesen beiden Genen wird eine hypoxische Regulation diskutiert. So wurde eine vermehrte SPARC-Expression in Gliomzellen gefunden, welche unter hypoxischen Bedingungen $\left(1 \% \mathrm{O}_{2}\right)$ gesetzt wurden. Im Gegenzug sorgte ein knock-down von HIF-1 $\alpha$ durch siRNA in diesen hypoxisch-inkubierten Zellen für eine Reduktion der SPARC-Überexpression. Es scheint demnach eine HIF-1 $\alpha$ abhängige Regulation der SPARC-Expression zu geben (Seno et al. 2009). Außerdem hat SPARC einen Einfluss auf das Wachstum von Tumoren. Es konnte gezeigt werden, dass die Expression von SPARC mit der Tumorprogression und dem Metastasierungspotential korreliert (Podhajcer et al. 2008).

SPP1 wird ebenfalls vermehrt von Zellen unter hypoxischen Bedingungen sezerniert, was klinisch relevant ist. Es wurde in diesem Zusammenhang beschrieben, dass in einer kleinen Patientengruppe mit Kopf-Hals-Tumoren erhöhte SPP1-Plasma-Spiegel für eine größere Anzahl an hypoxischen Tumoren sprechen. Diese sind merklich schwerer zu kontrollieren und $\mathrm{zu}$ therapieren und haben einen erheblichen Einfluss auf die Prognose des Patienten (Le et al. 2003).

Die beiden Gene SPARC und SPP1 wurden jedoch nur in den PHD2-knock-down-Klonen der MDA-MB-231-Zellen signifikant vermindert exprimiert. In den MCF7-Zellen war dieser Effekt nicht zu beobachten (Tab. 8, Seite 52). Die Expressionslevel der einzelnen SPP1Isoformen waren in den MCF7-Zellen zu gering, um überhaupt erfasst zu werden. Jedoch war die SGCE (Sarcoglycan epsilon)-Expression in den MCF7-PHD2-knock-down-Klonen C1 und C7 signifikant reduziert. SGCE ist als Teil des Dystrophin-Glykoprotein-Komplexes (DGC) vornehmlich für die mechanische Verbindung zwischen den Myozyten und der ECM verantwortlich (Ibraghimov-Beskrovnaya et al. 1992). Eine loss of function-Mutation in dem Gen, welches für SGCE kodiert, führt zum autosomal-dominant vererbten MyoklonusDystonie-Syndrom (Zimprich et al. 2001). Dieses Krankheitsbild ist durch bilaterale, Alkohol-sensitive Dystonien der Arme gekennzeichnet.

SPP1 beeinflusst ebenfalls die Zelladhäsion und die Tumorprogression und wurde neben SPARC als mögliches Kandidatengen identifiziert, welches PHD2-abhängig exprimiert wird. Es gibt drei Isoformen (SPP1-a, SPP1-b und SPP1-c), welche durch alternatives Splicing entstehen. Über die unterschiedlichen Funktionen der Isoformen ist bislang wenig geklärt, jedoch wurden vor allem die Isoformen SPP1-a und SPP1-b in Zellen eines hepatozellulären Karzinoms nachgewiesen. SPP1-c hingegen konnte vor allem in gesundem Lebergewebe nachgewiesen werden (Chae et al. 2009). 
Außerdem, analog zu SPARC, korreliert die SPP1-Expression im Tumorgewebe mit dem rezidivfreien Überleben von Brustkrebspatienten, deren Lymphknoten nicht befallen waren. In diesem Fall ist die Korrelation invers, was bedeutet, dass eine hohe SPP1-Expression mit einem geringeren rezidivfreien Überleben einherging. Dabei stammt das sezernierte SPP1 von den Tumorzellen selbst und nicht von eingewanderten Entzündungszellen (Tuck et al. 1998). SPP1 sorgt sowohl in malignen als auch in noch nicht maligne transformierten Zellen für eine erhöhte Invasivität durch die ECM. Dieser Befund verdeutlicht den Beitrag von SPP1 zu einer malignen, aggressiven Entartung von Brustkrebszellen (Tuck et al. 1999).

Im Gegensatz zu SPARC beeinflusst SPP1 die Zelladhäsion positiv. Über die Integrine $\alpha 5 \beta 1$, $\alpha 5 \beta 3$ und $\alpha 5 \beta 5$ sind Zellen eines Mammakarzinoms in der Lage, an SPP1, welches nach Sekretion mit zum Beispiel Fibronektin kreuzvernetzt als Bestandteil der ECM vorliegt, zu binden (Hu DD et al. 1995, Liaw et al. 1995). Im Rahmen dieser Arbeit wurde gezeigt, dass die MDA-MB-231-PHD2-knock-down-Zellen hochsignifikant weniger SPP1 als die Wildtyp-Zellen exprimierten (Tab. 7, Seite 51) und zusätzlich eine deutlich schlechtere Adhäsionsfähigkeiten auf Bestandteile der ECM aufwiesen (Abb. 10, Seite 39). Diese Befunde passen $\mathrm{zu}$ den in der Literatur beschriebenen Daten, dass SPP1 einen adhäsionsfördernden Effekt auf Tumorzellen hat. Da die PHD2-knock-down-Zellen jede der drei SPP1-Isoformen vermindert exprimierten, kann ein Isoform-spezifischer Effekt ausgeschlossen werden.

Neben SPARC und SPP1 wurde bereits Amphiregulin erwähnt, welches indirekt über die vermehrte Aktivität von HIF-2 $\alpha$ PHD2-abhängig exprimiert wird (Bordoli et al. 2011). Amphiregulin ist ein Glykoprotein, welches in MCF7-Zellen isoliert und als Ligand des EGF (epidermal growth factor)-Rezeptors identifiziert wurde (Shoyab et al. 1988). Es spielt eine Rolle im Rahmen der Tumorprogression und -invasivität von Brustkrebs. Es wird in Brustkrebszellen häufig überexprimiert und kann im Vergleich zum normalen Brustdrüsengewebe vor allem in invasiven Krebszellen nachgewiesen werden (Qi et al. 1994, Panico et al. 1996). Analog zu den Untersuchungen, die im Zusammenhang mit Amphiregulin durchgeführt wurden, muss in Zukunft untersucht werden, ob PHD2 die Expressionen von SPARC und SPP1 direkt, oder indirekt über zum Beispiel die Aktivitäten von HIF-1 $\alpha$ oder HIF-2 $\alpha$ reguliert.

Parallel muss neben den in vitro gewonnenen Daten der Einfluss dieser Gene in vivo untersucht werden. Dazu sollte eine Plasmid-vermittelte Re-Transfektion von PHD2 mit den PHD2-knock-down-Klonen durchgeführt werden. Anschließend sollten diese Zellen erneut subkutan in SCID-Mäuse implantiert und die Größen der entstandenen Tumore mittels flat 
panel volume computer tomography $\mathrm{zu}$ verschiedenen Zeitpunkten genau erfasst werden. Dadurch kann der Einfluss von PHD2 auf die Expression von SPARC und SPP1 und auf das Tumorwachstum in vivo bestimmt werden.

Diese Daten zusammen mit den in vitro gewonnen Ergebnissen könnten zu einer genaueren Charakterisierung des Metastasierungsprozesses beitragen, was langfristig zu neuen therapeutischen Möglichkeiten in der onkologischen Therapie führt. 


\section{$5 \quad$ Zusammenfassung}

Der unter hypoxischen Bedingungen stabilisierte Transkriptionsfaktor HIF-1, dessen Untereinheit HIF-1 $\alpha$ durch die PHDs Sauerstoff-abhängig hydroxyliert und somit für den proteasomalen Abbau markiert wird, scheint eine wichtige Rolle bei der Tumorentstehung und -metastasierung zu spielen. Diese Rolle ist jedoch nicht eindeutig geklärt. Die ubiquitär exprimierte Isoform PHD2, ein Hauptregulator der HIF-1 $\alpha$-Stabilität, scheint ebenfalls einen, möglicherweise HIF-1 $\alpha$-unabhängigen, Einfluss auf das Tumorverhalten zu haben.

Um diesen Einfluss genauer zu charakterisieren, wurde die Rolle von PHD2 in Bezug auf die Adhäsion von Tumorzellen an Bestandteile der extrazellulären Matrix (ECM) näher untersucht. Die Zelladhäsion ist eine kritische Eigenschaft im Prozess der Metastasierung und wurde deshalb in diesem Zusammenhang als zu untersuchender Parameter gewählt. Mittels Adhäsions-Assays konnte in diversen Tumorzelllinien (HeLa, MDA-MB-231, MCF7) eine positive Beeinflussung der Zelladhäsion durch PHD2 festegestellt werden. Durch ReTransfektion der PHD2-knock-down-Klone mit einem HA-PHD2-kodierenden Plasmid konnte die reduzierte Adhäsionsfähigkeit annähernd normalisiert werden. Dieser Befund unterstreicht die wichtige Rolle von PHD2 in der Regulation der Zelladhäsion von Tumorzellen. Auch ein transienter, über einen kurzen Zeitraum bestehender PHD2-knockdown, der durch Tetrazyklin-Zugabe in den P2.1.1-16-Zellen erreicht wurde, führte zu einer verminderten Adhäsion an Fibronektin. Ferner wurde in Maus-embryonalen Fibroblasten (MEFs) die verminderte Adhäsion durch das Fehlen von PHD2 auch in HIF-1 $\alpha$-defizienten Zellen beobachtet, was eine HIF-1 $\alpha$-unabhängige Regulation der Zelladhäsion durch PHD2 vermuten lässt.

Im weiteren Verlauf wurde genauer untersucht, wie PHD2 auf zellulärer Ebene die Adhäsion beeinflusst. Durch Inhibition der ROCK (rho-associated, coiled-coil-forming protein kinase) konnte eine signifikante Steigerung der Adhäsionsfähigkeit des PHD2-knockdown-Klons der HeLa-Zellen (3B7) im Adhäsions-Assay gezeigt werden. Durch Inhibition der ROCK liegt das Protein Cofilin vermindert phosphoryliert, also vermehrt aktiv, vor, was zu einem stärkeren Umbau des Zytoskeletts führt und somit an der Zelladhäsion beteiligt ist. Dieser Signalweg scheint hier von Bedeutung zu sein. Darüber hinaus wurden mittels Immunfluoreszenz die fokalen Kontakte diverser Zellen dargestellt. Es konnte jedoch kein unterschiedliches Muster in Expression und Verteilung der fokalen Kontakte durch den PHD2-knock-down detektiert werden. Durch qRT-PCR konnten zwei Gene ermittelt werden, die ein anderes Expressionsmuster in den PHD2-knock-down-Klonen aufweisen und im Zusammenhang mit Tumorgenese und Zelladhäsion stehen. So ist die Expression der Gene 
SPARC (secreted protein acidic and rich in cysteine) bzw. Osteonectin und SPP1 (secreted phosphoprotein 1) bzw. Osteopontin in den PHD2-knock-down-Klonen der MDA-MB-231Zellen deutlich reduziert, verglichen mit den Wildtyp-Zellen. Daher gilt es, diese Gene bei nachfolgenden in-vivo-Untersuchungen weiter in Bezug auf ihre Regulation durch PHD2 und ihren Beitrag zur Tumorentstehung und -metastasierung zu beobachten.

In der Abteilung für Herz- und Kreislaufphysiologie der Universität Göttingen konnten invivo-Daten durch Injektion der Wildtyp-, sh-transfizierten Kontroll-Zellen und der jeweiligen PHD2-knock-down-Klone der MDA-MB-231- und der MCF7-Zellen in SCID (severe combined immunodeficiency)-Mäuse mit anschließeneder Untersuchung der enstandenen Tumoren gewonnen werden. Im Rahmen dieser Arbeit konnten diese Daten durch Proliferations- und Vitalitätsdaten dieser Zellen in vitro ergänzt werden. Es zeigte sich dabei in der exponentiellen Wachstumsphase kein eindeutiger Unterschied zwischen Wildtyp-, shtransfizierten Kontroll-Zellen und PHD2-knock-down-Klonen (HeLa, MDA-MB-231 und MCF7).

Die in vitro gewonnenen Daten dieser Arbeit, durch die eine Regulation der Zelladhäsion durch PHD2 u.a. durch die PHD2-abhängige Beeinflussung der Genexpression von SPARC und SPP1 detektiert wurde, müssen im Folgenden in vivo ergänzt werden. Mittels erneuter Injektion von Tumorzellen, auch nach PHD2-Re-Transfektion der ursprünglichen PHD2knock-down-Klone, in SCID-Mäuse kann der Einfluss von PHD2 auf das Metastasierungsverhalten genauer charakterisiert werden. Diese Daten zusammen mit den in vitro gewonnenen Daten können zu einem besseren Verständnis des Metastasierungsprozesses führen. Dies ist die Grundvoraussetzung für die Entwicklung neuer Therapiestrategien. 


\section{$6 \quad$ Anhang}

\subsection{Abbildungsverzeichnis}

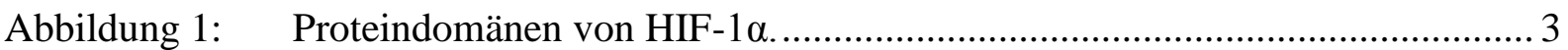

Abbildung 2: $\quad$ Durch die PHDs katalsysierte Hydoxylierung von HIF-1 1 . ......................... 5

Abbildung 3: $\quad$ Der PHD2-knock-down ist in allen drei Zelllinien (HeLa, MDA-MB-231

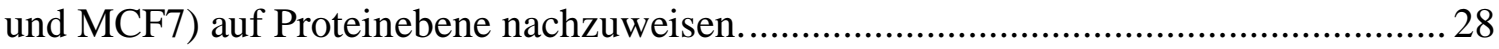

Abbildung 4: Verglichen mit den Wildtyp-Zellen führt der PHD2-knock-down in den HeLa- (A), den MDA-MB-231- (B) und den MCF7-Zellen (C) auf RNA-Ebene zu einer verminderten PHD2 -und einer erhöhten PHD3-Expression.

Abbildung 5: Der PHD2-knock-down in den HeLa-Zellen hat keinen Einfluss auf die Zellproliferation unter normoxischen $\left(20 \% \mathrm{O}_{2}\right)$ Bedingungen.

Abbildung 6: Der PHD2-knock-down in den MDA-MB-231-Zellen hat Einfluss auf die Zellproliferation (A) und die -vitalität (B) unter normoxischen $\left(20 \% \mathrm{O}_{2}\right)$ und hypoxischen $\left(1 \% \mathrm{O}_{2}\right)$ Bedingungen

Abbildung 7: Der PHD2-knock-down in den MCF7-Zellen hat einen geringen Einfluss auf die Zellproliferation (A) und -vitalität (B) unter hypoxischen $\left(1 \% \mathrm{O}_{2}\right)$ Bedingungen.... 34

Abbildung 8: Der Adhäsions-Assay eignet sich zur Beurteilung des zellulären Adhäsionsverhaltens

Abbildung 9: PHD2 beeinflusst die Adhäsion an Fibronektin von HeLa-Zellen.

Abbildung 10: PHD2 beeinflusst die Adhäsion an Fibronektin in MDA-MB-231-Zellen. 39

Abbildung 11: $\quad$ Der durch Tetrazyklin induzierbare PHD2-knock-down in den P2.1.1-16-

Zellen führt zu einer reduzierten Zelladhäsion. 40

Abbildung 12: PHD2 beeinflusst die Adhäsion an Laminin in MDA-MB-231-Zellen...... 41

Abbildung 13: Die PHD2-Abwesenheit in MDA-MB-231-Zellen ist für die verminderte

Adhäsion der PHD2-knock-down-Klone auf Fibronektin verantwortlich.

Abbildung 14: Die PHD2-Abwesenheit in MCF7-Zellen ist für die verminderte Adhäsion der PHD2-knock-down-Klone auf Fibronektin verantwortlich.................................... 43

Abbildung 15: HIF-1 $\alpha$ beeinflusst die Zelladhäsion. ....................................................... 44

Abbildung 16: PHD2 beeinflusst die Zelladhäsion HIF-1 $\alpha$-unabhängig. ........................... 45

Abbildung 17: Durch den ROCK-Inhibitor Y27632 kann die Adhäsion auf Fibronektin im PHD2-knock-down-Klon 3B7 der HeLa-Zellen signifikant gesteigert werden. 46 Abbildung 18: Der PHD2-knock-down der MDA-MB-231-Zellen verändert weder die Anzahl, noch die Verteilung der Fokalkontakte. 
Abbildung 19: Der PHD2-knock-down der MCF7-Zellen verändert weder die Anzahl, noch

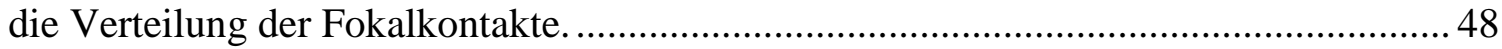

Abbildung 20: Heat-map der Ergebnisse aus dem mit den HeLa-Zellen durchgeführten $R T$

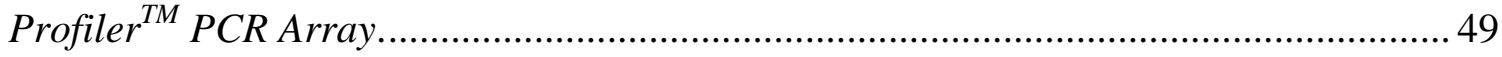




\subsection{Tabellenverzeichnis}

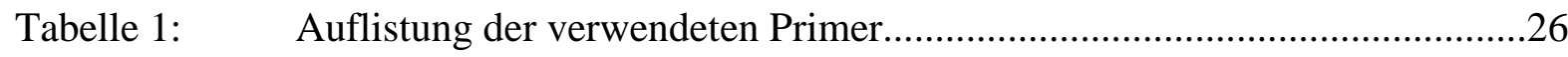

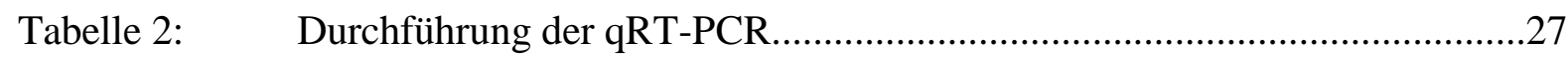

Tabelle 3: $\quad$ Auflistung von Verdoppelungszeiten (G) der HeLa-Wildtyp- (WT), -shtransfizierten Kontroll-Zellen (sh-Kontrolle) und der beiden PHD2-knock-down-Klone (1B6 und 3B7) unter normoxischen $\left(20 \% \mathrm{O}_{2}\right)$ Bedingungen....................................... 31

Tabelle 4: $\quad$ Auflistung von Verdoppelungszeiten (G) der MDA-MB-231-Wildtyp(WT), -sh-transfizierten Kontroll-Zellen (sh-Kontrolle) und der beiden PHD2-knockdown-Klone (\#3 und \#4) unter normoxischen $\left(20 \% \mathrm{O}_{2}\right)$ bzw. hypoxischen $\left(1 \% \mathrm{O}_{2}\right)$ Bedingungen.

Tabelle 5: Auflistung von Verdoppelungszeiten (G) der MCF7-Wildtyp- (WT), -shtransfizierten Kontroll-Zellen (sh-Kontrolle) und der beiden PHD2-knock-down-Klone (\#3 und \#4) unter normoxischen $\left(20 \% \mathrm{O}_{2}\right)$ bzw. hypoxischen $\left(1 \% \mathrm{O}_{2}\right)$ Bedingungen..35

Tabelle 6: Unterschiedliche Genexpressionen in den HeLa-Wildtyp- (WT), -shtransfizierten Kontroll-Zellen (shK) und den beiden PHD2-knock-down-Klonen 1B6 und $3 \mathrm{~B} 7$

Tabelle 7: Unterschiedliche Genexpressionen in den MDA-MB-231-Wildtyp- (WT), -shtransfizierten Kontroll-Zellen (shK) und den beiden PHD2-knock-down-Klonen \#3 und \#4.

Tabelle 8: Unterschiedliche Genexpressionen in den MCF7-Wildtyp- (WT), -shtransfizierten Kontroll-Zellen (shK) und den beiden PHD2-knock-down-Klonen C1 und C7 


\section{$7 \quad$ Literatur}

Agnew BJ, Minamide LS, Bamburg JR (1995): Reactivation of phosphorylated actin depolymerizing factor and identification of the regulatory site. J Biol Chem $\underline{270}$, 17582-17587

Albanese C, Johnson J, Watanabe G, Eklund N, Vu D, Arnold A, Pestell RG (1995): Transforming p21ras mutants and c-Ets-2 activate the cyclin D1 promoter through distinguishable regions. J Biol Chem $\underline{270}$, 23589-23597

Albelda SM, Mette SA, Elder DE, Stewart R, Damjanovich L, Herlyn M, Buck CA (1990): Integrin distribution in malignant melanoma: association of the beta 3 subunit with tumor progression. Cancer Res $\underline{50}, 6757-6764$

Albini A, Graf J, Kitten GT, Kleinman HK, Martin GR, Veillette A, Lippman ME (1986): 17 beta-estradiol regulates and v-Ha-ras transfection constitutively enhances MCF7 breast cancer cell interactions with basement membrane. Proc Natl Acad Sci USA $\underline{83}$, $8182-8186$

Al-Mehdi AB, Tozawa K, Fisher AB, Shientag L, Lee A, Muschel RJ (2000): Intravascular origin of metastasis from the proliferation of endothelium-attached tumor cells: a new model for metastasis. Nat Med $\underline{6}, 100-102$

Ameri K, Lewis CE, Raida M, Sowter H, Hai T, Harris AL (2004): Anoxic induction of ATF4 through HIF-1-independent pathways of protein stabilization in human cancer cells. Blood $\underline{103}, 1876-1882$

Appelhoff RJ, Tian YM, Raval RR, Turley H, Harris AL, Pugh CW, Ratcliffe PJ, Gleadle JM (2004): Differential function of the prolyl hydroxylases PHD1, PHD2, and PHD3 in the regulation of hypoxia-inducible factor. J Biol Chem $\underline{279}$, 38458-38465

Aragones J, Schneider M, Van Geyte K, Fraisl P, Dresselaers T, Mazzone M, Dirkx R, Zacchigna S, Lemieux H, Jeoung NH et al. (2008): Deficiency or inhibition of oxygen sensor Phd1 induces hypoxia tolerance by reprogramming basal metabolism. Nat Genet $\underline{40}, 170-180$

Arany Z, Huang LE, Eckner R, Bhattacharya S, Jiang C, Goldberg MA, Bunn HF, Livingston DM (1996): An essential role for p300/CBP in the cellular response to hypoxia. Proc Natl Acad Sci USA 93, 12969-12973

Arber S, Barbayannis FA, Hanser H, Schneider C, Stanyon CA, Bernard O, Caroni P (1998): Regulation of actin dynamics through phosphorylation of cofilin by LIM-kinase. Nature $\underline{393}, 805-809$ 
Arnesen T, Kong X, Evjenth R, Gromyko D, Varhaug JE, Lin Z, Sang N, Caro J, Lillehaug JR (2005): Interaction between HIF-1 alpha (ODD) and hARD1 does not induce acetylation and destabilization of HIF-1 alpha. FEBS Lett $\underline{579}$, 6428-6432

Barone MV, Crozat A, Tabaee A, Philipson L, Ron D (1994): CHOP (GADD153) and its oncogenic variant, TLS-CHOP, have opposing effects on the induction of G1/S arrest. Genes Dev $\underline{8}, 453-464$

Barth S, Nesper J, Hasgall PA, Wirthner R, Nytko KJ, Edlich F, Katschinski DM, Stiehl DP, Wenger RH, Camenisch G (2007): The peptidyl prolyl cis/trans isomerase FKBP38 determines hypoxia-inducible transcription factor prolyl-4-hydroxylase PHD2 protein stability. Mol Cell Biol 27, 3758-3768

Berking C, Takemoto R, Schaider H, Showe L, Satyamoorthy K, Robbins P, Herlyn M (2001): Transforming growth factor-beta1 increases survival of human melanoma through stroma remodeling. Cancer Res $\underline{61}$, 8306-8316

Berra E, Benizri E, Ginouves A, Volmat V, Roux D, Pouyssegur J (2003): HIF prolylhydroxylase 2 is the key oxygen sensor setting low steady-state levels of HIF-1alpha in normoxia. EMBO J 22, 4082-4090

Birner P, Schindl M, Obermair A, Plank C, Breitenecker G, Oberhuber G (2000): Overexpression of hypoxia-inducible factor 1alpha is a marker for an unfavorable prognosis in early-stage invasive cervical cancer. Cancer Res $\underline{60}$, 4693-4696

Bishop T, Gallagher D, Pascual A, Lygate CA, de Bono JP, Nicholls LG, Ortega-Saenz P, Oster H, Wijeyekoon B, Sutherland AI et al. (2008): Abnormal sympathoadrenal development and systemic hypotension in PHD3-/- mice. Mol Cell Biol 28, 33863400

Blais JD, Filipenko V, Bi M, Harding HP, Ron D, Koumenis C, Wouters BG, Bell JC (2004): Activating transcription factor 4 is translationally regulated by hypoxic stress. Mol Cell Biol 24, 7469-7482

Bohmer RM, Scharf E, Assoian RK (1996): Cytoskeletal integrity is required throughout the mitogen stimulation phase of the cell cycle and mediates the anchorage-dependent expression of cyclin D1. Mol Biol Cell ㅁ, 101-111

Bordoli MR, Stiehl DP, Borsig L, Kristiansen G, Hausladen S, Schraml P, Wenger RH, Camenisch G (2011): Prolyl-4-hydroxylase PHD2- and hypoxia-inducible factor 2dependent regulation of amphiregulin contributes to breast tumorigenesis. Oncogene $\underline{30}, 548-560$ 
Bradford MM (1976): A rapid and sensitive method for the quantitation of microgram quantities of protein utilizing the principle of protein-dye binding. Anal Biochem $\underline{72}$, $248-254$

Brökers N, Le-Huu S, Vogel S, Hagos Y, Katschinski DM, Kleinschmidt M (2009): Increased chemoresistance induced by inhibition of HIF-prolyl-hydroxylase domain enzymes. Cancer Sci 101, 129-136

Burridge K, Fath K, Kelly T, Nuckolls G, Turner C (1988): Focal adhesions: transmembrane junctions between the extracellular matrix and the cytoskeleton. Annu Rev Cell Biol $\underline{4}$, $487-525$

Carmeliet P, Dor Y, Herbert JM, Fukumura D, Brusselmans K, Dewerchin M, Neeman M, Bono F, Abramovitch R, Maxwell P et al. (1998): Role of HIF-1alpha in hypoxiamediated apoptosis, cell proliferation and tumour angiogenesis. Nature $\underline{394}$, 485-490

Carrozza MJ, Utley RT, Workman JL, Cote J (2003): The diverse functions of histone acetyltransferase complexes. Trends Genet $\underline{19}$, 321-329

Cervera AM, Apostolova N, Luna-Crespo F, Sanjuan-Pla A, Garcia-Bou R, McCreath KJ (2006): An alternatively spliced transcript of the PHD3 gene retains prolyl hydroxylase activity. Cancer Lett $\underline{233}, 131-138$

Chae S, Jun HO, Lee EG, Yang SJ, Lee DC, Jung JK, Park KC, Yeom YI, Kim KW (2009):

Osteopontin splice variants differentially modulate the migratory activity of hepatocellular carcinoma cell lines. Int J Oncol $\underline{35}, 1409-1416$

Chan DA, Kawahara TL, Sutphin PD, Chang HY, Chi JT, Giaccia AJ (2009): Tumor vasculature is regulated by PHD2-mediated angiogenesis and bone marrow-derived cell recruitment. Cancer Cell 15, 527-538

Cioffi CL, Liu XQ, Kosinski PA, Garay M, Bowen BR (2003): Differential regulation of HIF1 alpha prolyl-4-hydroxylase genes by hypoxia in human cardiovascular cells. Biochem Biophys Res Commun $\underline{303}$, 947-953

Coll JL, Ben-Ze'ev A, Ezzell RM, Rodriguez Fernandez JL, Baribault H, Oshima RG, Adamson ED (1995): Targeted disruption of vinculin genes in F9 and embryonic stem cells changes cell morphology, adhesion, and locomotion. Proc Natl Acad Sci USA 92, 9161-9165

Compernolle V, Brusselmans K, Acker T, Hoet P, Tjwa M, Beck H, Plaisance S, Dor Y, Keshet E, Lupu F et al. (2002): Loss of HIF-2alpha and inhibition of VEGF impair fetal lung maturation, whereas treatment with VEGF prevents fatal respiratory distress in premature mice. Nat Med $\underline{8}, 702-710$ 
Corley KM, Taylor CJ, Lilly B (2005): Hypoxia-inducible factor 1alpha modulates adhesion, migration, and FAK phosphorylation in vascular smooth muscle cells. J Cell Biochem 96, 971-985

Cummins EP, Berra E, Comerford KM, Ginouves A, Fitzgerald KT, Seeballuck F, Godson C, Nielsen JE, Moynagh P, Pouyssegur J et al. (2006): Prolyl hydroxylase-1 negatively regulates IkappaB kinase-beta, giving insight into hypoxia-induced NFkappaB activity. Proc Natl Acad Sci USA 103, 18154-18159

del Peso L, Castellanos MC, Temes E, Martin-Puig S, Cuevas Y, Olmos G, Landazuri MO (2003): The von Hippel Lindau/hypoxia-inducible factor (HIF) pathway regulates the transcription of the HIF-proline hydroxylase genes in response to low oxygen. J Biol Chem $\underline{278}, 48690-48695$

Ebert BL, Firth JD, Ratcliffe PJ (1995): Hypoxia and mitochondrial inhibitors regulate expression of glucose transporter-1 via distinct Cis-acting sequences. J Biol Chem $\underline{270}, 29083-29089$

Eck SL, Perkins ND, Carr DP, Nabel GJ (1993): Inhibition of phorbol ester-induced cellular adhesion by competitive binding of NF-kappa B in vivo. Mol Cell Biol $\underline{13}$, 6530-6536

Ema M, Taya S, Yokotani N, Sogawa K, Matsuda Y, Fujii-Kuriyama Y (1997): A novel bHLH-PAS factor with close sequence similarity to hypoxia-inducible factor 1alpha regulates the VEGF expression and is potentially involved in lung and vascular development. Proc Natl Acad Sci USA 94, 4273-4278

Epstein AC, Gleadle JM, McNeill LA, Hewitson KS, O'Rourke J, Mole DR, Mukherji M, Metzen E, Wilson MI, Dhanda A et al. (2001): C. elegans EGL-9 and mammalian homologs define a family of dioxygenases that regulate HIF by prolyl hydroxylation. Cell 107, 43-54

Erler JT, Bennewith KL, Nicolau M, Dornhofer N, Kong C, Le QT, Chi JT, Jeffrey SS, Giaccia AJ (2006): Lysyl oxidase is essential for hypoxia-induced metastasis. Nature $\underline{440}, 1222-1226$

Evans AJ, Russell RC, Roche O, Burry TN, Fish JE, Chow VW, Kim WY, Saravanan A, Maynard MA, Gervais ML et al. (2007): VHL promotes E2 box-dependent E-cadherin transcription by HIF-mediated regulation of SIP1 and snail. Mol Cell Biol 27, 157-169

Flamme I, von Reutern M, Drexler HC, Syed-Ali S, Risau W (1995): Overexpression of vascular endothelial growth factor in the avian embryo induces hypervascularization and increased vascular permeability without alterations of embryonic pattern formation. Dev Biol 171, 399-414 
Forsythe JA, Jiang BH, Iyer NV, Agani F, Leung SW, Koos RD, Semenza GL (1996):

Activation of vascular endothelial growth factor gene transcription by hypoxiainducible factor 1. Mol Cell Biol $\underline{16}$, 4604-4613

Foster K, Prowse A, van den Berg A, Fleming S, Hulsbeek MM, Crossey PA, Richards FM, Cairns P, Affara NA, Ferguson-Smith MA et al. (1994): Somatic mutations of the von Hippel-Lindau disease tumour suppressor gene in non-familial clear cell renal carcinoma. Hum Mol Genet $\underline{3}$, 2169-2173

Frisch SM, Francis H (1994): Disruption of epithelial cell-matrix interactions induces apoptosis. J Cell Biol 124, 619-626

Geiger B, Tokuyasu KT, Dutton AH, Singer SJ (1980): Vinculin, an intracellular protein localized at specialized sites where microfilament bundles terminate at cell membranes. Proc Natl Acad Sci USA 77, 4127-4131

Gnarra JR, Tory K, Weng Y, Schmidt L, Wei MH, Li H, Latif F, Liu S, Chen F, Duh FM et al. (1994): Mutations of the VHL tumour suppressor gene in renal carcinoma. Nat Genet $\underline{7}, 85-90$

Gohla A, Birkenfeld J, Bokoch GM (2005): Chronophin, a novel HAD-type serine protein phosphatase, regulates cofilin-dependent actin dynamics. Nat Cell Biol 7, 21-29

Gu YZ, Moran SM, Hogenesch JB, Wartman L, Bradfield CA (1998): Molecular characterization and chromosomal localization of a third alpha-class hypoxia inducible factor subunit, HIF3alpha. Gene Expr 7, 205-213

Hai T, Hartman MG (2001): The molecular biology and nomenclature of the activating transcription factor/cAMP responsive element binding family of transcription factors: activating transcription factor proteins and homeostasis. Gene $\underline{273}, 1-11$

Hirsilä M, Koivunen P, Gunzler V, Kivirikko KI, Myllyharju J (2003): Characterization of the human prolyl 4-hydroxylases that modify the hypoxia-inducible factor. J Biol Chem $\underline{278}, 30772-30780$

Hirsilä M, Koivunen P, Xu L, Seeley T, Kivirikko KI, Myllyharju J (2005): Effect of desferrioxamine and metals on the hydroxylases in the oxygen sensing pathway. FASEB J $\underline{19}, 1308-1310$

Holmes JH, Humphrey JD, Walton EA, O'Shea JD (1981): Cataracts, goitre and infertility in cattle grazed on an exclusive diet of Leucaena leucocephala. Aust Vet J $\underline{57}, 257-261$

Hopfer U, Hopfer H, Jablonski K, Stahl RA, Wolf G (2006): The novel WD-repeat protein Morg1 acts as a molecular scaffold for hypoxia-inducible factor prolyl hydroxylase 3 (PHD3). J Biol Chem 281, 8645-8655 
House CM, Frew IJ, Huang HL, Wiche G, Traficante N, Nice E, Catimel B, Bowtell DD (2003): A binding motif for Siah ubiquitin ligase. Proc Natl Acad Sci USA $\underline{100}$, 31013106

Hu CJ, Wang LY, Chodosh LA, Keith B, Simon MC (2003): Differential roles of hypoxiainducible factor 1alpha (HIF-1alpha) and HIF-2alpha in hypoxic gene regulation. Mol Cell Biol 23, 9361-9374

Hu DD, Lin EC, Kovach NL, Hoyer JR, Smith JW (1995): A biochemical characterization of the binding of osteopontin to integrins alpha $v$ beta 1 and alpha $v$ beta 5 . J Biol Chem $\underline{270}, 26232-26238$

Hu G, Fearon ER (1999): Siah-1 N-terminal RING domain is required for proteolysis function, and C-terminal sequences regulate oligomerization and binding to target proteins. Mol Cell Biol $\underline{19}, 724-732$

Hu G, Zhang S, Vidal M, Baer JL, Xu T, Fearon ER (1997): Mammalian homologs of seven in absentia regulate DCC via the ubiquitin-proteasome pathway. Genes Dev $\underline{11}, 2701$ 2714

Huang J, Zhao Q, Mooney SM, Lee FS (2002): Sequence determinants in hypoxia-inducible factor-1alpha for hydroxylation by the prolyl hydroxylases PHD1, PHD2, and PHD3. J Biol Chem 277, 39792-39800

Huang LE, Gu J, Schau M, Bunn HF (1998): Regulation of hypoxia-inducible factor 1alpha is mediated by an $\mathrm{O} 2$-dependent degradation domain via the ubiquitin-proteasome pathway. Proc Natl Acad Sci USA 925, 7987-7992

Huber MA, Azoitei N, Baumann B, Grunert S, Sommer A, Pehamberger H, Kraut N, Beug H, and Wirth T (2004): NF-kappaB is essential for epithelial-mesenchymal transition and metastasis in a model of breast cancer progression. J Clin Invest 114, 569-581

Hynes RO (1992): Integrins: versatility, modulation, and signaling in cell adhesion. Cell $\underline{69}$, $11-25$

Hynes RO (2002): Integrins: bidirectional, allosteric signaling machines. Cell 110, 673-687

Ibraghimov-Beskrovnaya O, Ervasti JM, Leveille CJ, Slaughter CA, Sernett SW, Campbell KP (1992): Primary structure of dystrophin-associated glycoproteins linking dystrophin to the extracellular matrix. Nature $\underline{355}, 696-702$

Ivan M, Kondo K, Yang H, Kim W, Valiando J, Ohh M, Salic A, Asara JM, Lane WS, Kaelin WG Jr. (2001): HIFalpha targeted for VHL-mediated destruction by proline hydroxylation: implications for O2 sensing. Science 292, 464-468 
Ivan M, Haberberger T, Gervasi DC, Michelson KS, Gunzler V, Kondo K, Yang H, Sorokina I, Conaway RC, Conaway JW et al. (2002): Biochemical purification and pharmacological inhibition of a mammalian prolyl hydroxylase acting on hypoxiainducible factor. Proc Natl Acad Sci USA 99, 13459-13464

Iyer NV, Kotch LE, Agani F, Leung SW, Laughner E, Wenger RH, Gassmann M, Gearhart JD, Lawler AM, Yu AY et al. (1998): Cellular and developmental control of O2 homeostasis by hypoxia-inducible factor 1 alpha. Genes Dev $\underline{12}, 149-162$

Jaakkola P, Mole DR, Tian YM, Wilson MI, Gielbert J, Gaskell SJ, Kriegsheim A, Hebestreit HF, Mukherji M, Schofield CJ et al. (2001): Targeting of HIF-alpha to the von HippelLindau ubiquitylation complex by O2-regulated prolyl hydroxylation. Science $\underline{292}$, $468-472$

Jeong, JW, Bae MK, Ahn MY, Kim SH, Sohn TK, Bae MH, Yoo MA, Song EJ, Lee KJ, Kim KW (2002): Regulation and destabilization of HIF-1alpha by ARD1-mediated acetylation. Cell $\underline{111}, 709-720$

Jiang BH, Zheng JZ, Leung SW, Roe R, Semenza GL (1997): Transactivation and inhibitory domains of hypoxia-inducible factor 1alpha. Modulation of transcriptional activity by oxygen tension. J Biol Chem 272, 19253-19260

Kamura T, Koepp DM, Conrad MN, Skowyra D, Moreland RJ, Iliopoulos O, Lane WS, Kaelin WG Jr., Elledge SJ, Conaway RC et al. (1999): Rbx1, a component of the VHL tumor suppressor complex and SCF ubiquitin ligase. Science 284, 657-661

Karin M, Cao Y, Greten FR, Li ZW (2002): NF-kappaB in cancer: from innocent bystander to major culprit. Nat Rev Cancer 2 , 301-310

Kato H, Inoue T, Asanoma K, Nishimura C, Matsuda T, Wake N (2006): Induction of human endometrial cancer cell senescence through modulation of HIF-1alpha activity by EGLN1. Int J Cancer 118, 1144-1153

Köditz J, Nesper J, Wottawa M, Stiehl DP, Camenisch G, Franke C, Myllyharju J, Wenger RH, Katschinski DM (2007): Oxygen-dependent ATF-4 stability is mediated by the PHD3 oxygen sensor. Blood 110, 3610-3617

Koukourakis MI, Giatromanolaki A, Skarlatos J, Corti L, Blandamura S, Piazza M, Gatter KC, Harris AL (2001): Hypoxia inducible factor (HIF-1a and HIF-2a) expression in early esophageal cancer and response to photodynamic therapy and radiotherapy. Cancer Res 61, 1830-1832 
Lando D, Peet DJ, Gorman JJ, Whelan DA, Whitelaw ML, Bruick RK (2002): FIH-1 is an asparaginyl hydroxylase enzyme that regulates the transcriptional activity of hypoxiainducible factor. Genes Dev $\underline{16}, 1466-1471$

Lassot I, Segeral E, Berlioz-Torrent C, Durand H, Groussin L, Hai T, Benarous R, MargottinGoguet F (2001): ATF4 degradation relies on a phosphorylation-dependent interaction with the SCF(betaTrCP) ubiquitin ligase. Mol Cell Biol 21, 2192-2202

Lavoie JN, L'Allemain G, Brunet A, Muller R, Pouyssegur J (1996): Cyclin D1 expression is regulated positively by the p42/p44MAPK and negatively by the p38/HOGMAPK pathway. J Biol Chem 271, 20608-20616

Le QT, Sutphin PD, Raychaudhuri S, Yu SC, Terris DJ, Lin HS, Lum B, Pinto HA, Koong AC, Giaccia AJ (2003): Identification of osteopontin as a prognostic plasma marker for head and neck squamous cell carcinomas. Clin Cancer Res $\underline{9}, 59-67$

Lee KA, Lynd JD, O'Reilly S, Kiupel M, McCormick JJ, LaPres JJ (2008): The biphasic role of the hypoxia-inducible factor prolyl-4-hydroxylase, PHD2, in modulating tumorforming potential. Mol Cancer Res $\underline{6}, 829-842$

Lee PJ, Jiang BH, Chin BY, Iyer NV, Alam J, Semenza GL, Choi AM (1997): Hypoxiainducible factor-1 mediates transcriptional activation of the heme oxygenase- 1 gene in response to hypoxia. J Biol Chem $\underline{272}$, 5375-5381

Liaw L, Lindner V, Schwartz SM, Chambers AF, Giachelli CM (1995): Osteopontin and beta 3 integrin are coordinately expressed in regenerating endothelium in vivo and stimulate Arg-Gly-Asp-dependent endothelial migration in vitro. Circ Res 77, 665-672

Lieb ME, Menzies K, Moschella MC, Ni R, Taubman MB (2002): Mammalian EGLN genes have distinct patterns of mRNA expression and regulation. Biochem Cell Biol $\underline{80}$, $421-426$

Lippman M, Bolan G, Huff K (1976): The effects of estrogens and antiestrogens on hormoneresponsive human breast cancer in long-term tissue culture. Cancer Res $\underline{36}, 4595-4601$

Lisztwan J, Imbert G, Wirbelauer C, Gstaiger M, Krek W (1999): The von Hippel-Lindau tumor suppressor protein is a component of an E3 ubiquitin-protein ligase activity. Genes Dev $\underline{13}, 1822-1833$

Lorick KL, Jensen JP, Fang S, Ong AM, Hatakeyama S, Weissman AM (1999): RING fingers mediate ubiquitin-conjugating enzyme (E2)-dependent ubiquitination. Proc Natl Acad Sci USA 무, 11364-11369 
Maekawa M, Ishizaki T, Boku S, Watanabe N, Fujita A, Iwamatsu A, Obinata T, Ohashi K, Mizuno K, Narumiya S (1999): Signaling from Rho to the actin cytoskeleton through protein kinases ROCK and LIM-kinase. Science $\underline{285}, 895-898$

Marshall TW, Aloor HL, Bear JE (2009): Coronin 2A regulates a subset of focal-adhesionturnover events through the cofilin pathway. J Cell Sci 122, 3061-3069

Matsumoto M, Minami M, Takeda K, Sakao Y, Akira S (1996): Ectopic expression of CHOP (GADD153) induces apoptosis in M1 myeloblastic leukemia cells. FEBS Lett $\underline{395}$, $143-147$

Maxwell PH, Wiesener MS, Chang GW, Clifford SC, Vaux EC, Cockman ME, Wykoff CC, Pugh CW, Maher ER, Ratcliffe PJ (1999): The tumour suppressor protein VHL targets hypoxia-inducible factors for oxygen-dependent proteolysis. Nature $\underline{399}, 271-275$

McGough A, Pope B, Chiu W, Weeds A (1997): Cofilin changes the twist of F-actin: implications for actin filament dynamics and cellular function. J Cell Biol 138, 771781

Meier F, Nesbit M, Hsu MY, Martin B, Van Belle P, Elder DE, Schaumburg-Lever G, Garbe C, Walz TM, Donatien P et al. (2000): Human melanoma progression in skin reconstructs : biological significance of bFGF. Am J Pathol 156, 193-200

Melillo G, Musso T, Sica A, Taylor LS, Cox GW, Varesio L (1995): A hypoxia-responsive element mediates a novel pathway of activation of the inducible nitric oxide synthase promoter. J Exp Med 182, 1683-1693

Meredith JE Jr., Fazeli B, Schwartz MA (1993): The extracellular matrix as a cell survival factor. Mol Biol Cell 4, 953-961

Metzen E, Berchner-Pfannschmidt U, Stengel P, Marxsen JH, Stolze I, Klinger M, Huang WQ, Wotzlaw C, Hellwig-Burgel T, Jelkmann W et al. (2003): Intracellular localisation of human HIF-1 alpha hydroxylases: implications for oxygen sensing. J Cell Sci 116, 1319-1326

Metzen E, Stiehl DP, Doege K, Marxsen JH, Hellwig-Burgel T, Jelkmann W (2005): Regulation of the prolyl hydroxylase domain protein 2 (phd2/egln-1) gene: identification of a functional hypoxia-responsive element. Biochem J $\underline{387}$, 711-717

Mierke CT, Kollmannsberger P, Zitterbart DP, Smith J, Fabry B, Goldmann WH (2008): Mechano-coupling and regulation of contractility by the vinculin tail domain. Biophys $\mathrm{J} \underline{94}, 661-670$

Milkiewicz M, Pugh CW, Egginton S (2004): Inhibition of endogenous HIF inactivation induces angiogenesis in ischaemic skeletal muscles of mice. J Physiol 560, 21-26 
Minamishima YA, Moslehi J, Bardeesy N, Cullen D, Bronson RT, Kaelin WG Jr. (2008): Somatic inactivation of the PHD2 prolyl hydroxylase causes polycythemia and congestive heart failure. Blood $111,3236-3244$

Miyamoto S, Teramoto H, Gutkind JS, Yamada KM (1996): Integrins can collaborate with growth factors for phosphorylation of receptor tyrosine kinases and MAP kinase activation: roles of integrin aggregation and occupancy of receptors. J Cell Biol $\underline{135}$, $1633-1642$

Möller A, House CM, Wong CS, Scanlon DB, Liu MC, Ronai Z, Bowtell DD (2009): Inhibition of Siah ubiquitin ligase function. Oncogene $\underline{28}$, 289-296

Moriyama K, Iida K, Yahara I (1996): Phosphorylation of Ser-3 of cofilin regulates its essential function on actin. Genes Cells $\underline{1}, 73-86$

Myllyla R, Kuutti-Savolainen ER, Kivirikko KI (1978): The role of ascorbate in the prolyl hydroxylase reaction. Biochem Biophys Res Commun $\underline{83}$, 441-448

Nakashima K, Sato N, Nakagaki T, Abe H, Ono S, Obinata T (2005): Two mouse cofilin isoforms, muscle-type (MCF) and non-muscle type (NMCF), interact with F-actin with different efficiencies. J Biochem $\underline{138}, 519-526$

Nakayama K, Frew IJ, Hagensen M, Skals M, Habelhah H, Bhoumik A, Kadoya T,

Erdjument-Bromage H, Tempst P, Frappell PB et al. (2004): Siah2 regulates stability of prolyl-hydroxylases, controls HIF1alpha abundance, and modulates physiological responses to hypoxia. Cell $\underline{117}, 941-952$

Niwa R, Nagata-Ohashi K, Takeichi M, Mizuno K, Uemura T (2002): Control of actin reorganization by Slingshot, a family of phosphatases that dephosphorylate ADF/cofilin. Cell $\underline{108}, 233-246$

Norris ML, Millhorn DE (1995): Hypoxia-induced protein binding to O2-responsive sequences on the tyrosine hydroxylase gene. J Biol Chem 270, 23774-23779

Ono S, Minami N, Abe H, Obinata T (1994): Characterization of a novel cofilin isoform that is predominantly expressed in mammalian skeletal muscle. J Biol Chem $\underline{269}$, 1528015286

Ozer A, Wu LC, Bruick RK (2005): The candidate tumor suppressor ING4 represses activation of the hypoxia inducible factor (HIF). Proc Natl Acad Sci USA 102, 74817486

Panetti, TS (2002): Tyrosine phosphorylation of paxillin, FAK, and p130CAS: effects on cell spreading and migration. Front Biosci $\underline{7}, 143-150$ 
Panico L, D'Antonio A, Salvatore G, Mezza E, Tortora G, De Laurentiis M, De Placido S, Giordano T, Merino M, Salomon DS et al. (1996): Differential immunohistochemical detection of transforming growth factor alpha, amphiregulin and CRIPTO in human normal and malignant breast tissues. Int J Cancer $\underline{65}, 51-56$

Peng J, Zhang L, Drysdale L, Fong GH (2000): The transcription factor EPAS-1/hypoxiainducible factor 2alpha plays an important role in vascular remodeling. Proc Natl Acad Sci USA $\underline{97}, 8386-8391$

Petitclerc E, Stromblad S, von Schalscha TL, Mitjans F, Piulats J, Montgomery AM, Cheresh DA, Brooks PC (1999): Integrin alpha(v)beta3 promotes M21 melanoma growth in human skin by regulating tumor cell survival. Cancer Res $\underline{59}$, 2724-2730

Podhajcer OL, Benedetti L, Girotti MR, Prada F, Salvatierra E, Llera AS (2008): The role of the matricellular protein SPARC in the dynamic interaction between the tumor and the host. Cancer Metastasis Rev 27, 523-537

Price LS, Leng J, Schwartz MA, Bokoch GM (1998): Activation of Rac and Cdc42 by integrins mediates cell spreading. Mol Biol Cell $\underline{9}, 1863-1871$

Pugh CW, O'Rourke JF, Nagao M, Gleadle JM, Ratcliffe PJ (1997): Activation of hypoxiainducible factor-1; definition of regulatory domains within the alpha subunit. J Biol Chem 272, 11205-11214

Qi CF, Liscia DS, Normanno N, Merlo G, Johnson GR, Gullick WJ, Ciardiello F, Saeki T, Brandt R, Kim N et al. (1994): Expression of transforming growth factor alpha, amphiregulin and cripto-1 in human breast carcinomas. Br J Cancer $\underline{69}, 903-910$

Rocha S (2007): Gene regulation under low oxygen: holding your breath for transcription. Trends Biochem Sci $\underline{32}$, 389-397

Rosenberger C, Solovan C, Rosenberger AD, Jinping L, Treudler R, Frei U, Eckardt KU, Brown LF (2007): Upregulation of hypoxia-inducible factors in normal and psoriatic skin. J Invest Dermatol 127, 2445-2452

Salnikow K, Donald SP, Bruick RK, Zhitkovich A, Phang JM, Kasprzak KS (2004): Depletion of intracellular ascorbate by the carcinogenic metals nickel and cobalt results in the induction of hypoxic stress. J Biol Chem $\underline{279}$, 40337-40344

Sato H (1962): Cancer cells in the circulating blood, with reference to cancer metastasis. Bull World Health Organ 26, 675-681

Saunders RM, Holt MR, Jennings L, Sutton DH, Barsukov IL, Bobkov A, Liddington RC, Adamson EA, Dunn GA, Critchley DR (2006): Role of vinculin in regulating focal adhesion turnover. Eur J Cell Biol 모, 487-500 
Scortegagna M, Ding K, Oktay Y, Gaur A, Thurmond F, Yan LJ, Marck BT, Matsumoto AM, Shelton JM, Richardson JA et al. (2003): Multiple organ pathology, metabolic abnormalities and impaired homeostasis of reactive oxygen species in Epas1-/- mice. Nat Genet 35, 331-340

Seno T, Harada H, Kohno S, Teraoka M, Inoue A, Ohnishi T (2009): Downregulation of SPARC expression inhibits cell migration and invasion in malignant gliomas. Int $\mathbf{J}$ Oncol $\underline{34}, 707-715$

Shattil SJ, Gao J, Kashiwagi H (1997): Not just another pretty face: regulation of platelet function at the cytoplasmic face of integrin alpha IIb beta 3. Thromb Haemost $\underline{78}$, $220-225$

Shoyab M, McDonald VL, Bradley JG, Todaro GJ (1988): Amphiregulin: a bifunctional growth-modulating glycoprotein produced by the phorbol 12-myristate 13-acetatetreated human breast adenocarcinoma cell line MCF-7. Proc Natl Acad Sci USA $\underline{85}$, 6528-6532

Stebbins CE, Kaelin WG Jr., Pavletich NP (1999): Structure of the VHL-ElonginC-ElonginB complex: implications for VHL tumor suppressor function. Science 284, 455-461

Stenman S, Vaheri A (1978): Distribution of a major connective tissue protein, fibronectin, in normal human tissues. J Exp Med 147, 1054-1064

Stiehl DP, Wirthner R, Köditz J, Spielmann P, Camenisch G, Wenger RH (2006): Increased prolyl 4-hydroxylase domain proteins compensate for decreased oxygen levels. Evidence for an autoregulatory oxygen-sensing system. J Biol Chem $\underline{281}$, 2348223491

Subauste MC, Pertz O, Adamson ED, Turner CE, Junger S, Hahn KM (2004): Vinculin modulation of paxillin-FAK interactions regulates ERK to control survival and motility. J Cell Biol 165, 371-381

Sumi T, Matsumoto K, Takai Y, Nakamura T (1999): Cofilin phosphorylation and actin cytoskeletal dynamics regulated by rho- and Cdc42-activated LIM-kinase 2. J Cell Biol 147, 1519-1532

Takeda K, Ho VC, Takeda H, Duan LJ, Nagy A, Fong GH (2006): Placental but not heart defects are associated with elevated hypoxia-inducible factor alpha levels in mice lacking prolyl hydroxylase domain protein 2. Mol Cell Biol 26, 8336-8346

Thompson EW, Reich R, Shima TB, Albini A, Graf J, Martin GR, Dickson RB, Lippman ME (1988): Differential regulation of growth and invasiveness of MCF-7 breast cancer cells by antiestrogens. Cancer Res $\underline{48}, 6764-6768$ 
Tian H, Hammer RE, Matsumoto AM, Russell DW, McKnight SL (1998): The hypoxiaresponsive transcription factor EPAS1 is essential for catecholamine homeostasis and protection against heart failure during embryonic development. Genes Dev 12, 33203324

Tian YM, Mole DR, Ratcliffe PJ, Gleadle JM (2006): Characterization of different isoforms of the HIF prolyl hydroxylase PHD1 generated by alternative initiation. Biochem $\mathrm{J}$ $\underline{397}, 179-186$

Timpl R, Rohde H, Robey PG, Rennard SI, Foidart JM, Martin GR (1979): Laminin--a glycoprotein from basement membranes. J Biol Chem 254, 9933-9937

Tuck AB, O'Malley FP, Singhal H, Harris JF, Tonkin KS, Kerkvliet N, Saad Z, Doig GS, Chambers AF (1998): Osteopontin expression in a group of lymph node negative breast cancer patients. Int J Cancer $\underline{79}, 502-508$

Tuck AB, Arsenault DM, O'Malley FP, Hota C, Ling MC, Wilson SM, Chambers AF (1999): Osteopontin induces increased invasiveness and plasminogen activator expression of human mammary epithelial cells. Oncogene $\underline{18}, 4237-4246$

van der Flier A, Sonnenberg A (2001): Function and interactions of integrins. Cell Tissue Res $\underline{305}, 285-298$

Vogel S, Wottawa M, Farhat K, Zieseniss A, Schnelle M, Le-Huu S, von Ahlen M, Malz C, Camenisch G, Katschinski DM (2010): Prolyl hydroxylase domain (PHD) 2 affects cell migration and F-actin formation via RhoA/rho-associated kinase-dependent cofilin phosphorylation. J Biol Chem $\underline{285}$, 33756-33763

Vuori K, Ruoslahti E (1993): Activation of protein kinase C precedes alpha 5 beta 1 integrinmediated cell spreading on fibronectin. J Biol Chem $\underline{268}, 21459-21462$

Wang GL, Semenza GL (1993): Characterization of hypoxia-inducible factor 1 and regulation of DNA binding activity by hypoxia. J Biol Chem $\underline{268}, 21513-21518$

Wang GL, Jiang BH, Rue EA, Semenza GL (1995): Hypoxia-inducible factor 1 is a basichelix-loop-helix-PAS heterodimer regulated by cellular O2 tension. Proc Natl Acad Sci USA $\underline{92}, 5510-5514$

Wang J, Xi L, Hunt JL, Gooding W, Whiteside TL, Chen Z, Godfrey TE, Ferris RL (2004): Expression pattern of chemokine receptor 6 (CCR6) and CCR7 in squamous cell carcinoma of the head and neck identifies a novel metastatic phenotype. Cancer Res $\underline{64}, 1861-1866$ 
Wang W, Mouneimne G, Sidani M, Wyckoff J, Chen X, Makris A, Goswami S, Bresnick AR, Condeelis JS (2006): The activity status of cofilin is directly related to invasion, intravasation, and metastasis of mammary tumors. J Cell Biol 173, 395-404

Warnecke C, Griethe W, Weidemann A, Jurgensen JS, Willam C, Bachmann S, Ivashchenko Y, Wagner I, Frei U, Wiesener M et al. (2003): Activation of the hypoxia-inducible factor-pathway and stimulation of angiogenesis by application of prolyl hydroxylase inhibitors. FASEB J 17, 1186-1188

Weber JD, Raben DM, Phillips PJ, Baldassare JJ (1997): Sustained activation of extracellularsignal-regulated kinase 1 (ERK1) is required for the continued expression of cyclin D1 in G1 phase. Biochem J $\underline{326}, 61-68$

Wiesener MS, Turley H, Allen WE, Willam C, Eckardt KU, Talks KL, Wood SM, Gatter KC, Harris AL, Pugh CW et al. (1998): Induction of endothelial PAS domain protein-1 by hypoxia: characterization and comparison with hypoxia-inducible factor-1alpha.

Blood 92, 2260-2268

Yang J, Zhang L, Erbel PJ, Gardner KH, Ding K, Garcia JA, Bruick RK (2005): Functions of the Per/ARNT/Sim domains of the hypoxia-inducible factor. J Biol Chem $\underline{280}$, 3604736054

Yang N, Higuchi O, Ohashi K, Nagata K, Wada A, Kangawa K, Nishida E, Mizuno K (1998): Cofilin phosphorylation by LIM-kinase 1 and its role in Rac-mediated actin reorganization. Nature $\underline{393}, 809-812$

You J, Mi D, Zhou X, Qiao L, Zhang H, Zhang X, Ye L (2009): A positive feedback between activated extracellularly regulated kinase and cyclooxygenase/lipoxygenase maintains proliferation and migration of breast cancer cells. Endocrinology 150, 1607-1617

Yu F, White SB, Zhao Q, Lee FS (2001): HIF-1alpha binding to VHL is regulated by stimulus-sensitive proline hydroxylation. Proc Natl Acad Sci USA $\underline{98}, 9630-9635$

Yuan Y, Hilliard G, Ferguson T, Millhorn DE (2003): Cobalt inhibits the interaction between hypoxia-inducible factor-alpha and von Hippel-Lindau protein by direct binding to hypoxia-inducible factor-alpha. J Biol Chem 278, 15911-15916

Zhang X, Jiang G, Cai Y, Monkley SJ, Critchley DR, Sheetz MP (2008): Talin depletion reveals independence of initial cell spreading from integrin activation and traction. Nat Cell Biol 10, 1062-1068

Zhong H, De Marzo AM, Laughner E, Lim M, Hilton DA, Zagzag D, Buechler P, Isaacs WB, Semenza GL, Simons JW (1999): Overexpression of hypoxia-inducible factor 1alpha in common human cancers and their metastases. Cancer Res $\underline{59}$, 5830-5835 
Zhu X, Ohtsubo M, Bohmer RM, Roberts JM, Assoian RK (1996): Adhesion-dependent cell cycle progression linked to the expression of cyclin D1, activation of cyclin E-cdk2, and phosphorylation of the retinoblastoma protein. J Cell Biol 133, 391-403

Zhu Z, Sanchez-Sweatman O, Huang X, Wiltrout R, Khokha R, Zhao Q, Gorelik E (2001): Anoikis and metastatic potential of cloudman S91 melanoma cells. Cancer Res $\underline{61}$, $1707-1716$

Zimprich A, Grabowski M, Asmus F, Naumann M, Berg D, Bertram M, Scheidtmann K, Kern P, Winkelmann J, Muller-Myhsok B et al. (2001): Mutations in the gene encoding epsilon-sarcoglycan cause myoclonus-dystonia syndrome. Nat Genet $\underline{29}, 66-$ 69 


\section{Danksagung}

Mein besonderer Dank gilt meiner Doktormutter Frau Prof. Dr. med. D. M. Katschinski, die es mir über die Vergabe des Themas ermöglicht hat, einen Einblick in wissenschaftliches Arbeiten zu erlangen. Außerdem bedanke ich mich für ihre ständige Bereitschaft, durch neue Überlegungen und Ideen mein Projekt inhaltlich zu unterstützen. Bedanken möchte ich mich ebenfalls für die zahlreichen Hilfestellungen bei der Fertigstellung dieser Arbeit.

Ferner danke ich meiner Betreuerin Frau Dr. rer. nat. Sabine Vogel, die mich stets mit viel Geduld, dauerhafter Hilfsbereitschaft und hoher Kompetenz im Labor ausgebildet und somit einen entscheidenden Anteil an dieser Arbeit hat. Ihr möchte ich zusätzlich für die Ratschläge und Ideen danken, welche diese Arbeit signifikant ergänzt haben.

Darüber hinaus gebührt mein Dank den übrigen Mitarbeitern der Arbeitsgruppe für ihren Beitrag zu dieser Arbeit: Fr. Dr. rer. nat. K. Farhat, Fr. M. Hölscher, Fr. S. Krull, Fr. M. von Ahlen, Fr. Dr. rer. nat. M. Wottawa, Fr. Dr. rer. nat. A. Zieseniß. Alle haben mich in jeder Hinsicht in meiner Arbeit $\mathrm{zu}$ jeder Zeit unterstützt, sodass die Bedingungen, wissenschaftliches Arbeiten zu erlernen, optimal waren. 


\section{Lebenslauf}

Am 02.10.1985 wurde ich, Moritz Thomas Schnelle, als drittes Kind der Anästhesistin Dr. med. Karin Schnelle und des Internisten Dr. med. Kuno Schnelle in Bochum geboren. Von 1992 bis 1996 besuchte ich die Wichlinghofer Grundschule, von 1996 bis 2005 das GoetheGymnasium in Dortmund. Die 11. Klasse verbrachte ich als Austauschschüler in den USA an der Marist High School in Eugene, Oregon (August 2002 bis Juni 2003). Die allgemeine Hochschulreife erhielt ich 2005 mit der Note 1,3 (Fächer: Mathematik, Englisch, Chemie, kath. Religion). Von Juli 2005 bis März 2006 leistete ich meinen Grundwehrdienst an der Marineoperationsschule in Bremerhaven ab, bevor ich im April 2006 mein Studium der Humanmedizin an der Georg-August-Universität zu Göttingen begann. Im Frühjahr 2008 bestand ich den ersten Abschnitt der Ärztlichen Prüfung mit der Note 1,0.

Diese Arbeit fertigte ich zwischen 2008 und 2012 in der Abteilung für Herz- und Kreislaufphysiologie am Institut für Physiologie und Pathophysiologie unter der Leitung von Frau Prof. Dr. med. D. M. Katschinski an. Innerhalb dieser Zeit absolvierte ich ein 7monatiges Forschungssemester (Februar 2011 bis September 2011) im Labor von Prof. R. S. Johnson an der University of California San Diego. In dieser Zeit wurde ich durch das Forschungsstipendium im Rahmen des Programmes Gö4med gefördert.

Im Februar 2012 werde ich mit dem Praktischen Jahr der medizinischen Ausbildung beginnen. 